\title{
Ionic liquid-based antimicrobial materials for water treatment, air filtration, food packaging and anticorrosion coatings
}

\section{Zari Fallah ${ }^{\text {a }}$, Ehsan Nazarzadeh Zare ${ }^{\mathrm{b}, *}$, Moonis Ali Khan ${ }^{\mathrm{c}}$, Sidra Iftekhar ${ }^{\mathrm{d}}$, Matineh Ghomi ${ }^{\mathrm{b}}$, Esmaeel Sharifi e,f, Mahmood Tajbakhsh ${ }^{\text {a }}$, Nasser Nikfarjam ${ }^{\mathrm{g}}$, Pooyan Makvandi ${ }^{\mathrm{h}}$, Eric Lichtfouse ${ }^{\mathrm{i}, \mathrm{j}}$, Mika Sillanpaa ${ }^{\mathrm{k}, \mathrm{l}}$, Rajender S. Varma ${ }^{\mathrm{m}}$}

a Faculty of Chemistry, University of Mazandaran, Babolsar 47416-95447, Iran

b School of Chemistry, Damghan University, Damghan 36716-41167, Iran

c Chemistry Department, College of Science, King Saud University, Riyadh 11451, Saudi Arabia

d Department of Applied Physics, University of Eastern Finland, Kuopio 70210, Finland

e Institute for Polymers, Composites and Biomaterials, National Research Council, IPCB-CNR, Naples 80125, Italy

${ }^{\mathrm{f}}$ Department of Tissue Engineering and Biomaterials, School of Advanced Medical Sciences and Technologies, Hamadan University of Medical Sciences, Hamadan 6517838736, Iran

${ }^{g}$ Department of Chemistry, Institute for Advanced Studies in Basic Sciences (IASBS), Zanjan 4513766731, Iran

h Istituto Italiano di Tecnologia (IIT), Center for Materils Interface, Viale R. Piaggio 34, 56025 Pontedera, Pisa, Italy

${ }^{\mathrm{i}}$ Aix-Marseille University, CNRS, IRD, INRA, Coll France, CEREGE, 13100 Aix en Provence, France

${ }^{\mathrm{j}}$ State Key Laboratory of Multiphase Flow in Power Engineering, Xi'an Jiaotong University, Xi'an, Shaanxi 710049, China

${ }^{\mathrm{k}}$ Environmental Engineering and Management Research Group, Ton Duc Thang University, Ho Chi Minh City, Viet Nam

${ }^{1}$ Faculty of Environment and Labour Safety, Ton Duc Thang University, Ho Chi Minh City, Viet Nam

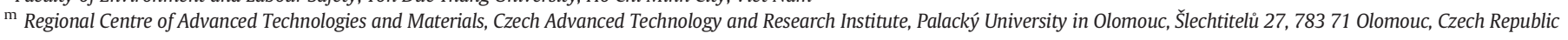

Keywords:

Ionic liquids

Antimicrobial

Physicochemical

Environmental application

\begin{abstract}
A B S T R A C T
Efforts to widen the scope of ionic liquids applications across diverse research areas have flourished in the last two decades with developments in understanding and tailoring their physical, chemical, and biological properties. The promising applications of ionic liquids-based materials as antimicrobial systems is due to their ability and flexibility to be tailored in varying sizes, morphologies, and surface charges. Ionic liquids are also considered as greener materials. Common methods for the preparation of ionic liquid-based materials include crosslinking, loading, grafting, and combination of ionic liquids with other polymeric materials. Recent research focuses on the tuning of the biological properties to design novel ionic liquids-based antimicrobial materials. Here, the properties, synthesis and applications of ionic liquids and ionic liquids-based materials are reviewed with focus on antimicrobial activities applied to water treatment, air filtration, food packaging, and anticorrosion.
\end{abstract}

\section{Contents}

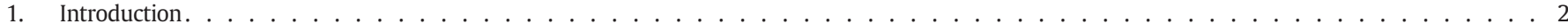

2. Preparation of ionic liquids . . . . . . . . . . . . . . . . . . . . . . . . . . . . . . . . . . . . . . . . . . . . . . . . . . . . 2

3. Physicochemical properties . . . . . . . . . . . . . . . . . . . . . . . . . . . . . . . . . . . . . . . . . 4

Abbreviations: AMIB IL, 1-aminoethyl-3-methylimidazolium bromide ionic liquid; [A336][NAA], aliquat 336-based methyltrioctylammonium naphthylacetate; BCILs, benzalkonium

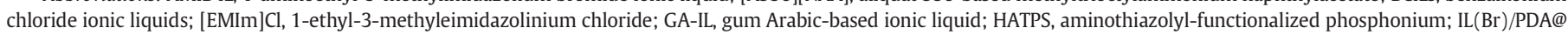

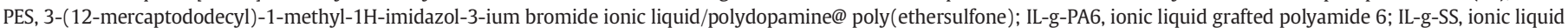

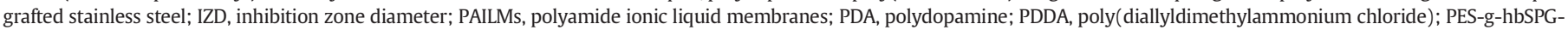

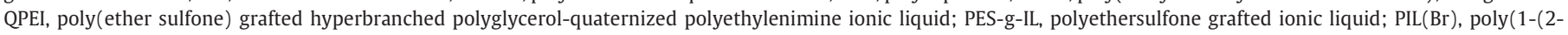

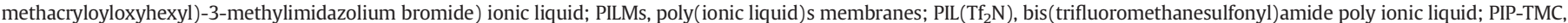

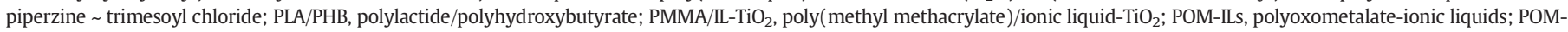

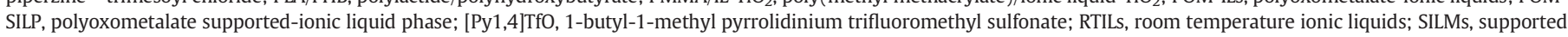

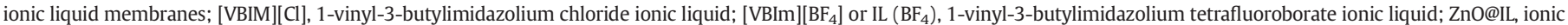
liquid coated on $\mathrm{ZnO}$ nanoparticles.

* Corresponding author.

E-mail addresses: e.nazarzadeh@du.ac.ir, ehsan.nazarzadehzare@gmail.com (E.N. Zare). 
3.1. Melting point. . . . . . . . . . . . . . . . . . . . . . . . . . . . . . . . . . . . . . . 4

3.2. Viscosity . . . . . . . . . . . . . . . . . . . . . . . . . . . . . . . . . . . . . 4

3.3. Conductivity . . . . . . . . . . . . . . . . . . . . . . . . . . . . . . . . . . . . . . . . . . 4

3.4. Density. . . . . . . . . . . . . . . . . . . . . . . . . . . . . . . . . . . . 5

3.5. Surface tension . . . . . . . . . . . . . . . . . . . . . . . . . . . . . . . . . . . . . . 5

4. Toxicity of ionic liquids . . . . . . . . . . . . . . . . . . . . . . . . . . . . . . . . . . . . . . . . . 5

5. Antimicrobial activity of ionic liquids . . . . . . . . . . . . . . . . . . . . . . . . . . . . . . . . . . . . . . . . . . . 5

6. Biodegradability of ionic liquids . . . . . . . . . . . . . . . . . . . . . . . . . . . . . . . . . . . . . . . 6

7. Environmental applications of ionic liquid-based antimicrobial materials . . . . . . . . . . . . . . . . . . . . . . . . . . . . . . . . . . . 6

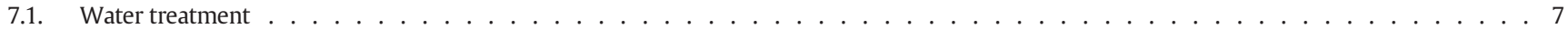

7.2. Air filtration . . . . . . . . . . . . . . . . . . . . . . . . . . . . . . . . . . . . . . . . 14

7.3. Food packaging . . . . . . . . . . . . . . . . . . . . . . . . . . . . . . . . . . . . 16

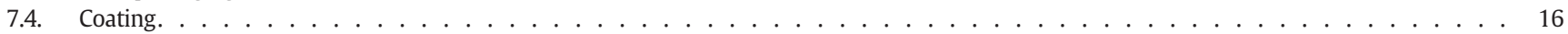

7.5. Anticorrosion . . . . . . . . . . . . . . . . . . . . . . . . . . . . . . . . . . . . . . 18

8. Conclusion . . . . . . . . . . . . . . . . . . . . . . . . . . . . . . . . . . . . . . . . . . . . . 22

References... . . . . . . . . . . . . . . . . . . . . . . . . . . . . . . . . . . . . . . . 23

\section{Introduction}

Over the past decades, microbial infections have become a major public health issue that has diverted global attention towards the development of new drugs. Additionally, the increase in antimicrobial resistance has emerged as another challenge to tackle [1]. A global action plan has therefore been formulated by the World Health Organization (WHO) about antimicrobial resistance with a list of antibiotic-resistant priority pathogens [2]. More responsible use of antibiotics is recommended along with the development of effective and new drug treatments, which is not an economically suitable alternative to pharmaceutical companies due to the time and expenses involved [3]. Although it is practically unavoidable to completely stop the appearance of resistance towards the new drugs considering the fact that antibiotics might not be the only cause for the surge in resistance. Hence, attaining the contemporary knowledge of the microbiological challenge is essential for the effective future design of antimicrobial agents which can circumvent or reduce the occurrence of multidrug resistance.

Renewed efforts have been deployed to overcome the associated danger of antimicrobial resistance such as the use of material with inherent antimicrobial features namely carbon-based nanomaterials, silver nanoparticles, and polymers [4]. Among others, the application of antimicrobial polymers has sprung up as a promising and attractive system; a large number of polymers have been broadly studied owing to their wide spectrum of activity bearing different groups such as pyridinium, triazolium, quaternary ammonium, guanidinium, imidazolium, or phosphonium groups [5]. The main underlying mechanism basically involves the electrostatic interactions of the negatively charged bacterial membrane with cationic polymer moieties along with the contribution of hydrophobic segments which play an important role in membrane rupture and cell lysis [1].

Ionic liquids have emerged as a novel class of low temperature $\left(<100{ }^{\circ} \mathrm{C}\right)$ molten salts which are composed of weakly coordinated cations and anions [6]. Although ionic liquids are discovered a long time ago, however, the researchers have been mainly interested in this appealing class as a low melting point 'fluid' salts in various industrial chemical processes as feasible substitutes to traditional volatile organic solvents as reaction media. The surprisingly diverse array of ionic liquids applications has been witnessed over the past decade [7]. The most distinct feature of ionic liquids includes low melting point, exceptional solvation potential, negligible vapor pressure, along with antibiofilm and antimicrobial activity. The chemical, physical, and biological properties can be tailored by the selection of different anions and cations. This distinctive, flexible, and unique characteristic in combination with the capability for numerous functionalities, could have the potential to offer innovative antimicrobial strategies in design which is needed to deal with the increasing challenge of bacterial resistance [8].
In recent years, versatile ionic liquids-based antimicrobial polymeric materials are mainly synthesized by combining ionic liquids by crosslinking, loading, and grafting them with other polymeric materials, nanomaterials, or solvents, which possess antimicrobial properties [1]. The ionic liquids-based antimicrobial materials have been used in various applications such as water treatment [9], air filtration [10], food packaging [11], anticorrosion [12], and coating processes [13] including biomedical applications (Table 1).

The antimicrobial properties of ionic liquids have been known for more than two decades, which mainly exhibits broad spectra of activity for Gram-negative and Gram-positive bacteria as well as fungi and mycobacteria. In general, the antimicrobial activity of ionic liquids increases with increasing lipophilicity, usually influenced by stretching the alkyl chain (chain-length effect) while the anions play a secondary role [8]. The combination of ionic liquids with other materials is known to enhance the intrinsic properties of pristine materials to destroy a wide range of microorganisms [14]. The previously published reviews mainly focus on the structural properties of ionic liquids [8] and poly(ionic liquid)s [1] and enlisted the alternative methods to obtain antibacterial materials based on ionic liquids. The lack of any detailed review related to this emerging topic prompted us to deliberate the environmental applications of ionic liquids-based antimicrobial materials.

This review presents several methods for the preparation of ionic liquids-based materials followed by a detailed discussion about their physicochemical and antimicrobial properties. Finally, the applications of various ionic liquids-based antimicrobial materials in the aforementioned environmental applications are highlighted with future perspectives.

\section{Preparation of ionic liquids}

The preparation of ionic liquids was initiated by Walden in 1914 with the synthesis of ethyl ammonium nitrate, $\left[\mathrm{EtNH}_{3}\right]\left[\mathrm{NO}_{3}\right]$ by a reaction between concentrated nitric acid and ethylamine [25]. After a long gap, in between the 70s and 80s, the alkylimidazolium halogenoaluminate ionic liquids, termed "first-generation ionic liquids" were developed via reaction between aluminum halides and imidazolium halides [26]. In 1992, air and water-stable imidazolebased, ionic liquids with a wide range of applications were developed [27] and were termed "second generation ionic liquids". Assorted synthesis strategies such as photo-crosslinking, radical polymerization, radiation-induced graft polymerization, light-induced polymerization, reversible addition fragmentation chain transfer (RAFT), atom transfer radical polymerization (ATRP), electrospinning, condensation reaction, metal-free organocatalytic ring-opening polymerization, and solution blending, have been deployed for their preparation [1]. Based on the chemical composition, ionic liquids are categorized as simple ionic 
Table 1

Various biomedical applications of ionic liquid-based antimicrobial materials.

\begin{tabular}{|c|c|c|c|c|}
\hline Ionic liquid & Added component & Antibacterial activity against & Application & Ref. \\
\hline Pyrrolidinium & Acrylonitrile, styrene & Escherichia coli, Staphylococcus aureus & Wound healing & [15] \\
\hline $\begin{array}{l}\text { 1,3-Bis(2-hydroxyethyl) imidazolium } \\
\text { bromide }\end{array}$ & Polypropylene glycol & $\begin{array}{l}\text { Escherichia coli, Staphylococcus aureus, } \\
\text { Pseudomonas aeruginosa }\end{array}$ & Wound healing & [16] \\
\hline 1-Vinyl-3-butylimidazolium bromide & PVA, acrylamide & $\begin{array}{l}\text { Escherichia coli, Staphylococcus aureus, } \\
\text { Bacillus subtilis }\end{array}$ & Wound healing & [17] \\
\hline 1-Vinyl-3-butylimidazolium bromide & $\begin{array}{l}\text { Polyethylene glycol dimethacrylate, } \\
N, N \text {-methylene-bis-acrylamide, methyl methacrylate, and } \\
\text { acrylamide }\end{array}$ & Escherichia coli, Staphylococcus aureus & Wound healing & [18] \\
\hline Pyrrolidinium & PVA (with/without tetrahydroxyborate anion) & Escherichia coli, Staphylococcus aureus & Wound healing & [19] \\
\hline $\begin{array}{l}\text { 1-N-butyl-3-methyl imidazoilium bis } \\
\text { (trifluoromethanesulfonyl)imide }\end{array}$ & BisGMA, TEGDMA, colloidal silicon dioxide & Streptococcus mutans & Orthodontic & [20] \\
\hline $\begin{array}{l}\text { 1-Butyl-3-methylimidazolium } \\
\text { hexafluorophosphate }\end{array}$ & PLGA or Soluplus ${ }^{\circledR}$ & Staphylococcus epidermidis & Periodontal & [21] \\
\hline Poly(ionic liquid) graft copolymer & - & Escherichia coli & Drug delivery & [22] \\
\hline Trimethylammonium & poly(meth)acrylates & Escherichia coli & Drug delivery & [23] \\
\hline $\begin{array}{l}\text { 1-Butyl-3-methylimidazolium } \\
\text { hexafluorophosphate }\end{array}$ & PLGA & Staphylococcus epidermidis & Drug delivery & [24] \\
\hline
\end{tabular}

Abbreviations: bisGMA; bisphenol A glycidyl methacrylate, PLGA; poly(lactic-co-glycolic acid), PVA; polyvinyl alcohol, TEGDMA; triethylene glycol dimethacrylate.

liquids such as $\left[\mathrm{EtNH}_{3}\right]\left[\mathrm{NO}_{3}\right]$, having unary anion and cation as constituents, and binary ionic liquids such as imidazolium-based ionic liquids (Fig. 1a) [28].

Metathesis, the exchange of halide salts or anion and acid-base neutralization reaction are the two conventional routes for ionic liquids preparation [29]. Quaternization of imidazole, amine, phosphane, and pyridine salts to respective cationic forms such as imidazolium, ammonium, phosphonium, and pyridinium occurs during a single-step ionic liquids synthesis [30], while hindrance of the desired anion directly through quaternization reaction gives rise to the multi-steps ionic liquids synthesis [23]. Fig. 1b illustrates both, the single and multi-step ionic liquids synthesis procedures, exemplified with an ammonium salt.

The metathesis reaction is commonly employed for imidazole-based ionic liquids synthesis. Depending on the solubility of target ionic liquids in water, metathesis can be divided into two reaction categories as (i) silver (Ag) salts-based reaction, or (ii) free acids or alkali metals/ ammonium salts reaction. During metathesis, 1,3-di-alkyl imidazolium cation reacts with anions derived from sodium $(\mathrm{Na})$, potassium $(\mathrm{K})$, or with $\mathrm{Ag}$ salts of $\mathrm{CH}_{3} \mathrm{COO}^{-}, \mathrm{NO}_{2}^{-}, \mathrm{NO}_{3}^{-}, \mathrm{SO}_{4}^{2-}$, and $\mathrm{PF}_{6}^{-}$. Ionic liquids synthesized by a reaction between imidazolium halide and $\mathrm{Ag}$-salts in methanol are air and water stable [31]. This is because of the lower solubility of Ag halides, notably AgI, which facilitates the separation of ionic liquids, consequently producing water-miscible high-quality ionic liquids in a good yield. However, the higher costs of Ag salts and the large quantities of solid waste generation limits their wide range of applications. The sulfate, phosphate, or sulfonate-based ionic liquids with traces of imidazole salts or acids can be prepared by neutralization of a base with a Bronsted acid or by direct alkylation of alkylimidazole. Thus, high purity ionic liquids cannot be developed through this procedure [32]. The acidic ionic liquids are synthesized through an addition reaction between Lewis acid ionic liquids $\left(\mathrm{AlCl}_{3}\right.$ based salts) or metal halides such as $\mathrm{FeCl}_{3}, \mathrm{CuCl}$, and $\mathrm{InCl}_{3}$, and halide salts [33]. The role of dimethyl carbonate for methylation as an alternate to alkyl halides during ionic liquids synthesis has been reported [34]. Avoidance of generation of by-products and absence of halide (as an impurity in ionic liquids) are the major merits of using dimethyl carbonate in ionic liquids synthesis. However, the presence of acid and ammonium salts restricts its use for ionic liquids synthesis [34]. A new class of highly viscous and conductive functionalized ionic liquids with low thermal stability has been generated by the reaction between zwitterions and acids [35]; zwitterions are formed by a single-step ring-opening reaction of sultones [36]. Along these conventional routes, some non-conventional solvent-free

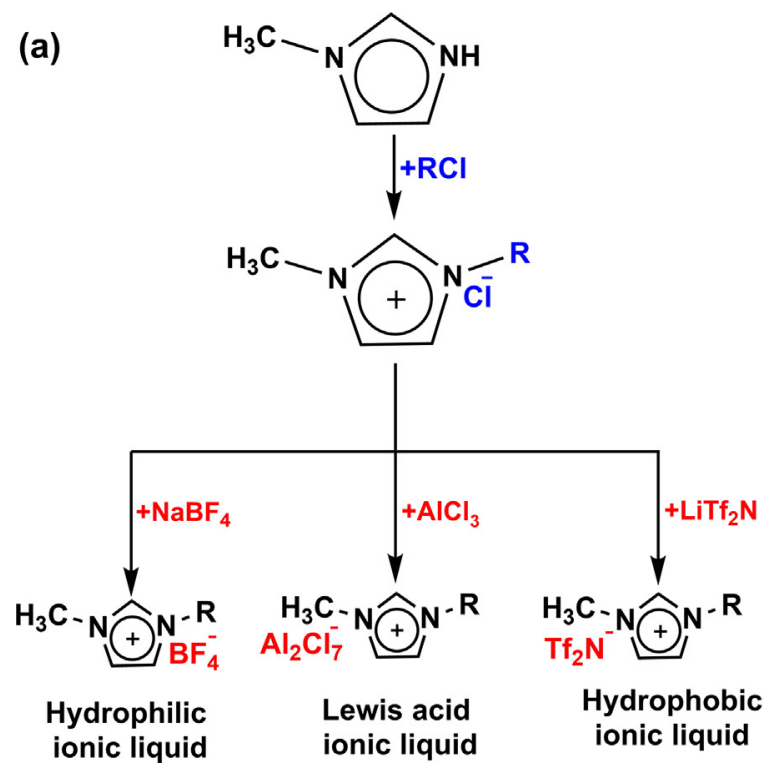

(b)

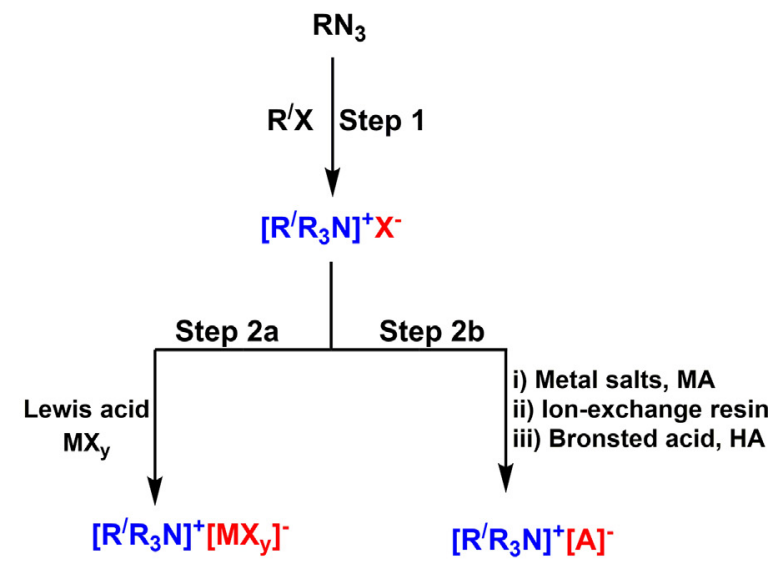

Fig. 1. The synthetic pathway for ionic liquids based on (a) imidazolium and (b) ammonium salt. 
synthesis procedures assisted by microwave irradiations [37] and ultrasound waves [38] have also been reported for the synthesis of ionic liquids. Compared to conventional ionic liquids synthesis routes, these non-conventional routes are rapid, selective, and environmentally benign due to the absence of any solvents during their synthesis.

A series of picolinium-based ionic liquids were synthesized through microwave irradiations (in a controllable single-mode microwave reactor) and compared with the conventional alkylation procedures using toluene as a solvent [39]. Comparatively better ionic liquids yield (76-91\%) was observed through solvent-free microwave-assisted synthesis route. Likewise, camphor-derived chiral imidazolium [40] and amino acid-based [41] ionic liquids were also synthesized through microwave irradiations and solvent-free ultrasound-assisted synthesis exemplified by $\mathrm{N}$-methyl-2-pyrrolidinium hydrogen sulfate-based ionic liquid [42]. Highly pure 1-butyl-3-methylimidazolium salts-based ionic liquids with better yield were synthesized through the ultrasound-assisted synthesis procedure [43]. Also, the synergic use of microwave and ultrasound in the synthesis of second-generation ionic liquids has been reported by a reaction between chloroalkanes and heterocycle compounds (1-methylimidazole pyridine and 1methylpyrrolidine) [44].

\section{Physicochemical properties}

In generally, ionic liquids are thermally stable, non-flammable, conductive, and barely exhibit vapor pressure [45]. Based on their wide range of applications, the physicochemical properties of ionic liquids can be tuned by modulating their molecular structure [46]. The specific physical and chemical properties of ionic liquids are exemplified and appended below with their significant properties being summarized in Table 2.

\subsection{Melting point}

The key criteria for ionic liquids are melting point $\left(\mathrm{T}_{\mathrm{m}}\right)$, glass transition temperature $\left(T_{g}\right)$, and decomposition temperature $\left(T_{d}\right)$ which depend on a balance between ion structural symmetry, chain flexibility, and charge accessibility [56]. At standard atmospheric pressure, the ionic liquids in the temperature range $200-300{ }^{\circ} \mathrm{C}$ exist in the liquid state [57]; instead of melting point, most of the ionic liquids exhibit glass transition temperature. Also, some room-temperature ionic liquids such as 1-ethyl-3-methylimidazolium tetrafluoroborate, $\left[\mathrm{C}_{2} \mathrm{mim}\right]$ $\left[\mathrm{BF}_{4}\right]$, below the melting point, exist as a supercooled liquid [58]. The melting point of ionic liquids is different from typical salts. For example, sodium chloride $(\mathrm{NaCl})$ and potassium chloride $(\mathrm{KCl})$ have respective melting point magnitudes of 801 and $772{ }^{\circ} \mathrm{C}$ compared to chloride, $\mathrm{Cl}^{-}$ions based ionic liquids with suitable organic cations like 1,3dimethylimidazolium chloride, [MIMM][Cl] (with the melting point: $125^{\circ} \mathrm{C}$ ) and 1-butyl-3-methylimidazolium chloride, [BMIM][Cl] (with the melting point: $65^{\circ} \mathrm{C}$ ) [30]. In the case of $\mathrm{NaCl}$ and $\mathrm{KCl}$ salts, both ions (cation and anion) are small, spherical, and have closely packed geometry, which results in extremely strong Coulombic forces, consequently have a high melting point magnitude. Contrarily, the ionic liquids with $\mathrm{Cl}^{-}$ion attached to large and asymmetric organic counter ions (cation) have low lattice energy, resulting in low melting point magnitude [30]. Likewise, protic ionic liquids with alkylammonium salts have melting point $>100^{\circ} \mathrm{C}$. However, the incorporation of carboxylic acids to alkylammonium cation and most of the salts with an imidazolium cation have very low melting point magnitude [53].

\subsection{Viscosity}

The viscosity $(\eta)$ of ionic liquids is mainly determined through their tendency to form a hydrogen bond, by the strength of van der Waals interactions among ions, and Coulombic interactions [59]. It is inversely proportional to diffusion rate. The increase in temperature and the presence of impurities (even in trace amounts) can drastically decrease the viscosity of ionic liquids. Highly viscous ionic liquids limit ions' movement compared to less viscous. Thus, for applications as a solvent, less viscous ionic liquids are desirable as they can increase mass transfer rates, while ionic liquids with higher viscosity favor lubrication and supported membrane separation applications. Generally, the viscosity of ionic liquids at room temperature ranged between 10 and $2000 \mathrm{cP}$ [60]. However, ionic liquids of tri-alkylimidazolium and ammonium families displayed viscosity between 2000 and $3000 \mathrm{cP}$, while ionic liquids of the phosphonium family are highly viscous with viscosity reaching $\sim 16,000 \mathrm{cP}$. In addition, the viscosity of the ionic liquid is directly proportional to the alkyl chain length of the cation. For example, the viscosity of 1-alkyl-3-methylimidazolium bistriflamide, [Cnmim] $\left[\mathrm{Ntf}_{2}\right]$ ionic liquids where alkyl chain length (ranges between 2 and 8 ) increases from 29 to $108.4 \mathrm{cP}$ with an increase in alkyl chain length [61]. Also, the viscosity depends on anions type, as observed among ionic liquids with the same cation chains and series of different anions. The observed viscosity is in the order: $\left[\mathrm{CH}_{3} \mathrm{COO}\right]^{-}>\left[\mathrm{PF}_{6}\right]^{-}>\left[\mathrm{C}_{1} \mathrm{SO}_{4}\right]^{-}$ $>\left[\mathrm{C}_{2} \mathrm{SO}_{4}\right]^{-}>\left[\mathrm{BF}_{4}\right]^{-}>[\mathrm{OTf}]^{-}>\left[\mathrm{NTf}_{2}\right]^{-}$. This change in viscosity might be due to the ability to form weak hydrogen bonds with the cation chain. The $\left[\mathrm{NTf}_{2}\right]^{-}$based ionic liquids combine better charge delocalization with greater chain flexibility, which increases the chain mobility so that the viscosity is lower than that of other anion-based ionic liquids [61]. Thus, ionic liquids with anions of high structural symmetry or spherical shape are more viscous.

\subsection{Conductivity}

The inherent motion of ions present in ionic liquids under the electric field generates conductivity [62]. At room temperature, the conductivities $(\sigma)$ of ionic liquids are typically ranged between 0.1 and 30 $\mathrm{mScm}^{-1}$. The conductivity is directly proportional to temperature and mobility, and inversely proportional to the viscosity of ionic liquids [63]. The point was confirmed by a sharp increase in 1-ethyl-3methylimidazolium tetrafluoroborate, $\left[\mathrm{C}_{2} \mathrm{C}_{1}\right.$ im $]\left[\mathrm{BF}_{4}\right]$ conductivity from $\sim 16$ to $\sim 120 \mathrm{mScm}^{-1}$ with a rise in temperature from 25 to $150{ }^{\circ} \mathrm{C}$

Table 2

Physical and chemical properties of some ionic liquids.

\begin{tabular}{|c|c|c|c|c|c|c|}
\hline Ionic liquid & Melting point $\left(\mathrm{T}_{\mathrm{m}}\right)(\mathrm{K})$ & Viscosity $(\eta)(\mathrm{cP})$ & Conductivity $(\sigma)\left(\mathrm{mScm}^{-1}\right)$ & Density $(\rho)\left(\mathrm{gcm}^{-3}\right)$ & Surface tension $(\gamma)\left(\mathrm{mNm}^{-1}\right)$ & Reference \\
\hline$\left[\mathrm{C}_{2} \mathrm{C}_{1} \mathrm{im}\right][\mathrm{Cl}]$ & 361.75 & 48.3 & 2.49 & 11.124 & - & [45] \\
\hline$\left[\mathrm{C}_{4} \mathrm{C}_{1} \mathrm{im}\right][\mathrm{Cl}]$ & 314.1 & 30.0 & 10.0 & 10.800 & 54.70 & [47] \\
\hline$\left[\mathrm{C}_{4} \mathrm{C}_{1} \mathrm{im}\right]\left[\mathrm{BF}_{4}\right]$ & 190.15 & 100 & 35 & 12.035 & 43.84 & [48] \\
\hline$\left[\mathrm{C}_{4} \mathrm{C}_{1} \mathrm{im}\right]\left[\mathrm{PF}_{6}\right]$ & 283.15 & 258 & 14.6 & 13.709 & 37.28 & [49] \\
\hline$\left[\mathrm{C}_{4} \mathrm{C}_{1} \mathrm{im}\right]\left[\mathrm{NTf}_{2}\right]$ & 270.15 & 49.0 & 39.0 & 14.397 & 37.0 & [50] \\
\hline$\left[\mathrm{C}_{4} \mathrm{pyr}\right]\left[\mathrm{NTf}_{2}\right]$ & 299.0 & 61.0 & 30.7 & 14.360 & 33.4 & [51] \\
\hline$\left[\mathrm{EtNH}_{3}\right]\left[\mathrm{NO}_{3}\right]$ & 282.15 & 32 & 269.0 & 12.160 & 47.30 & [52] \\
\hline$\left[\mathrm{EtNH}_{3}\right]\left[\mathrm{HSO}_{4}\right]$ & 313.15 & 128 & 44.0 & 14.380 & 56.30 & [53] \\
\hline$\left[\mathrm{N}_{2226}\right]\left[\mathrm{NTf}_{2}\right]$ & 287.1 & 187 & 8.87 & 12.886 & 34.10 & [54] \\
\hline$\left[\mathrm{P}_{66614}\right]\left[\mathrm{NTf}_{2}\right]$ & 206.1 & 336.7 & - & 10.661 & 30.90 & [55] \\
\hline
\end{tabular}


[6]. The relationship between conductivity and viscosity has been well demonstrated by Walden plot [64]. Usually, an increase in alkyl chain length decreases the conductivity of ionic liquids; for example, the conductivity of protic ionic liquids with alkylammonium and alkylimidazolium cations decreases with an increase in alkyl chain length [53]. The conductivity behavior of acidic ionic liquids was analyzed by Vogel-Tammann-Fulcher Eq. [65]. The ionic liquids with tetraalkylammonium, pyridinium, pyrrolidinium, and piperidinium as cations are classified as lower $\left(\leq 5 \mathrm{mScm}^{-1}\right)$ conductivity ionic liquids, while ionic liquids with imidazolium cations are classified as the ionic liquids with higher $\left(\leq 14 \mathrm{mScm}^{-1}\right)$ conductivities [63].

\subsection{Density}

Density is a crucial parameter for the simulation of heat and mass transfer, and hydrodynamics calculations [60]. It can be significantly affected by the presence of impurities and is used as a factor to ascertain the purity of ionic liquids [66]. The density of ionic liquids is often measured by a U-shape vibrating tube densimeter operating in static mode [67]. Under ambient conditions, the densities of ionic liquids generally varied between 0.8 and $3.3 \mathrm{~g} \mathrm{~cm}^{-3}$ [68]. The ionic liquids' density varies by the choice of anion and cation. The cations containing hydroxyl or ether groups form high-density ionic liquids, while high molecular masses anions generally led to higher density ionic liquids with the same imidazolium cation [69]. Also, the densities of ionic liquids with similar anionic parts progressively decrease with an increase in the alkyl chain length of the cationic part. The alkyl chain length elongation increases the free volume within the ionic liquid, accordingly lowering its density [60].

\subsection{Surface tension}

Surface tension is a powerful means to explore a variety of arrangements and orientations of free ions at the surface through a tensiometer [6]. It also measures the cohesive energy present at an interface and is usually quantified as a force/length measurement. Generally, the surface tension magnitude of most of the ionic liquids ranged between 1.55 and $65 \mathrm{mNm}^{-1}$, which is lower than the surface tension of water (i.e. $71.97 \mathrm{mNm}^{-1}$ at $25^{\circ} \mathrm{C}$ ) and higher than the surface tensions of many organic solvents [57]. The surface tension of many ionic liquids exhibits a linear decrease with the increase in temperature can be expressed by Eötvos Eq. [70]. Based on their properties, Table 3 summarizes the advantages and shortcomings of ionic liquids.

\section{Toxicity of ionic liquids}

Ionic liquids have been claimed as a greener and environmentally benign replacement for volatile and flammable organic solvents. However, their miscibility/solubility in water could be a potential threat to the aquatic ecosystem. Studies have found a strong relationship between ionic liquids' chemical structure and toxicity. Cationic moiety and the length of the alkyl chain significantly influences their toxicity level while an anion is a secondary contributor to toxicity [72]. Phosphonium and imidazolium-containing ionic liquids are highly toxic, while the least toxic ionic liquids comprise thiophenium and pyrrolidinium ions. Thus, based on cations, the toxicity of ionic liquids is as follow: phosphonium $>$ ammonium $>$ imidazolium $>$ pyridinium $>$ morpholinium $>$ pyrrolidinium $>$ thiophenium [73]. A reduction in imidazolium-based ionic liquids toxicity has been observed by the incorporation of oxygen or chlorine atoms into its long chain or by replacement of the alkyl chain with hydrogen atom [74].

The toxicity of imidazolium (1-octyl-3-methylimidazolium nitrate and 1-octyl-3-methylimidazolium chloride) and pyridinium ( $\mathrm{N}$ octyl-3-metylpyridinium chloride and -octyl-3-metylpyridinium bromide) containing ionic liquids on a marine diatom, Phaeodactylum tricornutum has been investigated; significant inhibition in growth
Table 3

Merits and demerits of ionic liquids [71].

Merits

- Number of imaginable solvents - Up to $10^{18}$ number of possible ionic liquids.

- Tunability - Based on applications can be tuned by varying functionalities and alkyl chain length.

- Vapor pressure - Under normal conditions low or negligible vapor pressure. Thus, non-volatile.

- Flammability - Non-flammable.

- Detachability - Volatile compounds can be easily separated.

- Stability - Stable for a wide temperature and electrochemical decomposition potential ranges.

Demerits

- Monetary value - About 5-20 times expensive than molecular solvents.

- Viscosity - Pure ionic liquids are highly viscous.

- Vapor pressure - Low vapor pressure hinder solvent separation during distillation.

- Synthesis - Generally, tiresome, costly and multi-step synthesis.

- Sustainability - Though considered as green solvents, but often toxic, non-biodegradable and non-sustainable.

- Hygroscopicity - Most of the ionic liquids are highly hydroscopic.

- Corrosiveness - Highly corrosive, thus, require special containers during commercial storage.

and photosynthesis was observed [75]. The toxic effect of chiral enantiomers of 1-alkyl-3-methylimidazolium tartrates (D- $(+)$-RMIM T and L-(+)-RMIM T) on algae, Scenedesmus obliquus has been examined; chiral ionic liquids caused oxidative stress in S. obliquus. In addition, the L- $(+)$-RMIM T enantiomer was comparatively more toxic than D-(+)-RMIM T enantiomer [76]. The toxicity of butyl- and octyl-substituted ionic liquids was assessed on Chlorella vulgaris, Scenedesmus quadricauda, and Botryococcus braunii where octylsubstituted ionic liquids were comparatively more toxic to algae than butyl- counterparts [77]. The toxic effects of ionic liquids with different cations viz. $N$-ethyl-pyridine alanine, tetraethyl phosphine 1-alpha-amino propionic acid salt, 1-ethyl-3-methylimidazolium alanine, and tetraethyl ammonium 1-alpha-amino propionic acid salt have been assessed on Triticum aestivum seedlings. Cation type and ionic liquids solution concentrations significantly influence the growth, chlorophyll content, and nutrient uptake of Triticum aestivum seedlings, while $N$-ethyl-pyridine alanine contributed to relatively stronger toxicity [78].

In another study, silkworm larvae were used as an in vivo model to assess the biotoxicity of 1-octyl-3-methylimidazole chloride, $\mathrm{N}$-octyl3-methylpyridien chloride, and 1-octyl-3-methylimidazole tetrafluoroborate. It was observed that ionic liquids could induce lipid peroxidation and cellular damage, which may be the primary reason for their toxicity [79]. The potential hazardous effects of ionic liquids on the human subject was studied by the evaluation of cytotoxicity through in vitro studies of imidazolium-based ionic liquids on the human tumor cell line HeLa. Results showed 4-5 fold lower $\mathrm{EC}_{50}$ values compared to common organic solvents [80].

\section{Antimicrobial activity of ionic liquids}

The World Health Organization (WHO) is working to establish a globalization program to combat microbial resistance and has compiled a list of priority pathogens for antibiotic resistance [81]. To counter the threat of antimicrobial resistance, various systems have been developed as alternatives to antibiotics, including the introduction of antimicrobial and promising ionic liquids [82]; their performance is comparable to that of ordinary antibiotics. Conventional antibiotics generally target bacteria with their antibacterial activity [83] and their mechanisms of action can be categorized as follow: (i) interfering with the cell wall synthesis, (ii) inhibiting the protein synthesis, (iii) inhibiting nucleic acid synthesis, (iv) interruption with the structure of the bacterial membrane, and (v) inhibition of metabolic pathways/bacterial enzymes [84]. 
In contrast, ionic liquids mainly disrupt the bacterial membrane by interacting and creating pores, cell leakage and death occur with their rapid action [85]. These membrane alterations, which lead to bacterial death, can be traced by the effect of ionic liquids on membrane properties. Ionic liquids can alter membrane properties such as membrane potential, viscoelasticity, phospholipids alignments, and ultimately the membrane fluidity. The latter affects the transport of molecules, their distinction, migration, adhesion and mechanical transport, and even the diffusion rate and stability of proteins within the membrane. The combination of these changes lead to bacterial cell death [86].

Operational viewpoint of the antibacterial effect of ionic liquids entails their easy attachment to the bacterial wall (mainly constructed by peptidoglycan), and complex cross-linked cell walls have occurred. In bacterial studies, it should not be overlooked that prokaryotic cells, unlike eukaryotic cells, do not have the uptake ability of external substances through endocytosis or pinocytosis, but uptake occurs through active/passive penetration into the cell wall [87]. Therefore, ionic liquid-based materials can easily act as a binding agent to the cell wall to produce antibacterial properties. In a study, the 1-vinyl-3-dodecyl imidazole as a cationic ionic liquid and chlorin e6 (containing carboxyl functional groups) as an anionic segment of an assembled compound was reported with dual antibacterial function. The cationic part of the ionic liquid attaches to the peptidoglycan wall and the anionic part is deprotonated in acidic media, illustrating an enhanced effect for eliminating the bacterial infection [88].

Besides the mentioned conditions, various structural features of ionic liquids such as chain length can affect their antibacterial performance. Increasing the alkyl chain length is an important and influential factor for ionic liquids, often up to a certain threshold or critical point, thus enhancing the antibacterial efficacy [89]; enhanced hydrophobic nature of the ionic liquid ensue wherein longer carbon chains (excess of 10 carbon atoms) destabilizes the cell membrane by penetrating the phospholipid bilayer and inducing membrane disruption [90]. In one study, the antibacterial properties of alkylimidazolium and alkoxyimidazolium lactates with various alkyl chains, viz.,11-12, and 12-14 carbon atoms respectively, were investigated, which also confirm the mentioned effective factor [91]. In a nutshell, the threshold value (i.e. the best chain length) for a specific ionic liquid depends on its structure and the final platform (i.e. hydrophobicity, crosslinking density of the final fabricated polymer, and composite) [89]. Deployment of such ionic liquids with lengthy alkyl chains, have a tendency to aggregate in solution resulting in amphiphilic micelles development [92].

The antimicrobial efficacy and antibiofilm activity of imidazoliumbased ionic liquids against Gram-positive and Gram-negative bacteria (e.g., Staphylococcus aureus, Escherichia coli, Pseudomonas aeruginosa, and Enterococcus faecalis) depends on the length of the alkyl chain and adjusting the head group, leading to enhanced lipophilicity, culminates in interaction and disruption of the bacterial membranes [93]. However, it reduces the surface tension with enhanced expectation of the interaction with the cell membrane, followed by infiltration of the compound into the bacterial membrane for efficient growth inhibition [94].

Other ionic liquids, such as those contain fumarate anion, are soluble in both polar organic solvents and aqueous media as well as in the common ionic liquids, e.g. the case of [BMIM][MRF] ionic liquid. The antibacterial activity here is related to the properties of fumarate anions, and the alkyl chain length and depends on the assessed microorganisms, (e.g., alkyl group containing 4 carbon atoms exhibit maximal activity against Gram-negative Escherichia coli, and the activity decreased with additional increase in the chain length. On the other hand, in the case of Gram-positive Bacillus subtilis higher alkyl chain length display better antimicrobial activities. These ionic liquids are more active relative to the commercially available potassium sorbate as a reference for antimicrobial activity in the case of zone diameters of the growth inhibition [91]. Combining the hydrophobic and hydrophilic properties of fumarate anion ionic liquids, allows it to have high antibioactivity along with appropriate water solubility. The hydrophobicity of such ionic liquids can be adjusted by altering the alkyl group chain length of fumarate while hydrophilicity of the ionic liquids is determined by the carboxylate end. Thus, the hydrophilic and hydrophobic parts of the fumarate anion deal with interaction among the ionic liquids and the bacteria cell walls [91].

The ionic liquids and organic salts containing ammonia hydrolysates of penicillin $\mathrm{G}$ and amoxicillin reveal antibacterial properties against sensitive and resistant Escherichia coli and methicillin-resistant Staphylococcus aureus strains [95]. Additionally, their ease of synthesis is credible for their future industrial production and can be an effective mean to challenge the emerging bacterial antibiotic resistance [95].

The redox-active ionic liquids may serve as photosensitizers, which is a promising option with antibacterial properties and no detectable resistance. Ionic liquids with optical sensitizer effect can disrupt pathogenic bacteria through singlet oxygen. The thought-provoking challenges of most photosensitizers are (i) their hydrophobicity and their aggregation in the physiological environment, (ii) structural instability in the acidic environment due to acidosis of inflammatory tissue, and (iii) their ineffectiveness against Gram-negative bacteria. The negatively charged cell wall of these bacteria prevents them from being used [88]. The mechanism of destruction of cell walls from Gram-negative bacteria and Gram-positive bacteria by ionic liquids is depicted in Fig. 2.

\section{Biodegradability of ionic liquids}

Biodegradation, an important principle of green chemistry, is a method to determine and predict the interacting behavior of ionic liquid with its surrounding environment [96]. The biodegradation assessment of ionic liquids under biotic conditions is mainly based on standardized assays implemented by the Organization of Economic Co-operation and Development (OECD) and the International Organization for Standardization (ISO) [96]. Dissolved organic carbon die-away test (OECD 301A), $\mathrm{CO}_{2}$ evolution (OECD 301B), MITI (I) (OECD 301C), closed bottle test (OECD 301D), and $\mathrm{CO}_{2}$ headspace test (ISO 14593) are some of the commonly standardized assays applied to determine the biodegradability of ionic liquids [97]; remaining ionic liquids that fared poorly in these procedures tend to have a greater potential to bioaccumulate in the environmental system. Additionally, the chemical structure of ionic liquids also influences their biodegradability. Reduction in mineralization of ionic liquids by microbes from activated sludge highlights the potential risk of these salts persisting in wastewater and, consequently, contaminating the aquatic and soil systems and living organisms [97].

\section{Environmental applications of ionic liquid-based antimicrobial materials}

Ionic liquids are often liquid at room temperature and possess unique properties which give them the potential ability to be used in various arena especially as green solvents [98]. Ionic liquids are selected as green solvents, a fascinating alternative for volatile organic solvents, because of their excellent physicochemical properties including nonflammability, negligible vapor pressure, non-volatility, solubility, and miscibility [99].

Worldwide interest in sustainable chemical developments compatible with the green chemistry principles has led to the innovative design of antimicrobial ionic liquid-based materials. As mentioned before (Section 5), many factors affect the antibacterial activities of ionic liquids. Optimization of these factors can lead to the production of targeted ionic liquids for use in water treatment, air filtration, anti-corrosion coatings, among other appliances. To improve the physical, chemical and mechanical properties of ionic liquids, they are mixed with other materials, including metallic/non-metallic nanoparticles and polymers. In the following sections, several applications of antimicrobial materials based on ionic liquids are summarized for use in diverse fields such as water purification, air filtration, food packaging, and coating. 


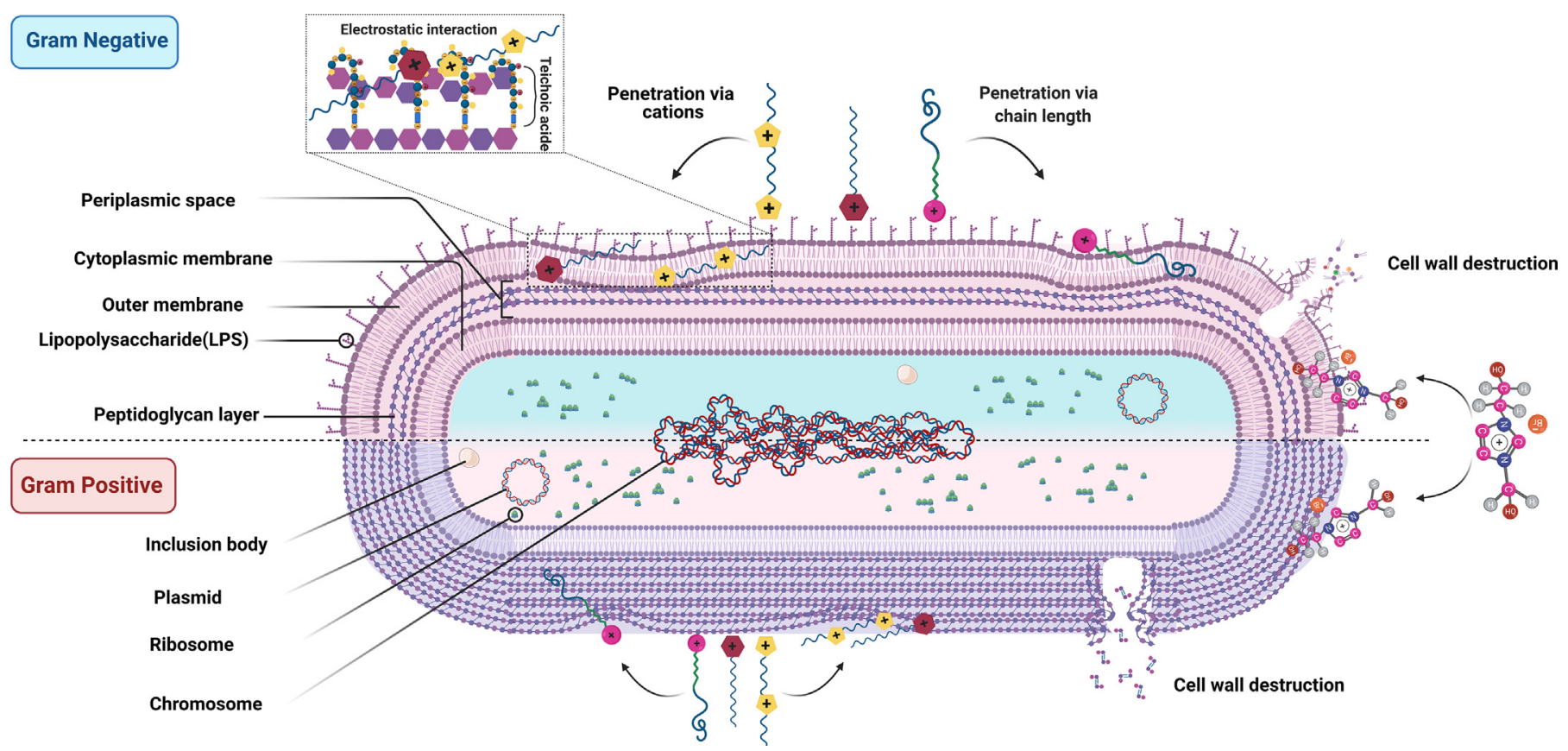

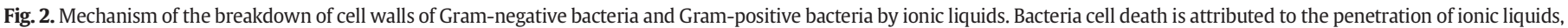
electrostatic interaction between the phospholipid bilayer functional groups, and ionic liquids approaching the membrane.

\subsection{Water treatment}

In the 21st-century, water pollution appeared as one of the most notable concerns owing to the rapid rise in population, urbanization, and industrialization. As announced by the world health organization, around 6 billion world's population will face the water scarcity problem by the year 2050 [100]. Giving due consideration to emerging water scarcity and depleting the access to freshwater with every passing day, several methods have been used in the treatment of wastewater as the main source of access to fresh water. The focus in water treatment is being diverted towards the implementation of an efficient and costeffective method enabling resource recovery [101]. Hence, the development of specific approaches and technologies for the decontamination of contaminated water is a pressing environmental challenge. Several types of adsorbents, such as natural/synthetic polymers, and biobased materials have been utilized for the removal of pollutants from wastewaters and aqueous media; use of adsorbents with the ability to decontaminate contaminated water is an enticing topic in water treatment. Consequently, the construction of innovative adsorbents with selective adsorption and effective adsorption/desorption behavior under mild and greener conditions is essential.

Ionic liquids play a significant role in water treatment due to their high potential for the removal of a wide range of pollutants from aqueous solutions [9]. Ionic liquid-based antimicrobial materials are attractive candidates as adsorbents with dual functions of adsorbing the organic/inorganic contaminants and removing the microbial pollutants from aqueous solutions. The following examples represent the impact of antimicrobial ionic liquids as chemical and biological adsorbents in water treatment processes.

The aminothiazolyl-functionalized phosphonium (HATPS) ionic liquid was fabricated and used as an effective adsorbent for the removal of heavy metal ions $\left(\mathrm{Fe}^{3+}, \mathrm{Zn}^{2+}, \mathrm{Cu}^{2+}\right.$, and $\left.\mathrm{Ag}^{+}\right)$from aqueous media (Fig. 3a and b) [102]. The new HATPS ionic liquid displayed an excellent

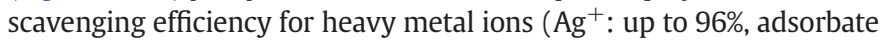
initial concentration; $C_{o}=0.03 \mathrm{M}$ and adsorbent dose; $\mathrm{m}=0.03 \mathrm{M}$ ), and could be simply regenerated and reused. The scavenging process occurred through complexation of heavy metal ions with deprotonated HATPS (ATPS) chelate or with HATPS as monoprotic bidentate $\mathrm{NO}^{-}$ ligand (Fig. 3c). Also, HATPS was applied as a spectrophotometric probe for $\mathrm{Fe}^{3+}$ determination in an aqueous solution with a lower limit of detection for $\mathrm{Fe}^{3+}=0.322 \mathrm{mg} \mathrm{L}^{-1}$. In addition, the scavenging outputs have been assigned as new candidates for antibiotics. Further, the antimicrobial studies exhibited high antibacterial activity for the scavenging outputs with preferable potency against Escherichia coli than Staphylococcus aureus [minimum inhibitory concentration $\left(\mu \mathrm{g} \mathrm{mL}{ }^{-1}\right)$ : Escherichia coli $=25.5-128.0$, and Staphylococcus aureus $=$ 32.5-250.0], but with lower fungicidal activity (Fig. 3d). The significant improvement in the bioactivity of metal-ATPS in comparison to the HATPS could be related to the merger of diverse bioactive pharmacophores into the metal-ATPS structure performing synergistic antimicrobial effects (Fig. 3e).

In another study, the aliquat 336-based methyltrioctylammonium naphthylacetate, [A336][NAA] ionic liquid was synthesized and applied as an extractor with antimicrobial activity for the removal of hexavalent chromium $\left(\mathrm{Cr}^{6+}\right)$ [103]. The extraction of $\mathrm{Cr}^{6+}$ by using [A336][NAA] dissolved in toluene provided the removal efficiency of $99.5 \%$ at $\mathrm{pH}=3$. The $\mathrm{Cr}^{6+}$ extraction in [A336][NAA]/toluene could be related to the complexation of both $[\mathrm{A} 336]^{+}$and $[\mathrm{NAA}]^{-}$with $\mathrm{Cr}^{6+}$ ions, and the charge balance of nitrate $\left(\mathrm{NO}_{3}^{-}\right)$ion in the complex. The antibacterial effects of [A336][NAA] (concentration $=1000 \mu \mathrm{g} \mathrm{m}^{-1}$ ) were examined via inhibition zone diameter (IZD) assay against Bacillus subtilis $(\mathrm{IZD}=12 \mathrm{~mm})$, Escherichia coli $(\mathrm{IZD}=10 \mathrm{~mm})$, Pseudomonas aeruginosa $(\mathrm{IZD}=13 \mathrm{~mm})$, Salmonella typhi $(\mathrm{IZD}=10 \mathrm{~mm})$, and Staphylococcus aureus (IZD $=10 \mathrm{~mm}$ ). Moreover, the ionic liquid antifungal activity was tested towards Aspergillus niger (IZD $=16 \mathrm{~mm}$ ), Candida sp. $($ IZD $=9 \mathrm{~mm})$, Penicillium sp. (IZD $=15 \mathrm{~mm})$, Microsporum gypseum $($ IZD $=12 \mathrm{~mm})$, and Trichophyton sp. $($ IZD $=17 \mathrm{~mm})$. The bacterial and fungal inhibition results showed that the growth of all the tested organisms was significantly inhibited by [A336][NAA].

The generation of magnetic property in adsorbents for water treatment is economically more desirable because of their easier recycling. Consequently, the magnetic polyoxometalate supported-ionic liquid phase (POM-SILP: specific surface area $=100 \mathrm{~m}^{2} \mathrm{~g}^{-1}$ and pore volume $=0.70 \mathrm{~cm}^{3} \mathrm{~g}^{-1}$ ) was prepared for the removal of organic, inorganic, microbial, and microplastics pollutants from water (Fig. 4) [104]. The composite was prepared based on the creation of polyoxometalate ionic 

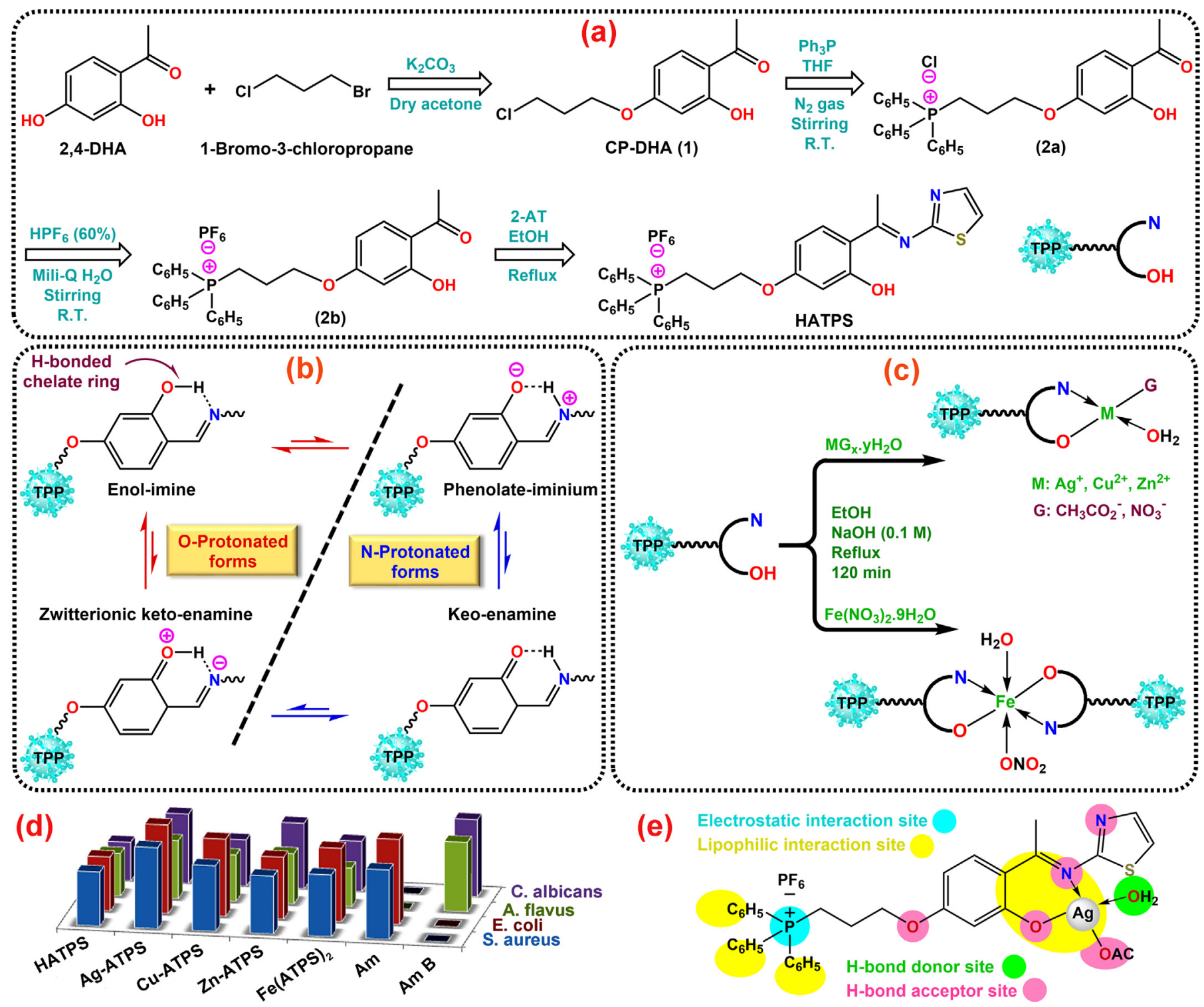

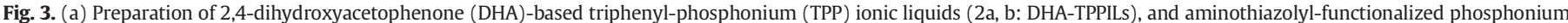

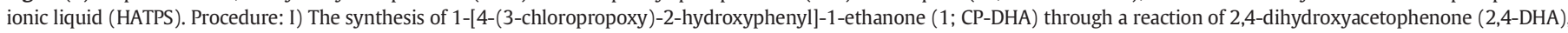

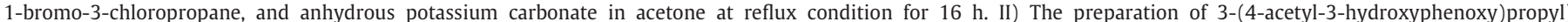

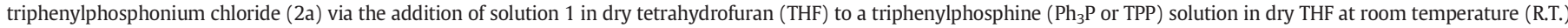

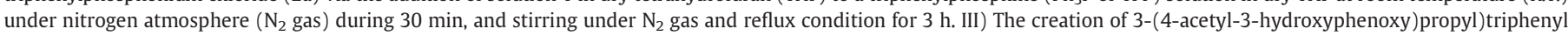

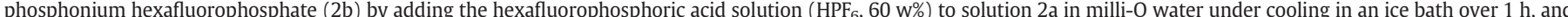

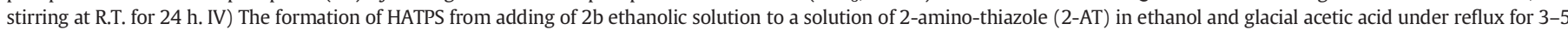

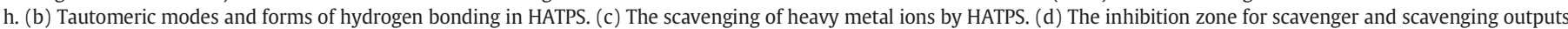

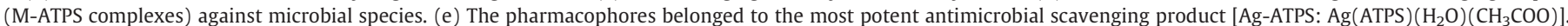
Reproduced with modification and permission from ref. [102].

liquid onto the microporous magnetic $\mathrm{Fe}_{2} \mathrm{O}_{3} @ \mathrm{SiO}_{2}$ core/shell (Fig. 4a). The magnetic POM-SILP displayed high adsorption efficiency for heavy metal ions $\left(\mathrm{Pb}^{2+}, \mathrm{Ni}^{2+}, \mathrm{Cu}^{2+}\right.$, and $\left.\mathrm{Co}^{2+}\right)$ removal from aqueous solutions. The Lacunary Keggin tungstate anions combined with POM-ILs featured heavy metal ions binding sites. In addition, when magnetic POM-SILP was used to adsorb the patent blue $\mathrm{V}$, the results indicated a removal efficiency of more than $99 \%$ due to the presence of waterimmiscible POM-ILs bearing large and hydrophobic Q7 cations in magnetic POM-SILP structure with binding capability towards organic contaminants (Fig. 4b). Furthermore, the spherical polystyrene beads (as a model of environmentally persistent microplastic) removal was assessed by magnetic POM-SILP (Fig. 4c). The polystyrene removal investigation exhibited that the viscous POM-IL coating with long-chain quaternary organo-ammonium cation onto the magnetic core surface could attach the magnetic POM-SILP onto the polystyrene beads, and thus enabling their magnetic retrieval from the water. Besides, the antibacterial water purification effects of magnetic POM-SILPs were assayed against Bacillus subtilis and Escherichia coli bacteria. The antibacterial activity of magnetic POM-SILP was confirmed using scanning electron microscopy and transmission electron microscopy images that illustrated the bacterial morphology was affected by the presence of magnetic POM-SILP; bacterial removal was $100 \%$ for both bacterial strains at the magnetic POM-SILP concentration of $10 \mathrm{mg} \mathrm{mL}^{-1}$. The antibacterial activity of magnetic POM-SILP against Bacillus subtilis remained unchanged after consecutive third cycles, while the particle influences on Escherichia coli decreased after two cycles. 

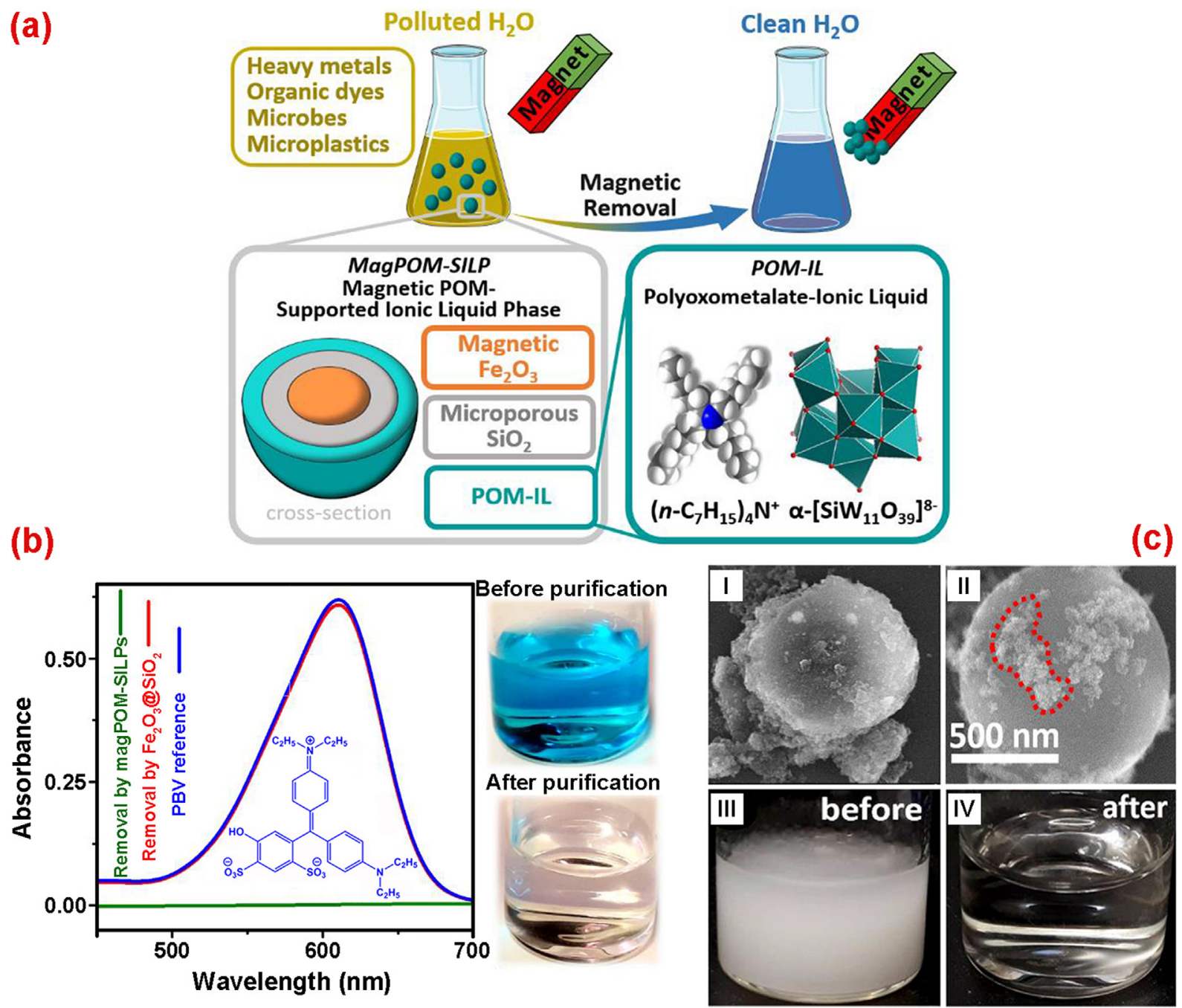

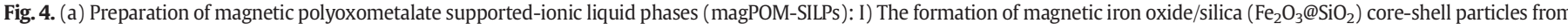

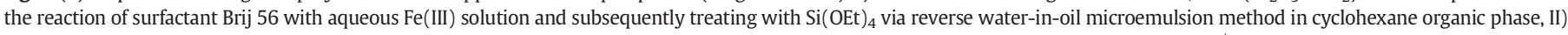

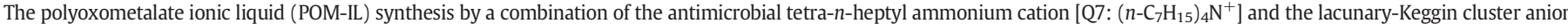

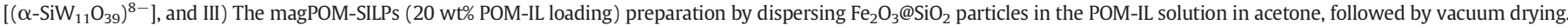

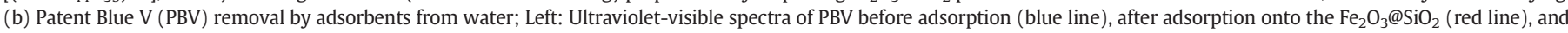

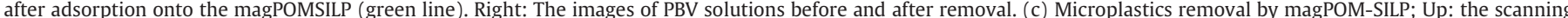

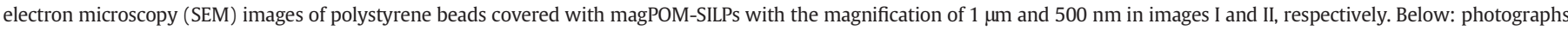
of microplastic solutions before and after polystyrene adsorption. Reprinted with modification and permission from ref. [104].

Photocatalysis is one of the effective and widely used methods for the degradation of contaminants and elimination of microbial species in water. In this context, the poly(methyl methacrylate)/ionic liquid$\mathrm{TiO}_{2}$ (PMMA/IL-TiO ${ }_{2}$ ) nanocomposite film was prepared from 1-butyl3-methylimidazolium tetrafluoroborate ionic liquid and methyl methacrylate in presence of benzoyl peroxide initiator and triton X-100 surfactant via micro-emulsion technique [105]. The PMMA/IL-TiO $\mathrm{Pilm}_{2}$ showed a photodecomposition effect on the trypan blue dye as well as antibacterial activity against Bacillus sp. The PMMA/IL-TiO ${ }_{2}$ exhibited a high photocatalytic effect under visible light due to the ionic liquid role in improving the transportation of photo-induced electrons and holes. The highest photocatalytic efficiency along with antibacterial activity was obtained for PMMA/IL-TiO 2 film with $40 \mu \mathrm{m}$ thickness and $0.01 \mathrm{wt} \%$ of $\mathrm{TiO}_{2}$.

Benzimidazole-based ionic liquid coated on $\mathrm{ZnO}$ nanoparticles (ZnO@IL) was synthesized and applied as a photocatalyst for the 4nitroaniline oxidation under ultraviolet light (Fig. 5a) [106]. The 4nitroaniline oxidation by ZnO@IL revealed that a significant degradation occurred according to the first-order kinetic (Fig. 5b), and a higher oxidation rate $\left(\mathrm{k}=2.01 \times 10^{-4} \mathrm{mMs}^{-1}\right)$ was observed at $\mathrm{pH}=4 \mathrm{com}$ pared with that at $\mathrm{pH}=10\left(\mathrm{k}=0.26 \times 10^{-4} \mathrm{mMs}^{-1}\right)$. The ZnO@IL $(150$ $\mu \mathrm{L}, 5 \mathrm{mM})$ exhibited antibacterial activity against bacteria $\left(2.5 \times 10^{5}\right.$ CFU/mL) with microbial inhibition of $43 \%$ and $40 \%$ against S. aureus (Gram-positive), and E. coli (Gram-negative), respectively (Fig. 5c). The cell growth inhibition of ZnO@IL was associated with the imidazolium ring and the carboxylate group as essential reactive center that could generate the reactive oxygen species, interact with proteins (amide, carboxyl, phosphate, hydroxyl tails, and carbohydrate-related moieties) or intercalate between the purine and pyrimidine components in DNA of both types' bacteria (Fig. 5d). The ZnO@IL could easily enter into the cell, affect metabolic functions, prevent the respiration system, break the cell wall, leach out the cell materials, and eventually leading to cell death (Fig. 5e).

Adhering to the goals of green chemistry, biopolymers from natural and renewable sources in view of their abundance, and biocompatibility, have garnered much attention for the preparation of natural polymer-based ionic liquids with antimicrobial activity for water treatment [107]. In this respect, spherical microgel comprising gum Arabic- 
(a)

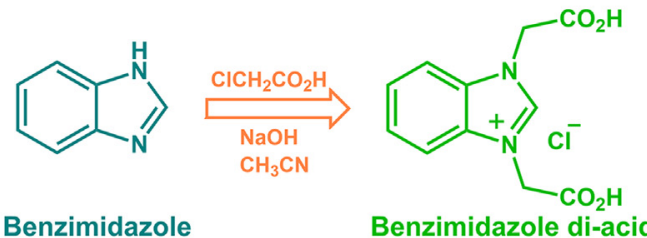
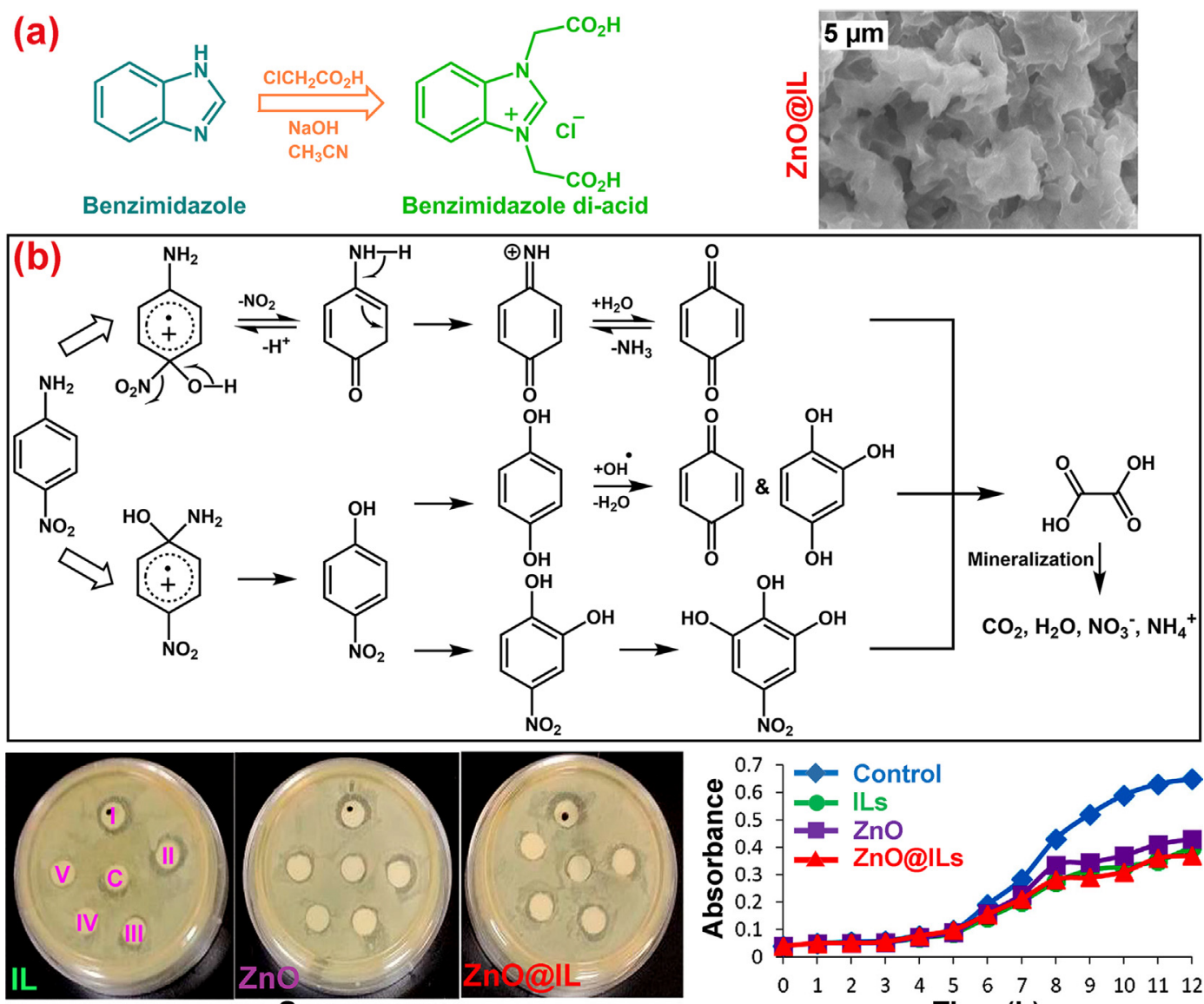

(c)

S. aureus

Time (h)
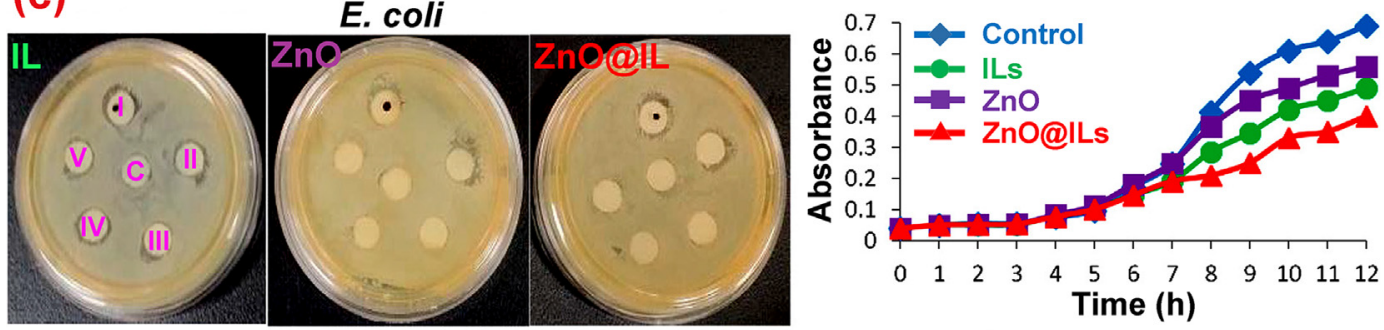

(d)

\begin{tabular}{lrr} 
Compounds & \multicolumn{2}{c}{ IZD (mm) } \\
$(5 \mathrm{mM})$ & S. aureus & E. coli \\
\hline ILs & $9.5 \pm 0.2$ & $7.5 \pm 0.5$ \\
ZnO & $10.5 \pm 0.4$ & $8.0 \pm 0.4$ \\
ZnO@ILs & $11.5 \pm 0.5$ & $10.0 \pm 0.3$
\end{tabular}

(e)

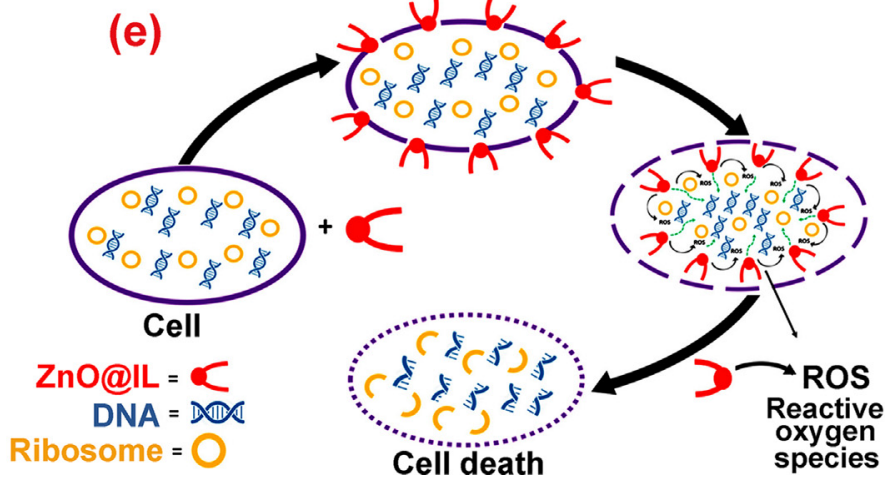

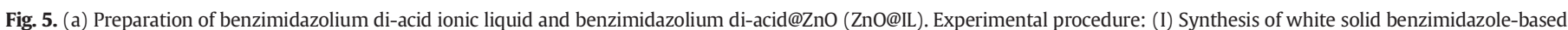

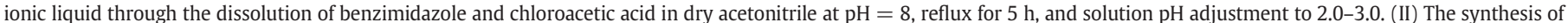

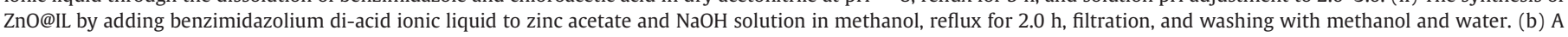

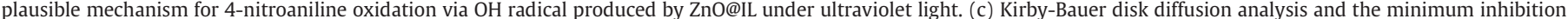

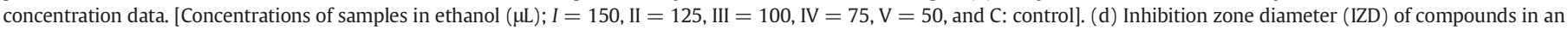
antibacterial test. (e) The proposed interactions between bacterial cells and ZnO@ILs. Reprinted with modification and permission from ref. [106].

based ionic liquid (GA-IL), was prepared from the gum Arabic in a single step, and super porous gum Arabic cryogel was synthesized under cryogenic conditions (Fig. 6a). Then, the chemical modification of gum
Arabic microgel and cryogel was performed with polyethyleneimine and triethylenetetraamine to produce the modified gum Arabic microgels/cryogels. Finally, the GA-IL-based microgels/cryogels were 
formed by the anion exchange reaction of protonated modified gum Arabic microgels/cryogels with ammonium hexafluoroborate, sodium dicyanamide, and sodium tetrafluoroborate (Fig. 6b). Bare, modified, and GA-IL cryogels have been deployed for the adsorption of drug (sodium diclofenac) and pesticide (paraquat) from aqueous solutions because of their superior porous nature (Fig. 6c). Adsorption studies
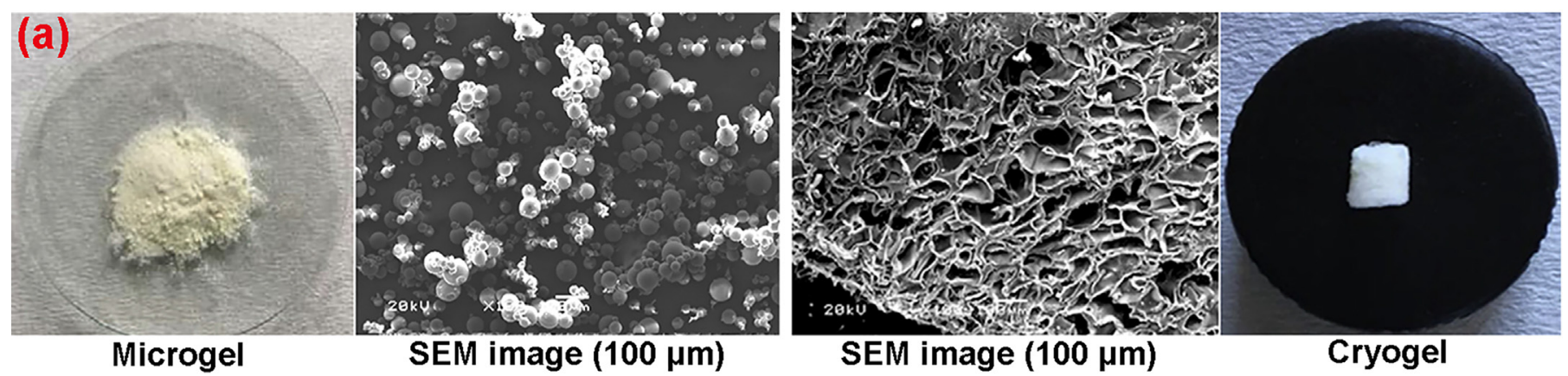

(b)

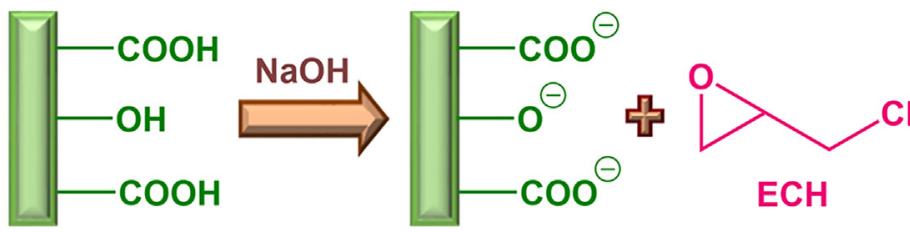

Gum Arabic (GA)

Microgel/Cryogel

Sodium dicyanamide

(SDC): $\mathrm{Na}{ }^{\oplus} \Theta_{\mathrm{N}}(\mathrm{CN})_{2}$

\section{Anion exchange}

Ammonium hexafluorophosphate (AHFP): $\mathrm{NH}_{4}^{\oplus} \mathrm{PF}_{6}^{\Theta}$

\section{Sodium tetrafluoro borate}

(STFB): $\mathrm{Na}^{\oplus} \mathrm{BF}_{4}^{\ominus}$

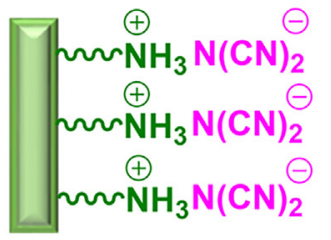

SDC-GA IL

Microgel/Cryogel

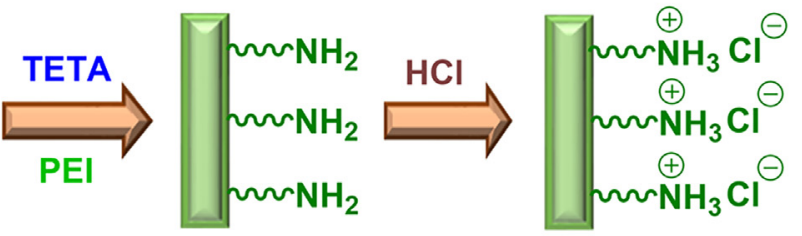

Modified (M-) GA Quaternized (Q-) GA Microgel/Cryogel Microgel/Cryogel

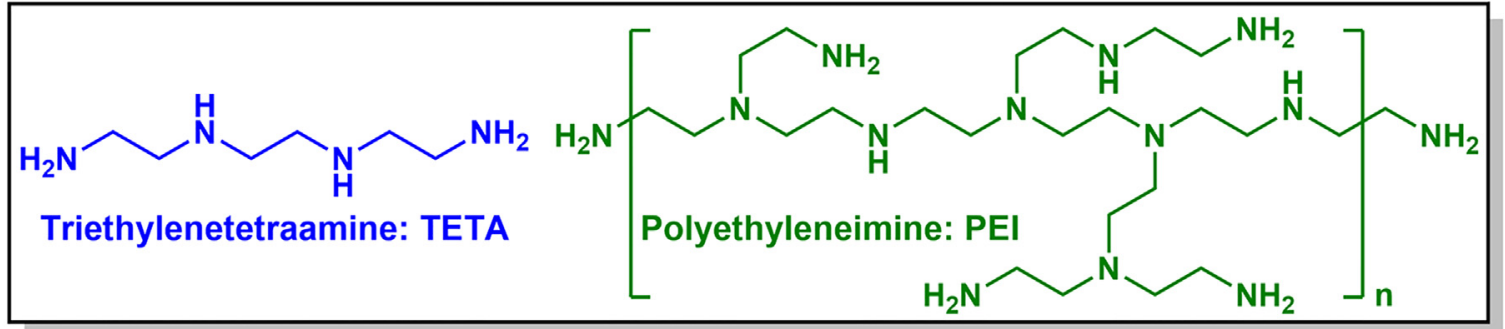

(c)
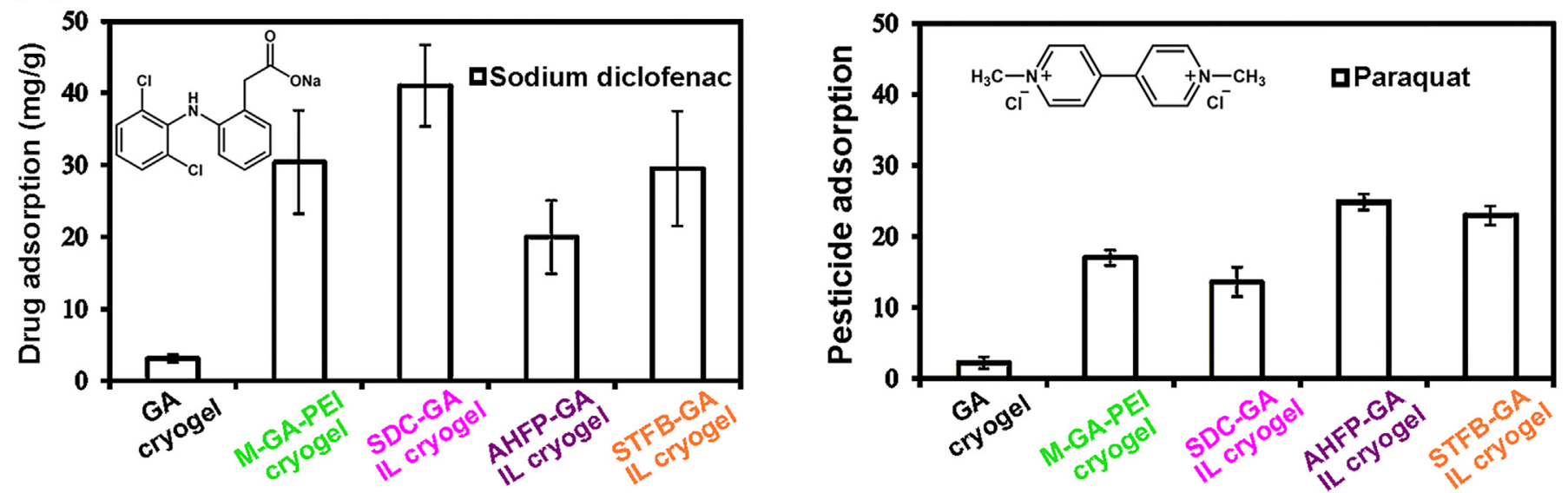
revealed that the modified and GA-IL cryogel could remove the higher amount of sodium diclofenac and paraquat in comparison to bare cryogel due to their tunable chemical and physical properties. Furthermore, the antimicrobial effect of gum Arabic microgels was assayed by disc diffusion method, and the quaternized polyethyleneimine microgel was found to be an effective antibacterial agent for the growth inhibition of Gram-positive (Staphylococcus aureus) and Gram-negative (Escherichia coli) bacteria with $13 \pm 1 \mathrm{~mm}$ inhibition zones.

Membrane separation is an imperative technology employed worldwide to produce clean and pure water with low energy consumption and a small energy footprint [108]. One of the emerging and intriguing candidates for membrane fabrication in the water treatment arena are polymeric ionic liquids in which functional polymers bear the moieties of antimicrobial ionic liquids. The structural synergy between the macromolecular architecture and antimicrobial ionic liquid component extends the window of physicochemical characteristics of membranes, thus, enriching their application and functional range by linking the advantageous attributes of ionic liquids [109].

Polyamide ionic liquid membranes (PAILMs) have been prepared through surface modification of polyamide with 1-aminoethyl-3methylimidazolium bromide ionic liquid (AMIB IL) [110]. The PAILMs were synthesized by 'piperzine $\sim$ trimesoyl chloride' (PIP-TMC) interfacial polymerization. The AMIB IL was attached to the membrane surface through 'acyl chloride $\sim$ amine' amidation reaction. The thin film of polyamide composite membranes exhibited antibacterial activity, antibiotics separation, high water permeability, and salt rejection. The modified membrane (PIP-TMC-AMIB) displayed water flux and salt rejection of $135 \pm 5 \mathrm{~L} \mathrm{~m}^{-2} \mathrm{~h}^{-1}$ and $95 \pm 1 \%\left(\mathrm{Na}_{2} \mathrm{SO}_{4}\right)$ at 6 bar pressure, indicating a four-fold improvement compared to the pristine PIP-TMC membrane. The selective and rapid transportation of water from inside the PIP-TMC-AMIB could be related to the higher surface energy, hydrophilicity, and loose structures after membrane modification with AMIB. The salt rejection of PIP-TMC-AMIB could be consistent with the negative charge of the modified membrane and a strong electrostatic repulsion between $\mathrm{SO}_{4}^{2-}$ and negatively charged membranes. Also, the PIPTMC-AMIB was used for the filtration of antibiotics solutions containing ciprofloxacin, erythrocin, levofloxacin, oxytetracycline, and tetracycline. In the antibiotics filtration, the PIP-TMC-AMIB showed higher water flux $\left(150 \pm 5 \mathrm{~L} \mathrm{~m}^{-2} \mathrm{~h}^{-1}\right)$ in comparison with $\mathrm{Na}_{2} \mathrm{SO}_{4}$ filtration because of the osmosis pressure effect and exhibited high antibiotics rejection $(93.5 \pm 3 \%)$. In addition to the high performance for salt and antibiotics rejection, the PIP-TMC-AMIB displayed efficient separation of sodium chloride/antibiotics mixtures, as well as promising stability and antibacterial activity with an inhibition effect of 99\% against Escherichia coli growth.

Recently, an ionic liquid grafted polyamide 6 (IL-g-PA6) was synthesized by grafting the 1-vinyl-3-butylimidazolium chloride ionic liquid ([VBIM][Cl]) onto the polyamide 6 main chains via radiation-induced grafting methodology (Fig. 7a) [111]. The bulky cations of grafted ionic liquid as spacers could enlarge the distance between polyamide 6 chains, and decrease the hydrogen bonding strength in the polyamide 6 matrix. Thus, the ion-containing polyamide 6 could be easily meltspun into fibers due to the good melt processability. The fibers derived from ion-containing polyamide 6 showed antibacterial activities particularly against Escherichia coli, as well as, antistatic performances and good mechanical properties (Fig. 7b). The IL-g-PA6 with a unique ion structure was applied to design a porous membrane through the immersion precipitation phase inversion method [112]. The adsorption capability of IL-g-PA6 membranes was assayed for the chromate removal, and results revealed that the observed excellent adsorption efficacy was associated with the special interaction between grafted ionic liquid and chromate ions (Fig. 7c). These researches offered a new strategy to prepare the interesting scavenger membranes by using the IL-gPA6 for the removal of heavy metal ions and microbial contaminations from aqueous solutions.

Supported ionic liquid membranes (SILMs) have been prepared by using imidazolium-based ionic liquids and hydrophobic polytetrafluoroethylene, and were deployed for the $\pi$ electroninduced separation of aromatic compounds (toluene, styrene, divinylbenzene, congo red, eriochrome black $\mathrm{T}$, and ramazol brilliant blue R) from non-aqueous (hexane) and aqueous media [113]. The separation efficacy of SILMs was established with the trend, toluene $<$ styrene $<$ divinylbenzene from non-aqueous solutions, and in the case of dyes, the congo red and ramazol brilliant blue $\mathrm{R}$ were preferentially removed from aqueous solutions. The ionic liquid affinity towards $\pi$ electron cloud is the driving force for this separation trend, while the highest selectivity for congo red was related to the complicated electronic configuration. The antibacterial effects of SILMs were assayed against Staphylococcus aureus and Pseudomonas aeruginosa. The SILMs exhibited satisfactory antibacterial activity against Gram-positive bacteria, and the colony-forming unit value $(2.82 \mathrm{E}+09)$ was significantly reduced to $1.10 \mathrm{E}+03,1.2 \mathrm{E}+04$, and $4.4 \mathrm{E}+06$ after $5 \mathrm{~h}$ of exposure to SILMs with bromohexane, chlorobutane, and allylbromide moieties, respectively. The trend of antibacterial activities of ionic liquids (bromohexane $>$ chloro butane $>$ allylbromide) could be associated with greater number of carbon atoms on the side chain of imidazolium ring.

In another study, a polyethersulfone grafted ionic liquid porous membrane (PES-g-IL $\left[\mathrm{BF}_{4}\right]$ ) was fabricated by chemical bonding of 1vinyl-3-butylimidazolium tetrafluoroborate ionic liquid ([VBIm] $\left[\mathrm{BF}_{4}\right]$ or IL $\left(\mathrm{BF}_{4}\right)$ ) on the main chains of polyethersulfone (PES) through radiation-induced grafting technique (Fig. 8a) [114]. The PES-g-IL $\left(\mathrm{BF}_{4}\right)$ membranes revealed extremely improved water flux, antifouling, and antibacterial properties in comparison to the neat polyethersulfone porous membranes (Fig. 8b).

Antimicrobial poly(ionic liquid)s, synthesized by polymerizable antimicrobial ionic liquids, encompass the combination of antimicrobial ionic liquids' unique properties together with intrinsic polymer properties. The antimicrobial poly(ionic liquid)s seem to be the promising materials to design the antimicrobial membranes with improved durability and processability, enhanced mechanical and thermal stability, along with increased permeation rates and separation capability [115].

In this context, antibacterial poly(ionic liquid)s membranes (PILMs) have been fabricated through a two-step synthetic method: I) preparation of ionic liquid monomers (1-vinyl-3-butylimidazolium chloride, 1-vinyl-3-hexylimidazolium bromide, and 1-vinyl-3allylimidazolium bromide), and II) the synthesis of PILMs by the reaction of ionic liquid monomers and co-monomers (acrylonitrile and styrene) with the 1,4-divinylbenzene cross-linker [116]. These PILMs showed considerable stability in apolar-aprotic, polar-aprotic, and polar-protic solvents, demonstrating their wide applications in various solvents. Pre-compaction of PILMs led to stable water flux, and membranes derived from ionic liquids with chlorobutane, bromohexane, and allybromide moieties showed water flux of $315 \mathrm{~L} \mathrm{~m}^{-2} \mathrm{~h}^{-1}$ at 1.5 psi, 948 and $982 \mathrm{~L} \mathrm{~m}^{-2} \mathrm{~h}^{-1}$ at 0.5 psi, respectively. The PILMs were applied for protein (bovine serum albumin and dextran) rejection, and

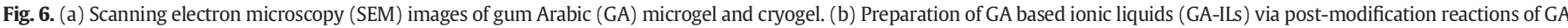

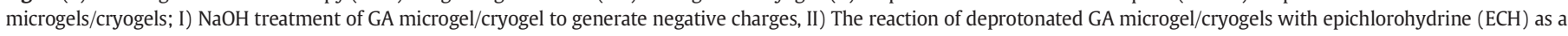

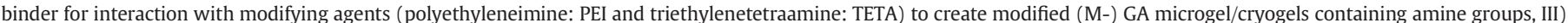

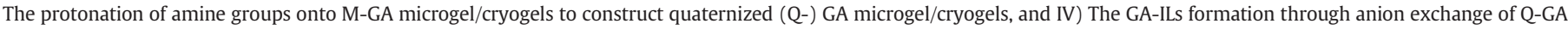

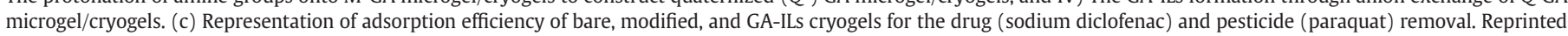
with modification and permission from ref. [107]. 
(a)

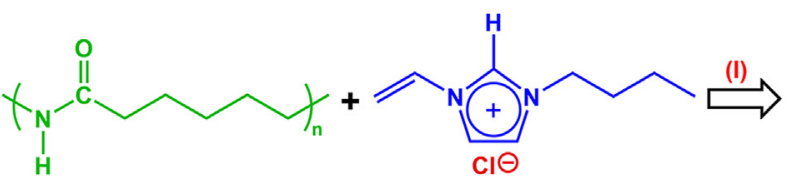

Polyamide 6 (PA6) 1-vinyl-3-butylimidazolium chloride [VBIM][Cl]

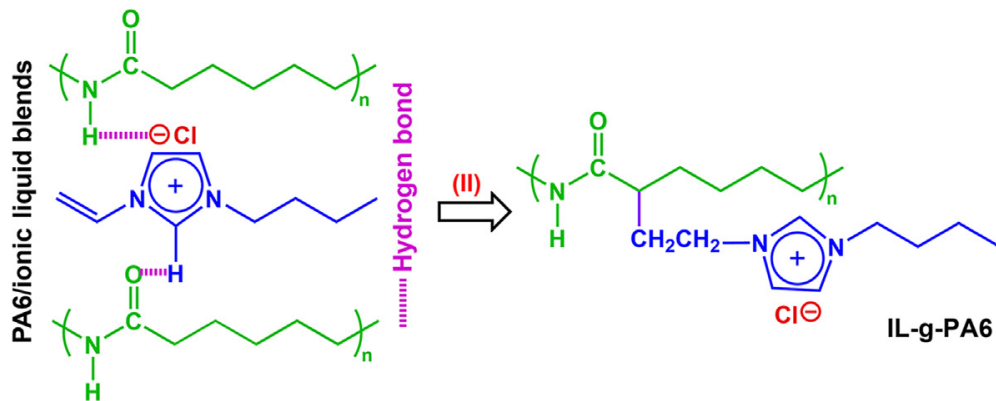

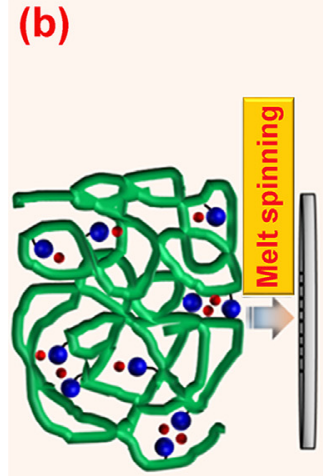

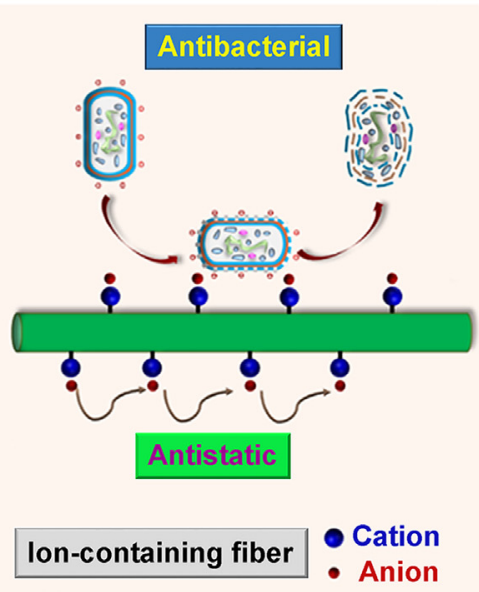

(c)
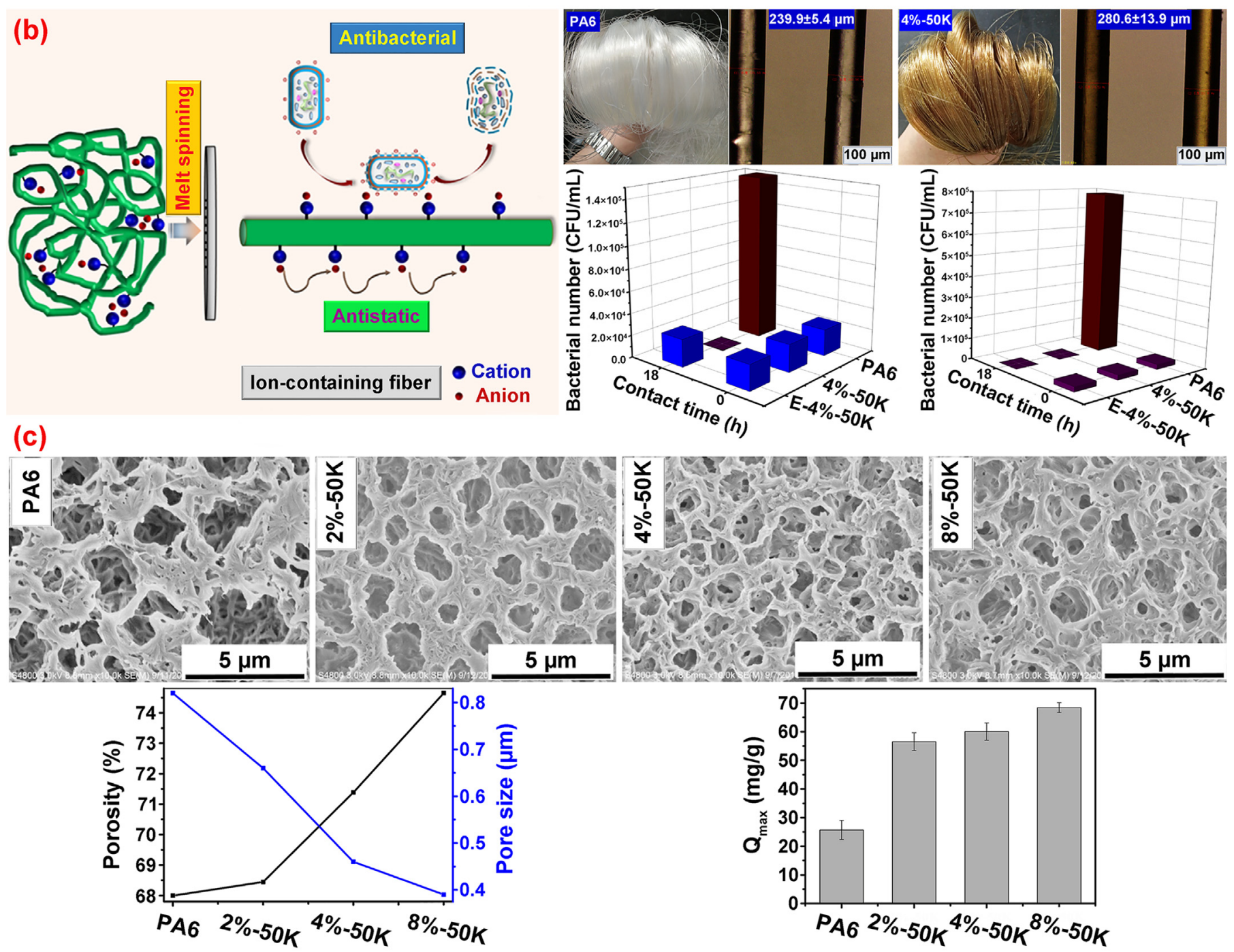

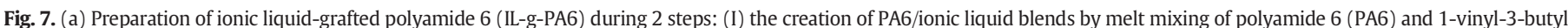

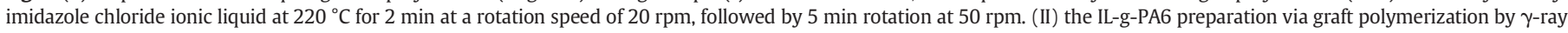

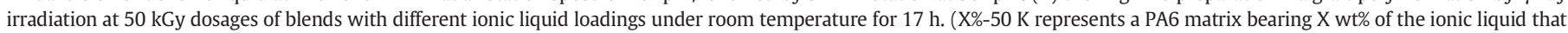

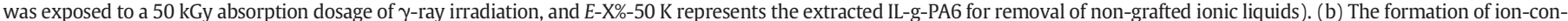

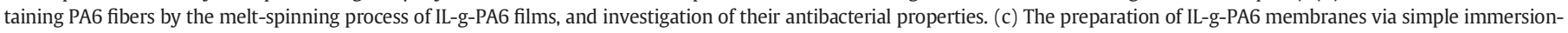

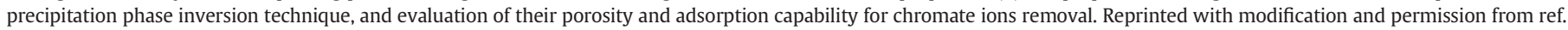
$[111,112]$.

results confirmed that the tenability of membrane's rejection related to the polymerization time and imidazolium ring substitution. The Staphylococcus aureus and Pseudomonas aeruginosa growth were inhibited by PILMs, and the antibacterial effect was dependent on the imidazolium ring substituents.

Recently, antibacterial poly(amino acid ionic liquids) membranes (PAAILMs) were synthesized by blending the poly(amino acid ionic liquids) with polyvinylidene fluoride and were applied to separate the amino acids viz. L-aspartic acid and L-phenylalanine. The PAAILM with L-lysine anion showed $65 \%$ selectivity for the mixed amino acids through one-step separation based on repulsion between positively charged membrane surface and electronegative amino acids. These PAAILMs displayed high mechanical strength and thermostability along with efficient antifouling and antibacterial effects [117]. 

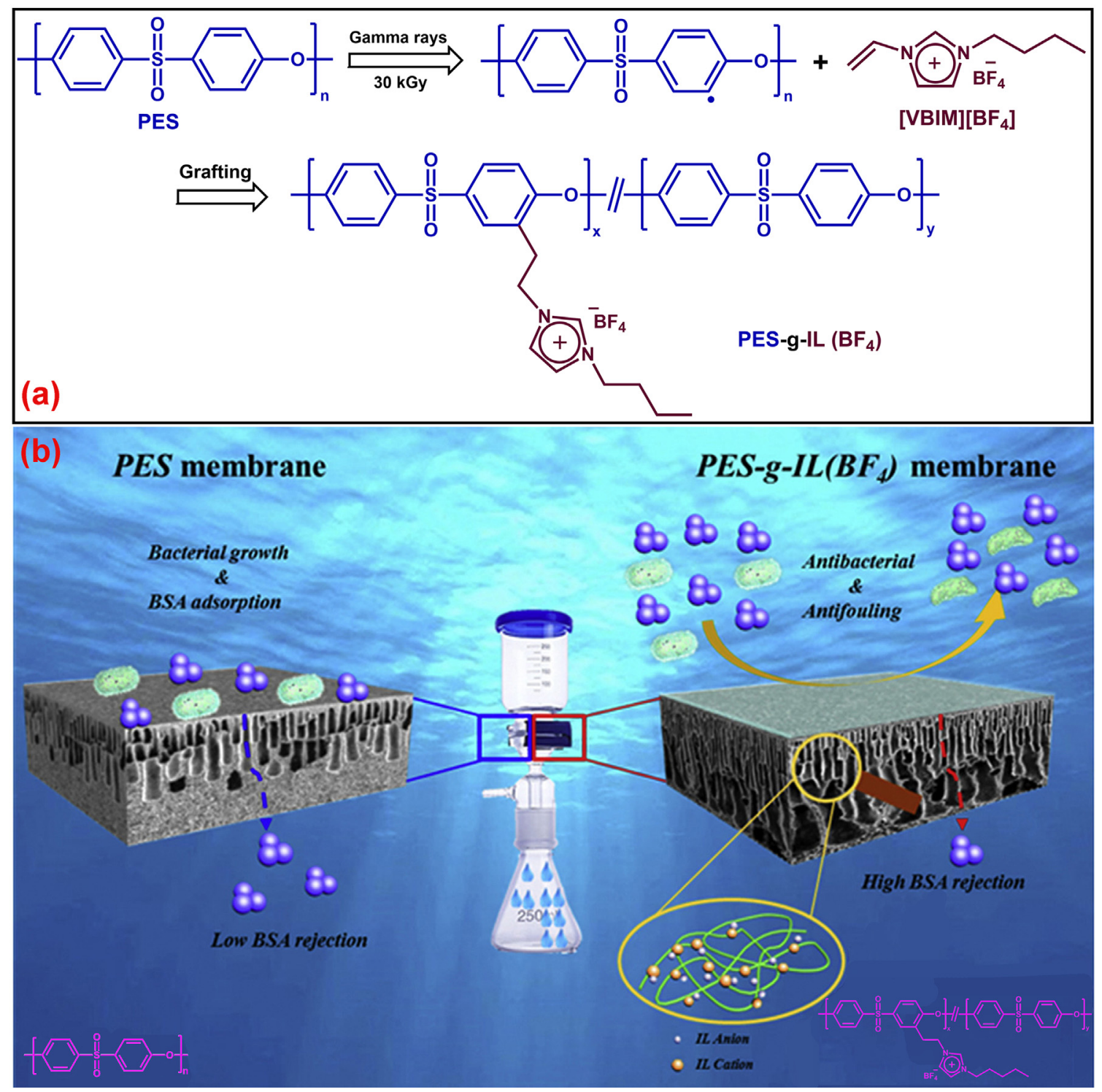

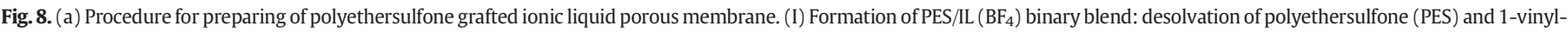

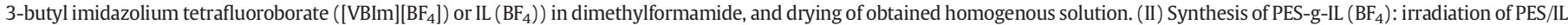

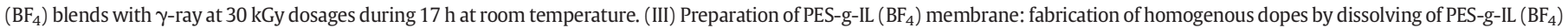

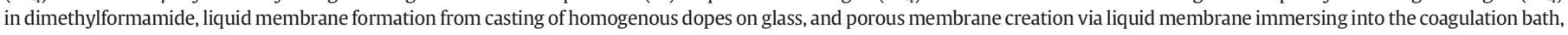

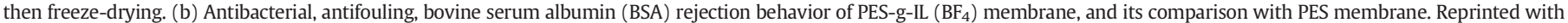
modification and permission from ref. [114].

Antibacterial hyperbranched poly(ionic liquid) functionalized poly (ether sulfone) membrane (PES-g-hbSPG-QPEI) was fabricated via sequential immobilization of hyperbranched polyglycerol (hbSPG) and quaternized polyethylenimine (QPEI) or poly(diallyldimethylammonium chloride) solution (PDDA) on the poly(ether sulfone) (PES) membranes pretreated with polydopamine (PDA) and utilized for osmotic power generation as superior antifouling agents with self-healing property (Fig. 9a). The healable antifouling characteristics of PES-g-hbSPG-QPEI hollow fiber membranes were confirmed by the excellent anti-protein sorption performances and improved antibacterial activities on both, the aged and non-aged samples soaked in real wastewater for two months. Under pressure, retarded osmosis analysis, the poly(ether sulfone) membranes were seriously polluted under high-pressure operation leading to a $60 \%$ flux drop. After back-flushing and hydraulic pressure impulsion, the non-aged membrane was obtained at a recovery rate of $98 \%$ and a flux reduction of $30 \%$, while the aged membranes were obtained in a flux reduction of $40 \%$. The polyionic liquid coating layers with intrinsically antifouling and healable behaviors demonstrated the excellent potential for the construction of high-performance pressure retarded osmosis membranes towards osmotic power generation. The higher chain mobility of polyionic liquid network awards the selfhealing properties to membranes, in which the reversible ion-pair exchange could readily compensate damaged interface edges, leading to repeated healing function, prolonged membrane lifespan, and preserved membrane performance (Fig. 9b). The PES-g-hbSPG-QPEI with hbSPG containing abundant sulfonate groups on the surface-displayed less prone to a bacterial attachment (Fig. 9c) [118].

\subsection{Air filtration}

The rapid urbanization and industrialization for improving the human life have brought unwanted air pollution issues. Air pollutants, especially carbon dioxide and particulate materials are considered the most serious environmental problems causing intense damage to 
(a)
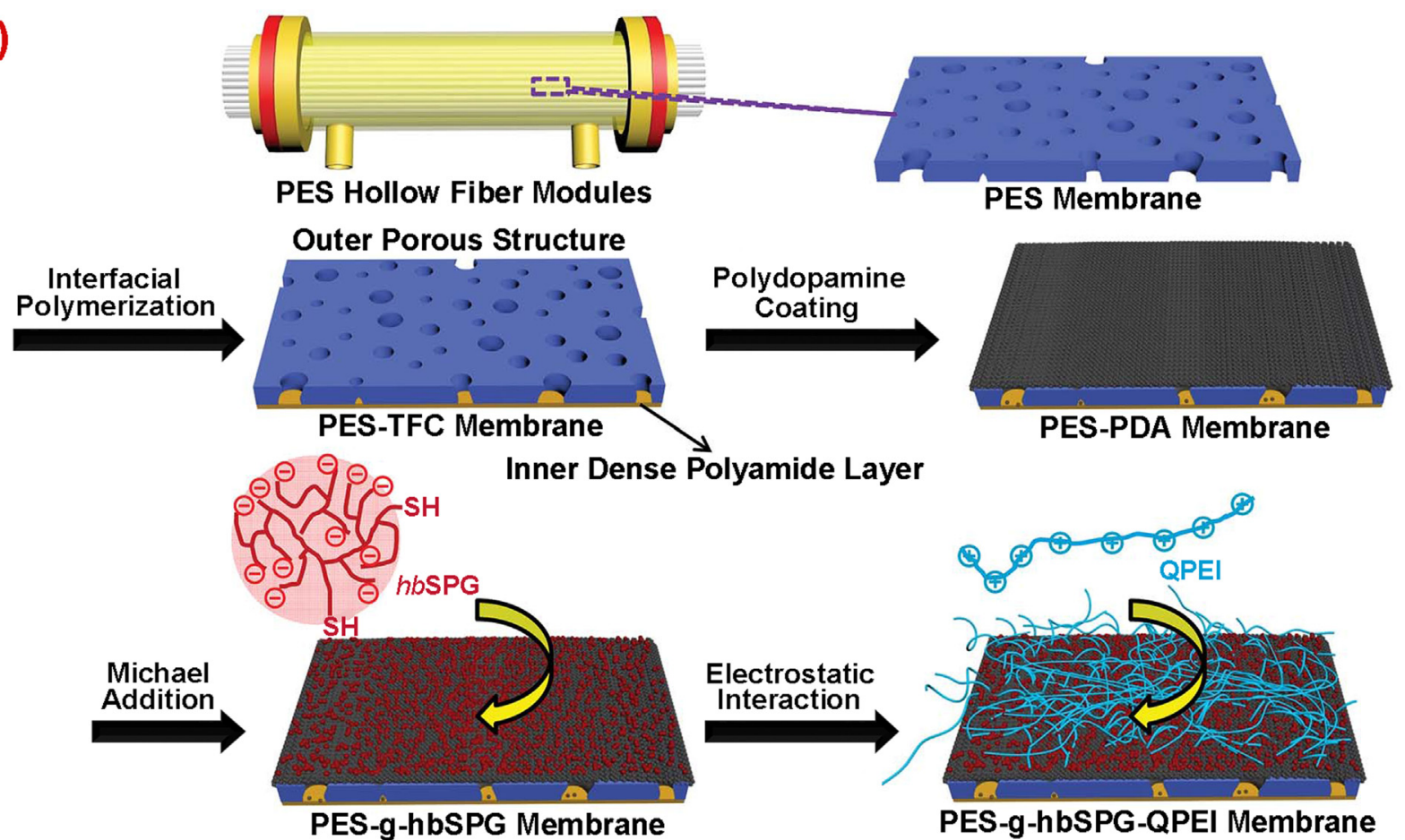

(b)
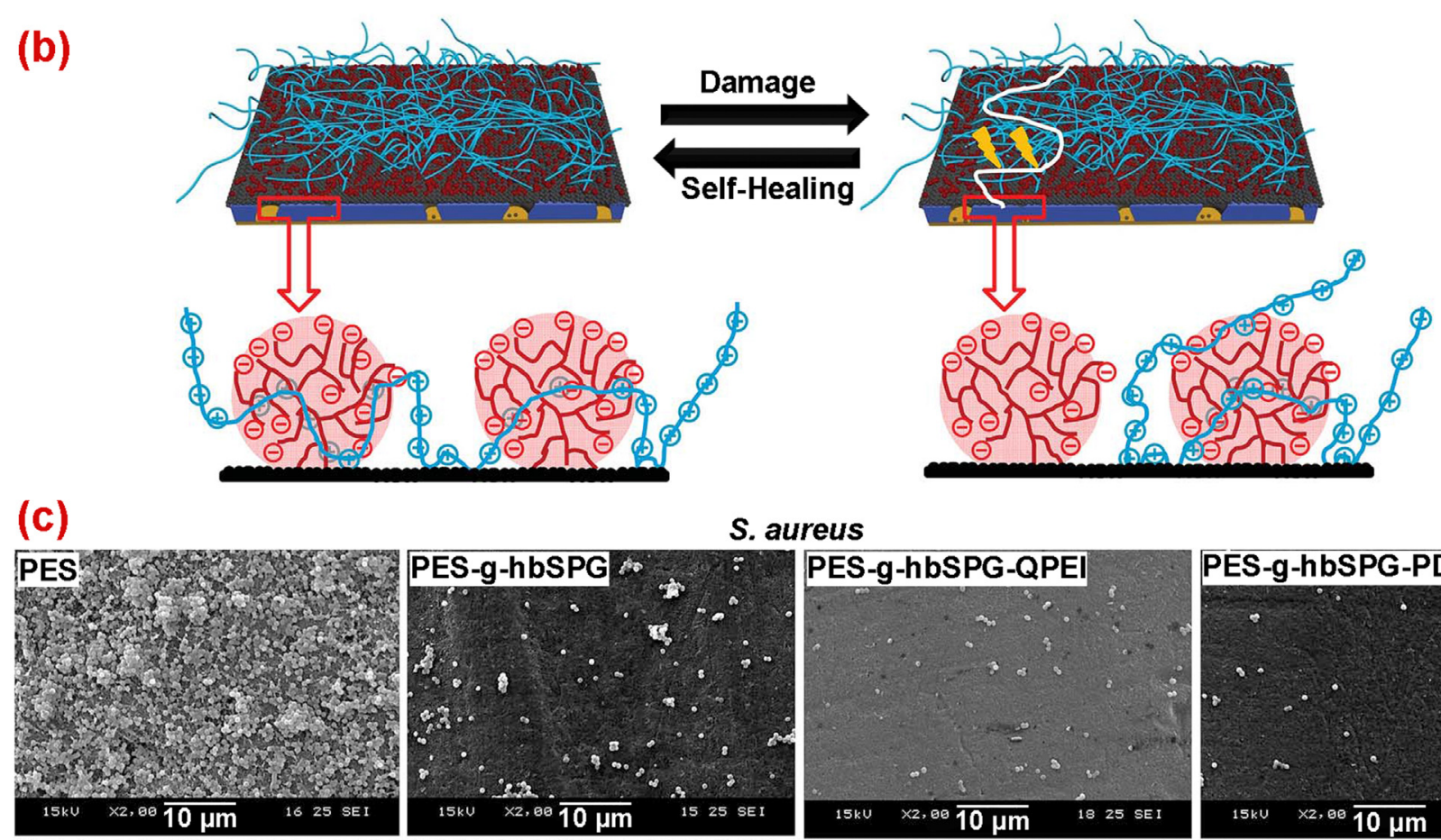

(c)

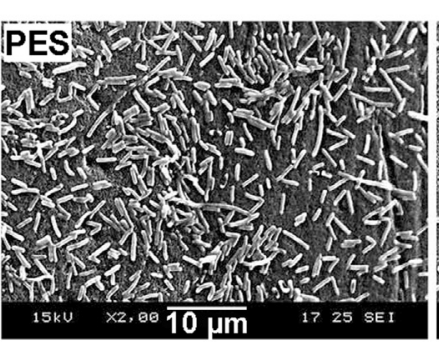

S. aureus

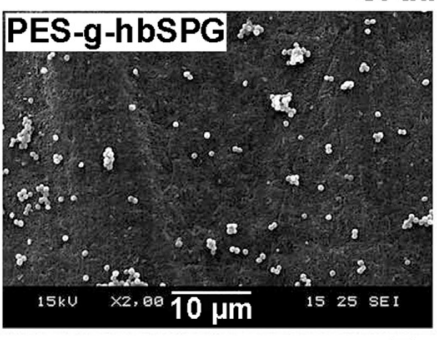

E. coli
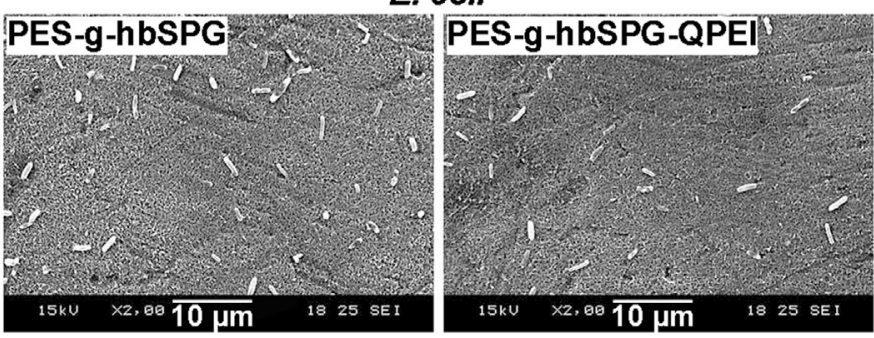
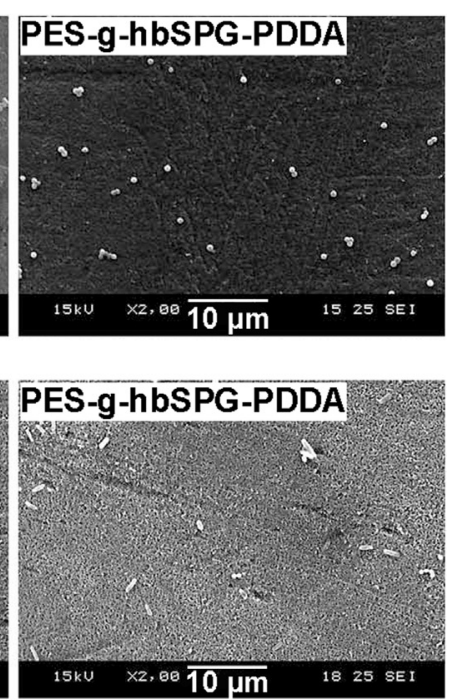
human health [121]. Air pollution is not only harmful to the air passages and lungs but can also damages other organs of the human body [122]. Hence, there have been growing concerns about reducing or eliminating the risks emanating from the air pollutants. Air filtration techniques can eradicate air pollutants and effectively improve the respiratory air quality [123]. The filtration compounds play a key role in the air filtration process, and the design of innovative air filters has received major attention in recent years [123]. However, conventional filtration materials are ineffective for removing extremely small size particles (with particulate material $2.5 \mathrm{~nm}$ ). Consequently, air filtration by using nanofibrous filters and nanofibrous membranes has garnered considerable popularity; especially, electrospun nanofibrous membranes have gained significance in the filtration arena due to their prominent properties [124].

Tiny particulate materials such bioaerosols may carry various viruses, bacteria, and fungi which can cause severe allergic, respiratory, and infectious diseases through airborne transmission, thus necessitating the fabrication of antimicrobial and antiviral air filters [125,126]. Today, ionic liquids-based materials are among the most potential candidates for air filter fabrication because of their exceptional gas separation, photoresists, anticorrosion, and antimicrobial properties thus enabling the development of a fairly new approach in the last two decades. Various types of ionic liquids-based membranes have been applied for air treatment including supported ionic liquid membranes, polymer/ionic liquid composite, polymer/ionic liquid/inorganic composite, and ionic liquid-gelled membranes [127].

In this context, an antimicrobial fibrous mat (PLA/PHB-IL) was prepared from polylactide/polyhydroxybutyrate (PLA/PHB) nanofibers that are functionalized with quaternary ammonium-based ionic liquid and utilized for aerosol particle filtration [10]. The capability of the electrospun nanofibrous mat was considered by assessing the filter penetration of sodium chloride aerosol particles, and the results revealed that the quality factors were dependent on the electrospinning time to attain a fiber diameter of $\sim 500 \mathrm{~nm}$ with the distribution of 350 fibers in filter mat. The PLA/PHB-IL biodegradable filters displayed fungicide activity against Aspergillus niger and Chaetomium globosum, and the antifungal effects could be improved with increasing ionic liquid concentration. Consequently, the ionic liquid functionalized nanofibers not only could be used for antimicrobial air filtration but also can create "eco-friendly" compounds due to their biodegradable behavior.

The cellulose acetate/poly(ionic liquid) composite was prepared as an antimicrobial air filter for the elimination of inhalable particulate materials via macromolecular design and electrostatic spinning technique (Fig. 10a) [128]. The diameter of fibers was efficiently reduced by an introduction and increased content of poly(ionic liquid)s, and so the nanofibrous filters were obtained with a removal rate of $99.65 \%$ for particulate materials $10 \mathrm{~nm}$ (Fig. 10b). The nano-filters exhibited antibacterial activities against Escherichia coli and Staphylococcus aureus, without obvious cytotoxic effects on cultured cells (Figs. 10c and d). The nanofilters preserved the fibrous morphology and outstanding antimicrobial effects after multiple recycling, owing to the sturdy covalent bonds of poly(ionic liquid)s with cellulose acetate (Fig. 10d). In contrast, the filters containing ionic liquids moieties with excellent hydrophilicity and solubility are prone to be lost during application making it hard to recycle. As a result, the need of the hour for progress in this field is to prepare filters with low air resistance, high recyclability as well as good biocompatibility, and environmentally friendly behavior.

\subsection{Food packaging}

Food packaging is an integral part of the food industry to improve the food protection and safety. The development of novel innovative packaging materials with antimicrobial properties can be achieved by adding agents such as antimicrobial ionic liquids to inhibit microbial growth by reducing live counts of microbes [129]. Green antimicrobial composite films have been prepared using 1-allyl-3-mthylimidazolium chloride and biopolymers such as cellulose, starch, and lignin. as suitable candidates for fresh food packaging [130].

A bioactive ionic liquid i.e. choline salicylate was utilized for the production of gelatin-based ionogel films (Figs. 11a) with enhanced antimicrobial and antioxidant features [11]. The ionic liquid acted as a plasticizer in the structure of the film and did not experience any chemical changes during the synthesis process. The ionic liquid/gelatin-based films exhibited excellent bacterial growth inhibition compared to the films without ionic liquid. This may be due to the good antibacterial effect of cholinium salicylate against Bacillus subtilis (Fig. 11b). The ionic liquid-loaded films also demonstrated the ability to improve the shelf life of Malus pumila (red apple) by preventing air oxidation (Fig. 11c); films displayed exceptional ultraviolet shielding and antioxidant properties with high mechanical strength. The results of antioxidant activity induced by free radical scavenging assay revealed that the radical scavenging effect did not occur in the film without ionic liquid whereas the ionic liquid loaded films with increased ionic liquid concentration displayed increased antioxidant capacity (Fig. 11d).

Likewise, cholinium citrate and cholinium hexanoate ionic liquids were used in combination with pullulan and chitosan for the preparation of biocompatible and antibacterial transparent films. The films prepared with chitosan indicated antibacterial activity against Klebsiella pneumoniae and Staphylococcus aureus, whereas for pullulan the film is bioactive when prepared with cholinium citrate [131].

Overall, the application of ionic liquids for the preparation of food packaging films is very limited compared to bioactive or biopolymerbased films. In the future, research needs to be preferentially focused on the development of active, intelligent, and stable films as well as efforts to enhance safety by preventing the associated toxicity of film which could be encountered when they are exposed to the natural environment. These materials packaging films can be optimized further and commercialized for deployment as active and intelligent packaging for visual quality evaluation of fresh food products [132].

\subsection{Coating}

A topical issue for materials sciences is the protection of materials surfaces by coating, thus an inclusive diversity of coating techniques are accessible with a common purpose of surface protection from chemical or physical damages, and biodegradation [13]. Although the coating strategy affords advantages, there are still disadvantages restricting their usage. According to the rules governing human health and environmental protection, the use of hazardous compounds is severely forbidden in coating technology. These restrictions along with the absence of alternate coating techniques to fulfill all the technological requirements prompted the creation of a new coating strategy. In this regard, scientists are paying significant attention to designing and fabricating smart and green coating materials. The manufacture of

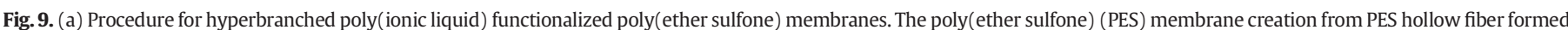

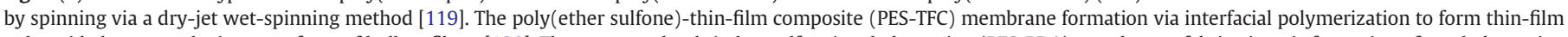

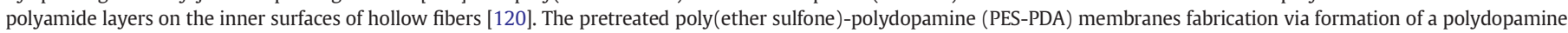

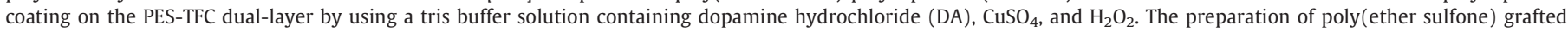

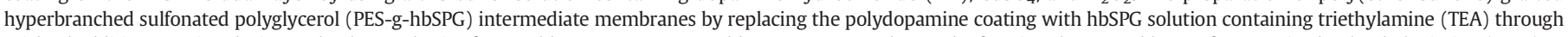

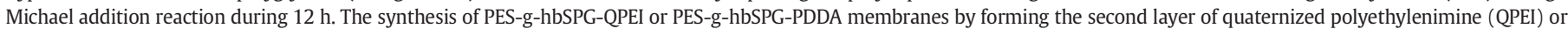

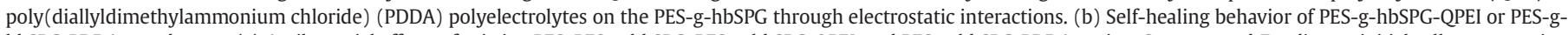

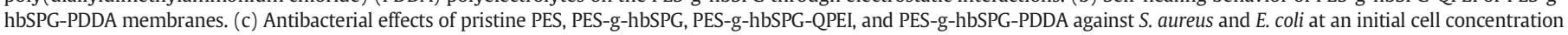
of $10^{8} \mathrm{CFU} / \mathrm{mL}$ at $37^{\circ} \mathrm{C}$ for $6 \mathrm{~h}$. Reprinted with modification and permission from ref. [118]. 
non-toxic smart coatings has gained widespread attention through the developments of low-hazardous air/water pollutants and low-volatile organic compounds, endowed with super-hydrophobic, anti-wearing, antimicrobial, anti-corrosion, self-cleaning, and self-healing behaviors
[133]. The smart coatings, fabricated from responsive materials that respond actively to environmental changes, have special tasks including sensing, protecting, and healing [134]. The protection quality of coatings was improved via the development of advanced smart

(a)

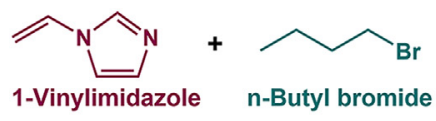

$\underset{\substack{\text { R.T. } \\ 5 \text { Days }}}{\stackrel{\text { thyl acetate }}{\longrightarrow}}$<smiles>C=Cn1cc[n+](CCCC)c1</smiles>

Days 1-Vinyl-3-butylimidazolium bromide [VBIm]Br
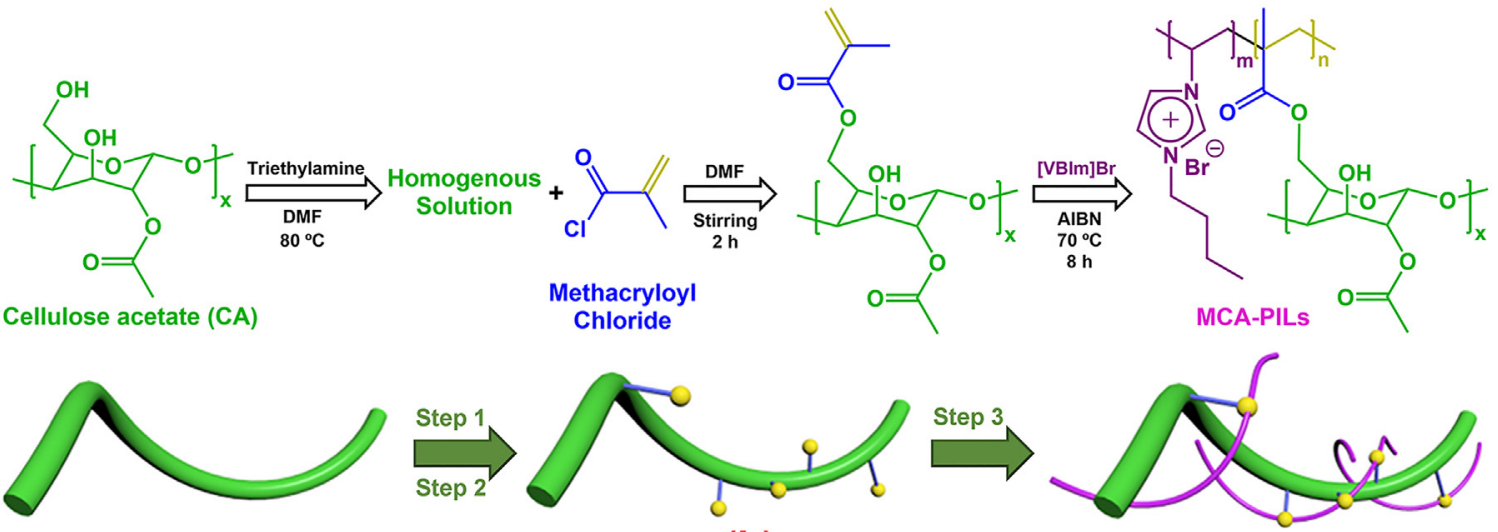

(b)

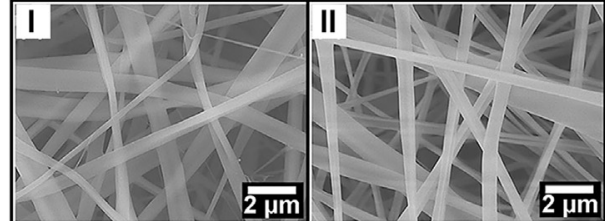

E. coli
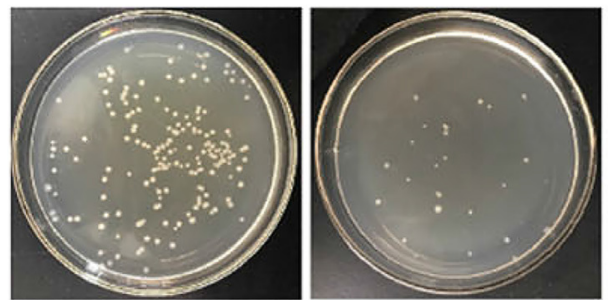

S. aureus
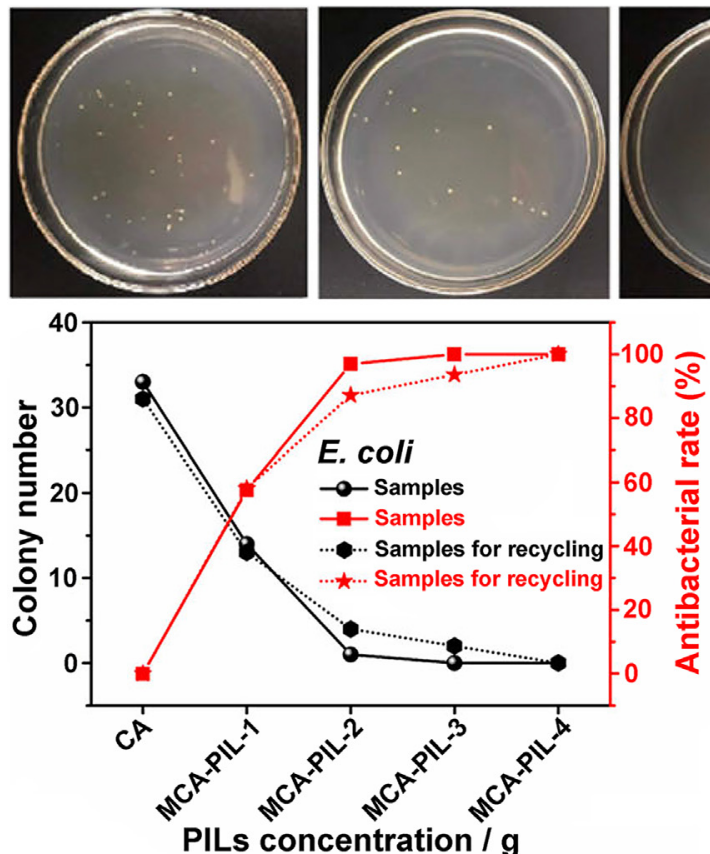

(c)
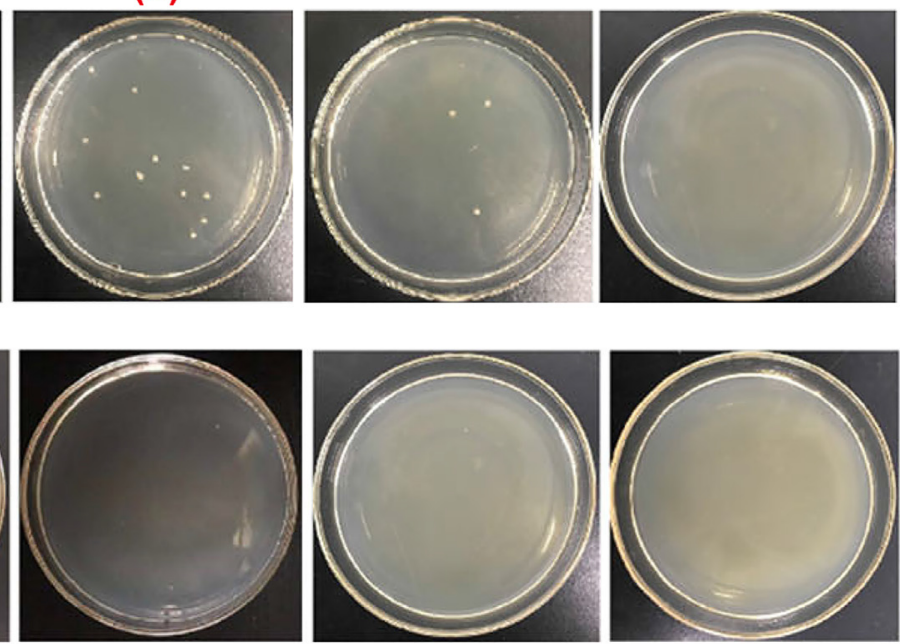

(d)

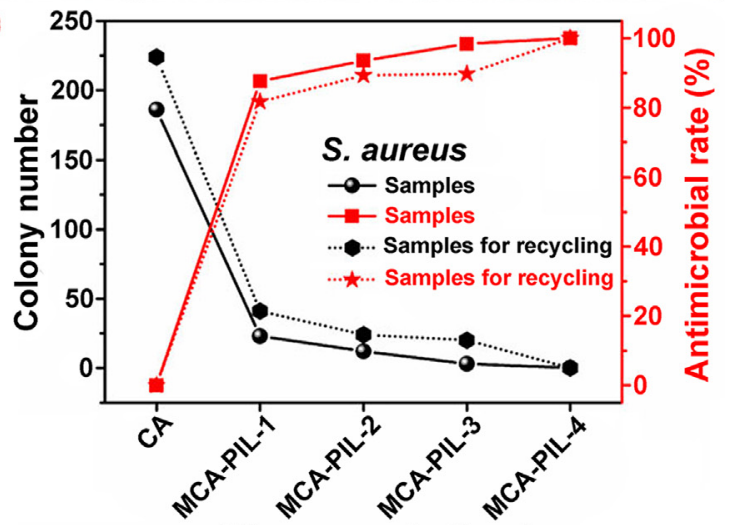

PILs concentration / g 
coating techniques by using ionic liquid-based materials with unique properties.

The antibacterial stainless steel has been prepared through ionic liquids grafting onto the stainless steel surface via silane modification followed by the thiol-ene click reaction [135]. The antibacterial effect of ionic liquids grafted stainless steel (IL-g-SS) was investigated against Escherichia coli, and the results indicated the significant antibacterial activity of IL-g-SS which could be due to the lipophilicity of imidazolium ring with long alkyl chains. The antibacterial activity of IL-g-SS could also be related to the counter anion of imidazolium cation. It has been reported that the ionic liquids with bromide anion exhibited better antibacterial activity than ionic liquids with hexafluorophosphate and tetrafluoroborate anions. The stability of IL-g-SS surface was assayed, and the obtained results established that the Escherichia coli growth was efficiently inhibited by IL-g-SS after 5 cycles, representing its considerable durability and stability under operating conditions.

In another study, the ionic liquid-based block copolymers, alternating copolymers, and statistical copolymers were prepared from ionic liquid homopolymers containing a polycation/polyanion structure fabricated with ionic liquid monomers substituted with a polymerizable group [136]. The prepared polyionic liquids, via free radical polymerization and group transfer polymerization mechanisms, were applied as binders in coating processes due to their admirable film formation behavior; their antimicrobial activities were examined against Escherichia coli and Micrococcus luteus. These studies demonstrated that the antibacterial effect of hydrophilic homopolymers containing imidazolium or pyrrolidinium cation and 4-vinylbenzene moiety, and hydrophilic copolymers with alternating positive and negative sections can lead to the formation of antimicrobial polyionic liquids surfaces.

Ionic liquid bearing 3-(12-mercaptododecyl)-1-methyl-1Himidazol-3-ium bromide ( $\mathrm{IL}(\mathrm{Br}))$ moiety was prepared with the minimum inhibitory concentration against Staphylococcus aureus $(4 \mu \mathrm{g}$ $\mathrm{mL}^{-1}$ ) and Escherichia coli $\left(8 \mu \mathrm{g} \mathrm{mL} \mathrm{L}^{-1}\right)$. The molecular brushes decorated ion-responsive surface $\mathrm{IL}(\mathrm{Br}) / \mathrm{PDA} @ P E S$ was fabricated from the thiol-terminated IL(Br) clicked onto the poly(ethersulfone) (PES) membrane using polydopamine (PDA) coating as a post-functionalization platform [137]. The antibacterial IL(Br)/PDA@PES surface was assayed for bacteria-killing, and the antibacterial results showed the high bactericide efficiency of 94\% and 99\% against Escherichia coli and Staphylococcus aureus, respectively. The IL(Br)/PDA@PES surface could release the dead bacteria by an anion-exchange of $\mathrm{Br}^{-}$with $\mathrm{Tf}_{2} \mathrm{~N}^{-}$because of the ionic liquid ion sensitivity, and the releasing efficacies were $95 \%$ and 97\% for Escherichia coli and Staphylococcus aureus, respectively. So, this intelligent antibacterial coating fabricated via a facile mussel-inspired method could achieve long-term sterilization through a simple counter anions exchange.

The neutral and ionic hybrid compounds, containing diaminothiadiazole Schiff-bases or 1,2,4-triazole and ionic liquid terminal sections, have been synthesized by a combination of quaternization, heterocyclization, and Schiff-base strategies [138]. The triazole derivative was prepared to form 4-tert-butylphenol through subsequent alkylation, hydrazinolysis, nucleophilic addition, and heterocyclization reactions. The in vitro bacterial growth inhibition of ionic liquid-based hybrids exhibited broad bactericide efficiency and modest to excellent antibacterial effects compared with $\mathrm{DCMU} \circledast$, as a standard antifoulant, against Staphylococcus aureus, Escherichia coli, Aeromonas hydrophila, and Vibrio sp. as common parts of marine bacteria with biofilm- inducing ability. The ionic liquid-based hybrids were combined with the inert commercial paint matrix to create the anti-biofouling coatings. The anti-biofouling ionic liquid-based hybrids could successfully prevent the creation of slime films, the adhesion and invasion of marine biofouling organisms including asidian, bryozoan, macroalgae, tube worms, and zooids onto the coated surfaces. The most effective antifouling behavior was dedicated to 2,5-bis-(3-methoxysalicylideneimino)1,3,4-thiadiazole with astonishing resistance for colonization of zooids ( $0 \%$ settlement during 147 days), red algae (0\% settlement during 147 days), and tube worms (12\% settlement after 147 days). Thus, the blending of ionic liquid-based hybrid can offer promising antifouling composites for coating purposes to fight against marine biofoulings.

Ionic liquids encompassing benzylidene-bis-iminothiazole and salicylidene-iminothiazole Schiff bases have been prepared and explored for their antifouling and antibacterial properties [139]. The synthesized ionic liquids-based Schiff bases inhibited the growth of broad-spectrum bacteria, against Escherichia coli, Aeromonas hydrophila, Vibrio sp., and Staphylococcus aureus as the most common marine biofilm-inducing bacteria, with moderate to excellent bactericide actions. Inhibition zone examination demonstrated that the synthesized ionic liquids-based Schiff bases displayed higher efficacy against Gram-negative bacteria, Escherichia coli, and Aeromonas hydrophila. The integration of bactericidal ionic liquid-based Schiff bases into the matrix of inert commercial paints for coating formulations meaningfully improved the antifouling property of coatings applied in polyacrylic panels.

Biofouling assessment of new ionic liquid-based Schiff bases indicated that the majority of tested coatings showed the considerable anti-biofouling effect relative to the Diuron ${ }^{\circledR}$ antifoulant-containing coating under strict marine conditions. The extraordinary usefulness of ionic liquid-based Schiff bases for inhibition of biofilm formation, fouling with bryozoans, colonization of barnacle and macro-algal, tube-worms settlement, and growth of ascidians and zooids can provide the next generation of outstanding antifouling additives.

The thermostable and hydrophobic epoxy-amine networks have been fabricated from imidazolium ionic liquid monomers containing a resembling structure of bisphenol A diglycidyl ether epoxy prepolymer, with no usage of toxic epichlorohydrin and bisphenol A via a one-step polyaddition reaction-based polymerization [140]. These cross-linked epoxy networks represented strong inhibition against Escherichia coli biofilm formation ( $95 \%$ ), and their antibacterial activity is primarily associated with the hydrophobicity of polymeric networks. Thus, the development of epoxy coatings was considered a promising strategy for the construction of an antibacterial active surfaces.

\subsection{Anticorrosion}

Microorganisms in non-sterile solutions can significantly affect the materials/solutions interface structure and can form biofilms onto the surface of materials. The microbial colonization and the biofilms accumulation onto materials surface can cause localized gradients of dissolved oxygen, corrosive anions, and $\mathrm{pH}$, resulting in an accelerated corrosion rate [141]. Therefore, the microbial corrosion which is initiated by microbes must be mitigated by killing the microorganisms or inhibiting their growth rate not only in the solutions but also on the surfaces of the materials in the environment. For this purpose, the design of new compounds with biostatic or biocidal properties was considered

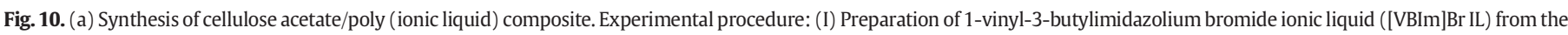

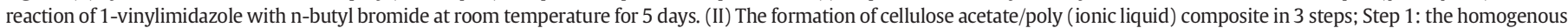

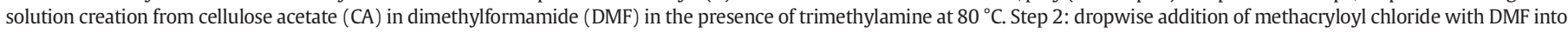

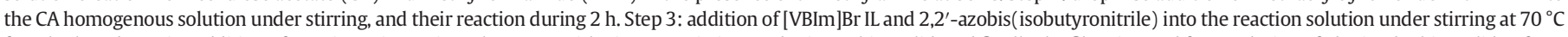

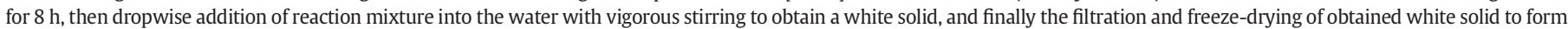

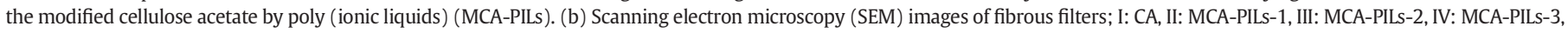

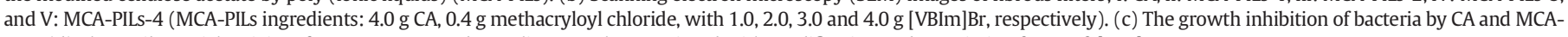
PILs. (d) The antibacterial activity of CA, MCA-PILs, and recycling samples. Reprinted with modification and permission from ref. [128].
} 


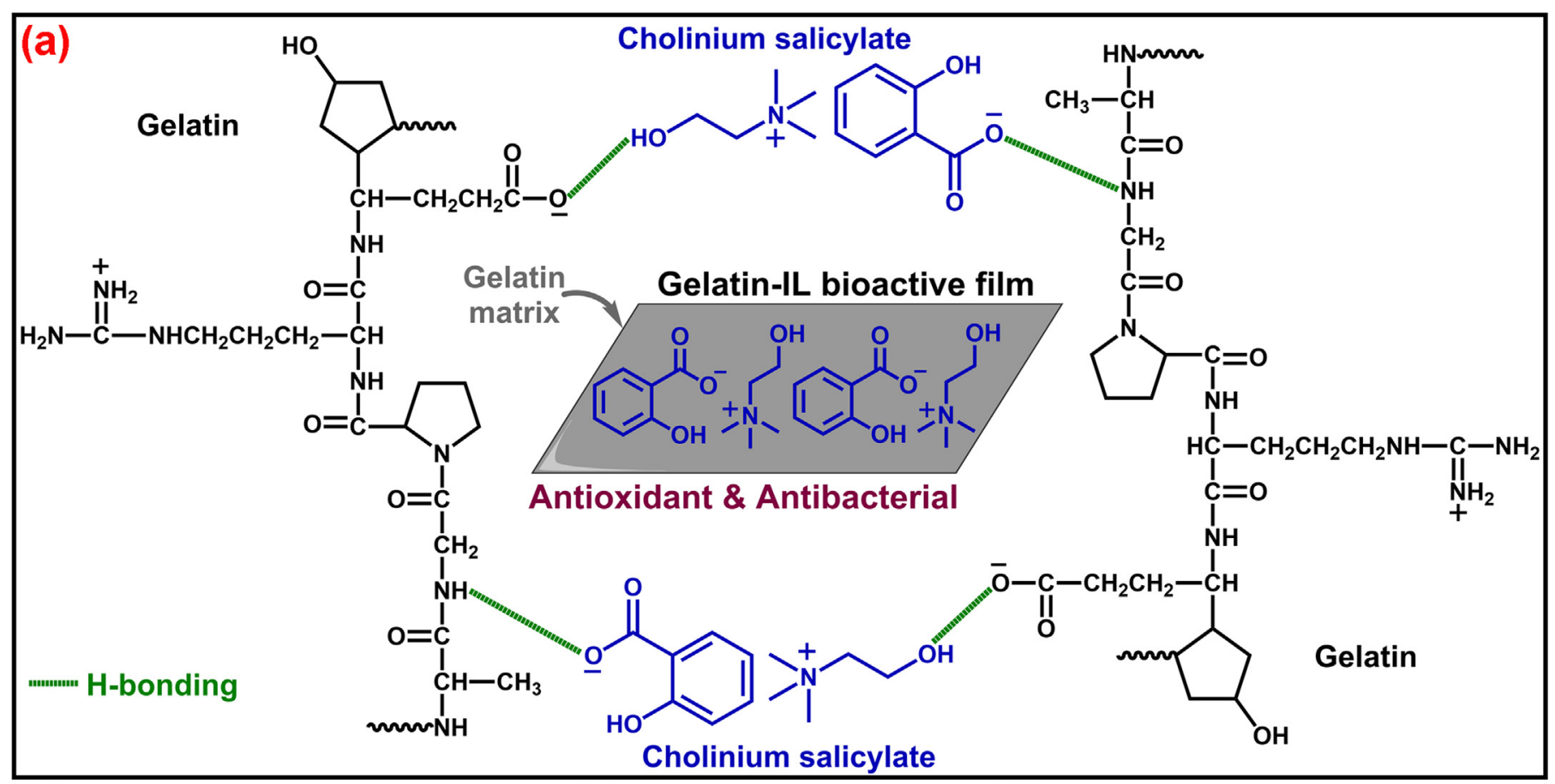

(b)

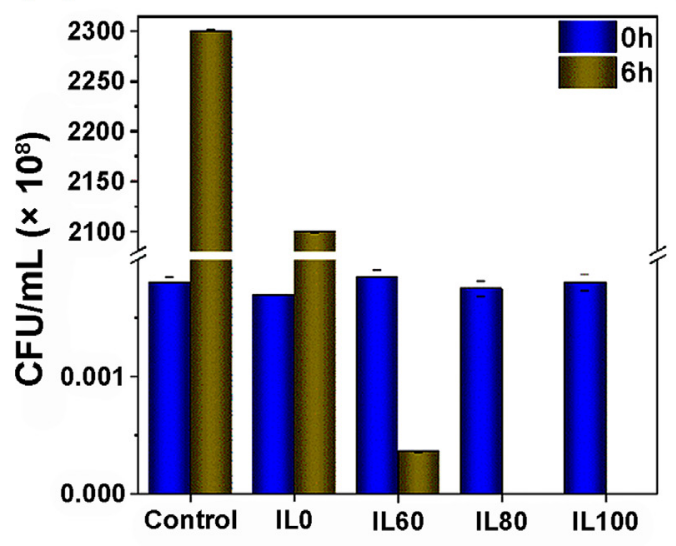

(c)

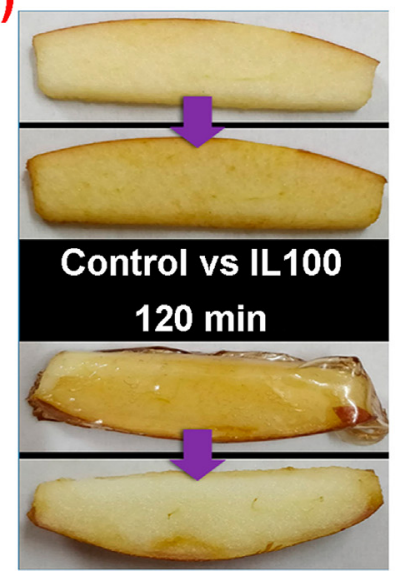

(d)

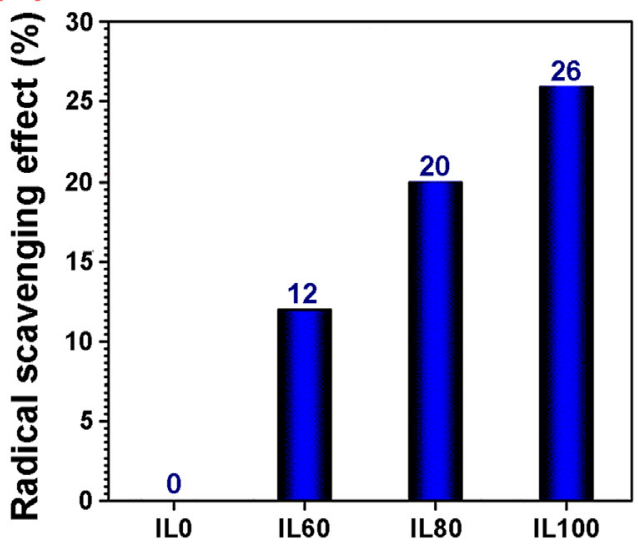

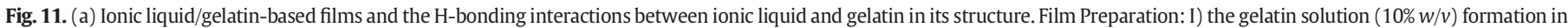

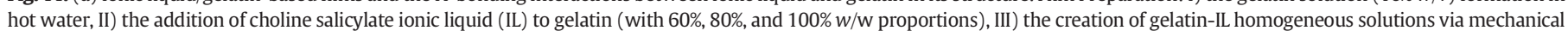

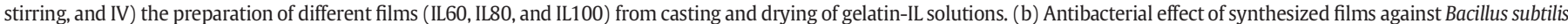

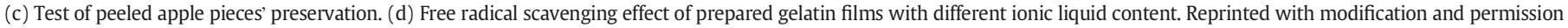
from ref. [11].

which avoids the environmental microbial corrosion. In this context, the role of ionic liquid-based antimicrobial materials with anticorrosion impacts is reviewed here.

Metal and alloy microbial corrosion is an environmental issue that has been a serious industrial problem because it constitutes about one-fifth of the overall damages caused by corrosion. Hence, the anticorrosion effects of ionic liquid-based antimicrobial materials were investigated onto metals and metal-based materials. Recently, the antibacterial and anti-corrosion effects of 1-butyl-1-methyl pyrrolidinium trifluoromethyl sulfonate ([Py1,4]TfO) ionic liquid were studied on the planktonic and sessile bacterial growth, and mild steel corrosion [12]. The obtained results revealed that the sessile and planktonic bacterial growth was efficiently inhibited by using the [Py1,4]TfO, and the inhibition efficacy was dependent on the $[\mathrm{Py} 1,4]$ TfO concentration. The growth inhibition of sessile bacteria required a higher concentration of $[$ Py1,4]TfO in comparison to the planktonic bacteria. The anticorrosive efficiency of [Py 1,4]TfO on the mild steel has also been evaluated in $3.5 \% \mathrm{NaCl}$ solutions via potentiodynamic polarization and impedance spectroscopy analyses. The anticorrosive effect of more than $80 \%$ was attained by using $100 \mathrm{mg} \mathrm{L}^{-1}$ of $[$ Py1,4]TfO on the surface of mild steel. The anticorrosion influence of $[\mathrm{Py} 1,4]$ TfO is related to the adsorption of ionic liquid onto the mild steel surface and the formation of a protective layer against the corrosion attack.

The anticorrosion and antibacterial activities of ionic liquidsbased on benzalkonium chloride derivatives (BCILs; $N$-benzyl- $N$, $\mathrm{N}$-dimethyldodecan-1-aminium chloride: ILa, $\mathrm{N}, \mathrm{N}$-dimethyl- $\mathrm{N}$-(4methylbenzyl)dodecan-1-aminium chloride: ILb, $N$-(4-chlorobenzyl)$\mathrm{N}, \mathrm{N}$-dimethyldodecan-1-aminium chloride: ILc, and $\mathrm{N}, \mathrm{N}$-dimethyl- $\mathrm{N}$ (4-nitrobenzyl)dodecan-1-aminium chloride: ILd) were examined for the carbon steel immersed in the contaminated solution by sulfatereducing bacteria [142]. The BCILs displayed high anticorrosive efficacy in contaminated solution by sulfate-reducing bacteria even at low concentration, due to the capability of BCILs to adsorb on the surface of carbon steel. The order of BCILs biocidal activity was determined to be ILc $<$ ILd $<$ ILa $<$ ILb, and the minimum inhibitory concentration against planktonic sulfate-reducing bacteria mixed consortium was reported 


\section{POM-ILs POM-ILs formula}

POM-IL $1 \quad\left[\left(\mathrm{n}-\mathrm{C}_{7} \mathrm{H}_{15}\right)_{4} \mathrm{~N}\right]_{8}\left[\alpha-\mathrm{SiW}_{11} \mathrm{O}_{39}\right]$

POM-IL $2 \quad\left[\left(\mathrm{n}-\mathrm{C}_{6} \mathrm{H}_{13}\right)_{3}\left(\mathrm{C}_{14} \mathrm{H}_{29}\right) \mathrm{N}\right]_{8}\left[\alpha-\mathrm{SiW}_{11} \mathrm{O}_{39}\right]$

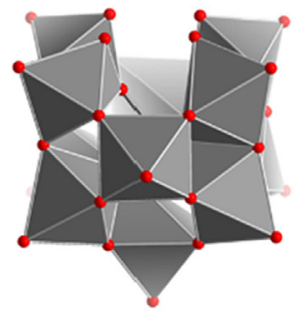

$$
\left[\alpha-\mathrm{SiW}_{11} \mathrm{O}_{39}\right]^{8-}
$$

\section{Stone type Coating}

$\begin{array}{lc}\text { BB } & - \\ \text { BB } & \text { POM-IL 1 } \\ \text { BB } & \text { POM-IL 2 } \\ \text { RO } & - \\ \text { RO } & \text { POM-IL 1 } \\ \text { RO } & \text { POM-IL 2 } \\ \text { DO } & - \\ \text { DO } & \text { POM-IL 1 } \\ \text { DO } & \text { POM-IL 2 }\end{array}$

(a)

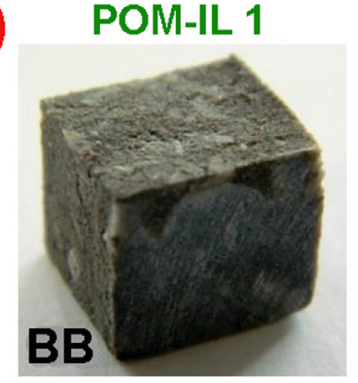

Acid rain test Weight loss [Wt\%]

$28.0 \pm 0.4$

$7.0 \pm 0.5$

$10.6 \pm 0.4$

$32.1 \pm 0.6$

$5.9 \pm 0.4$

$7.6 \pm 0.4$

$84.4 \pm 0.4$

$13.5 \pm 0.4$

$18.5 \pm 0.4$
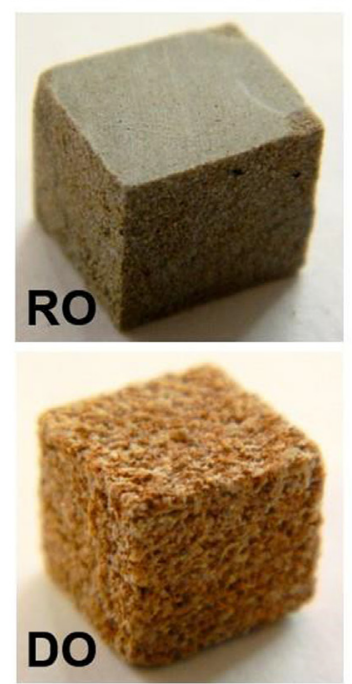
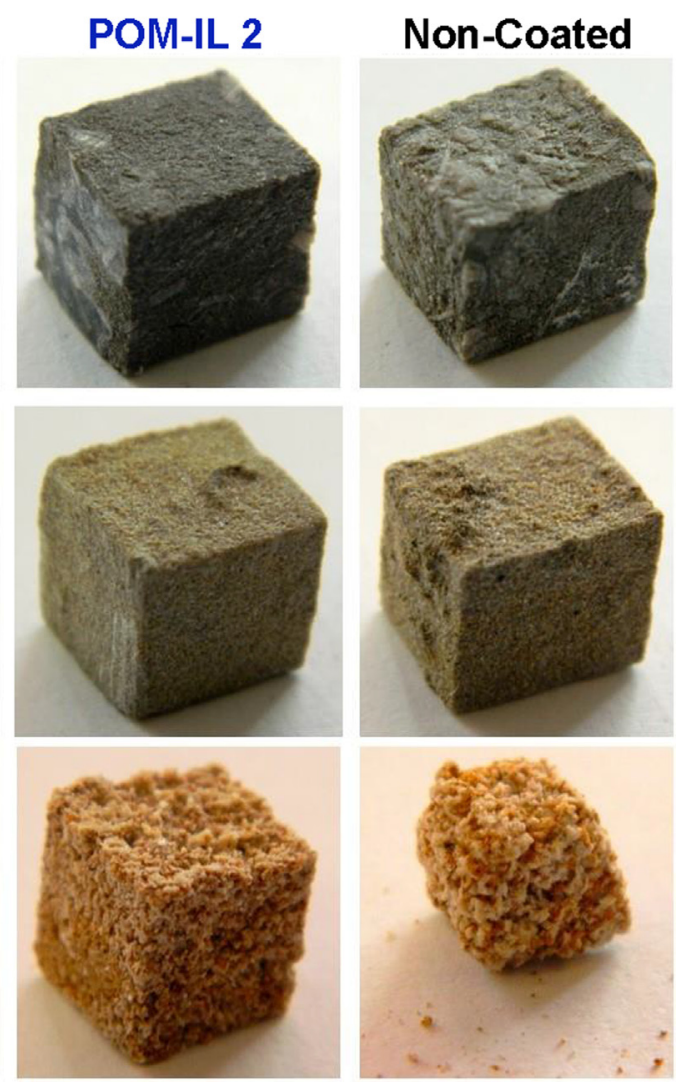

(b)

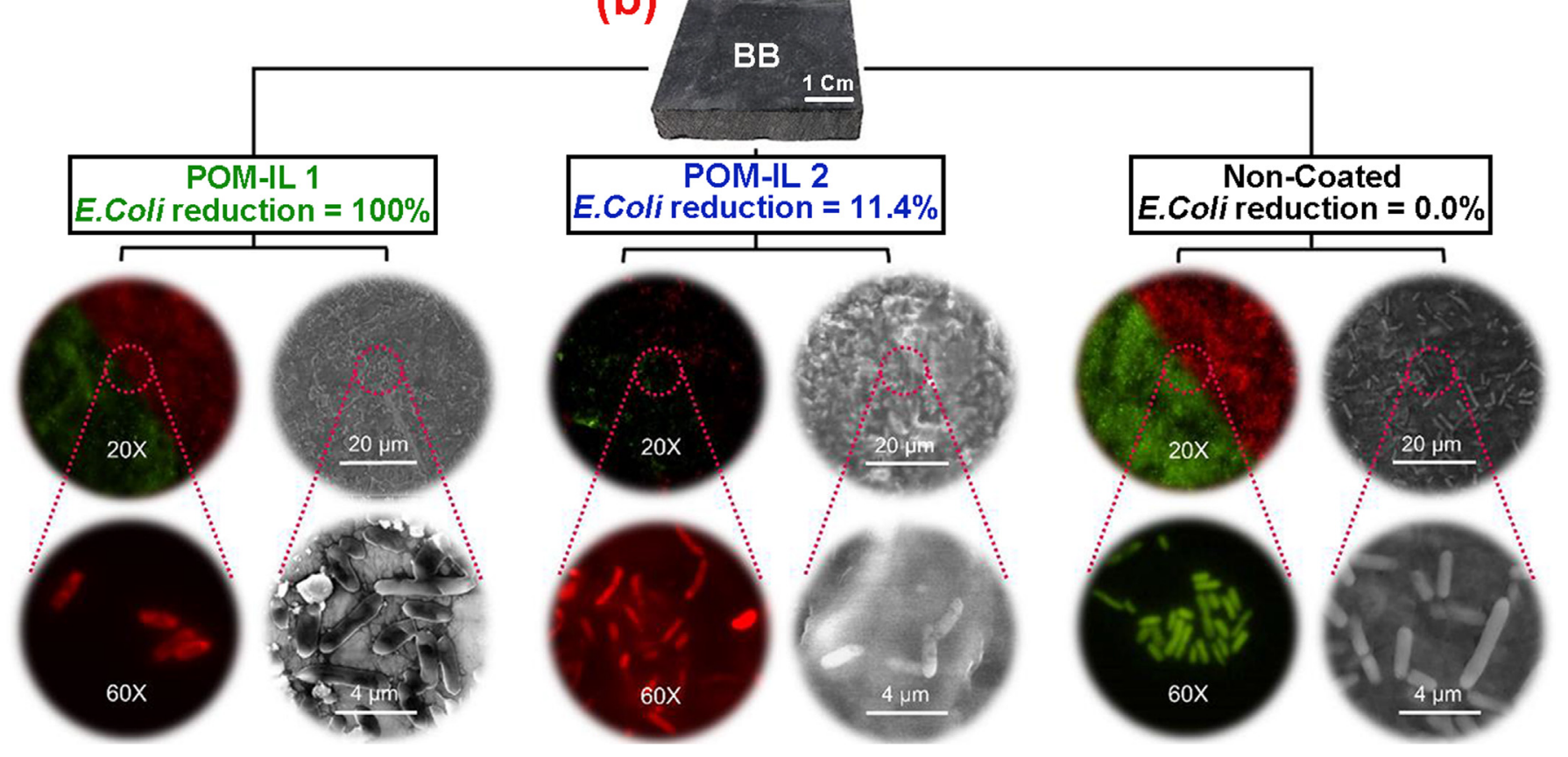

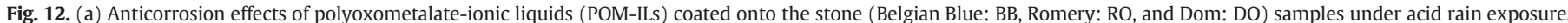

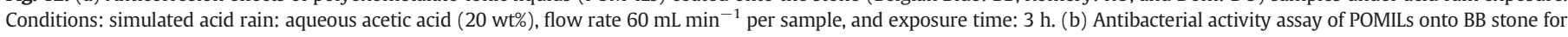

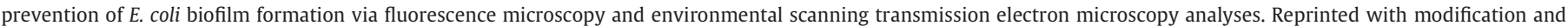
permission from ref. [144].

to be $200,100,50$, and $25 \mu \mathrm{g} \mathrm{mL}{ }^{-1}$ for ILc, ILd, ILa, and ILb, respectively. The BCILs biocidal effects against sulfate-reducing bacteria were controlled by an electron transfer mechanism. The sulfate-reducing bacteria tend to respond to the electron donors ILa and ILb with higher biocidal efficacy compared to the electron withdrawers ILc and ILd with lower biocidal activities. The results confirmed that the BCILs performance as corrosion inhibitors depended on the structure and concentration of ionic liquids cation. Therefore, the BCILs are considered promising protective additives in the petroleum industry to protect metal structures from corrosion and bio-corrosion. 
(a)<smiles>[19N][Mg]</smiles>

POM-IL Short Name

$\left[P W_{12} \mathrm{O}_{40}\right]\left[\left(\mathrm{C}_{6} \mathrm{H}_{13}\right)_{4} \mathrm{~N}\right]$ $\left[\mathrm{PW}_{12} \mathrm{O}_{40}\right][\mathrm{THexA}]_{3}$

$\left[\mathrm{PW}_{12} \mathrm{O}_{40}\right]\left[\left(\mathrm{C}_{7} \mathrm{H}_{15}\right)_{4} \mathrm{~N}\right]_{3}$ $\left[\mathrm{PW}_{12} \mathrm{O}_{40}\right]\left[\mathrm{THepA}_{3}\right.$

$\left[\mathrm{PW}_{12} \mathrm{O}_{40}\right]\left[\left(\mathrm{C}_{8} \mathrm{H}_{17}\right)_{4} \mathrm{~N}\right]_{3}$ $\left[\mathrm{PW}_{\mathbf{1 2}} \mathrm{O}_{40}\right][\text { TOctA }]_{3}$

$\left[\mathrm{SiW}_{11} \mathrm{O}_{39}\right]\left[\left(\mathrm{C}_{8} \mathrm{H}_{17}\right)_{4} \mathrm{~N}\right]_{8}$ $\left[\mathrm{SiW}_{11} \mathrm{O}_{39}\right][\text { TOCtA }]_{8}$ $\left[\mathrm{SiW}_{11} \mathrm{O}_{39}\right]\left[\left(\mathrm{CH}_{3}\right)_{3}\left(\mathrm{C}_{8} \mathrm{H}_{17}\right) \mathrm{N}\right]_{8} \quad\left[\mathrm{SiW}_{11} \mathrm{O}_{39}\right][\mathrm{TMOA}]_{8}$ $\left[\mathrm{SiW}_{12} \mathrm{O}_{40}\right]\left[\left(\mathrm{CH}_{3}\right)_{3}\left(\mathrm{C}_{8} \mathrm{H}_{17}\right) \mathrm{N}\right]_{4} \quad\left[\mathrm{SiW}_{12} \mathrm{O}_{40}\right]\left[\mathrm{TMOA}_{4}\right.$ $\left[\mathrm{SiW}_{11} \mathrm{O}_{39}\right]\left[\left(\mathrm{C}_{6} \mathrm{H}_{13}\right)_{3}\left(\mathrm{C}_{14} \mathrm{H}_{29}\right) \mathrm{N}\right]_{8}\left[\mathrm{SiW}_{11} \mathrm{O}_{39}\right][\text { THTDA }]_{8}$ $\left[\mathrm{SiW}_{12} \mathrm{O}_{40}\right]\left[\left(\mathrm{C}_{6} \mathrm{H}_{13}\right)_{3}\left(\mathrm{C}_{14} \mathrm{H}_{29}\right) \mathrm{N}\right]_{4}\left[\mathrm{SiW}_{12} \mathrm{O}_{40}\right][\text { THTDA }]_{4}$
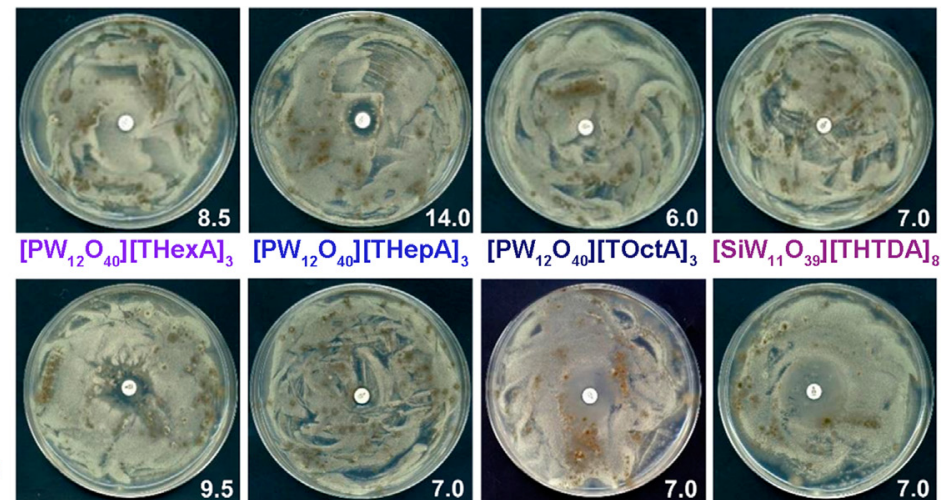

$\left[\mathrm{SiW}_{11} \mathrm{O}_{39}\right][\text { THTDA }]_{8}$

$\left[\mathrm{PW}_{12} \mathrm{O}_{40}\right][\mathrm{THexA}]_{3}$

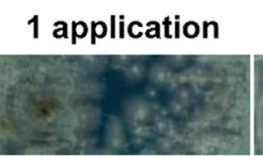

no activity

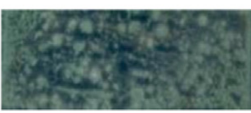

no activity

$\left[P W_{12} \mathrm{O}_{40}\right][\text { TOctA }]_{3}$

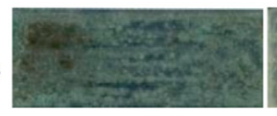

no activity

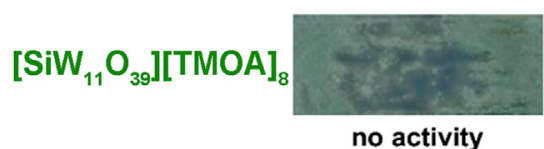

no activity

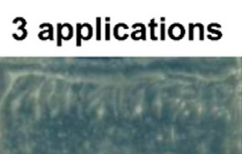

no activity

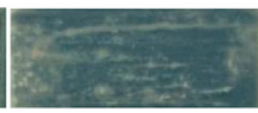

no activity

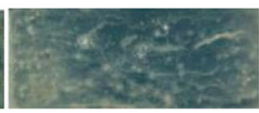

no activity

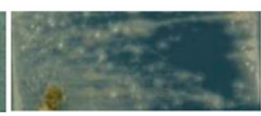

low activity

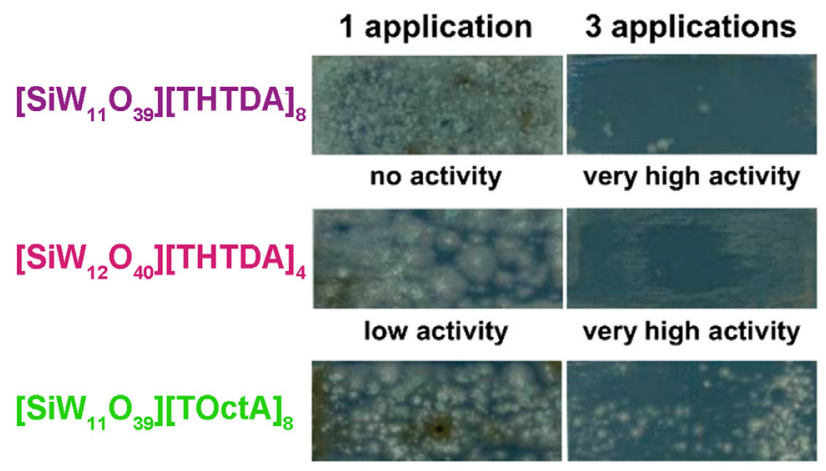

low activity

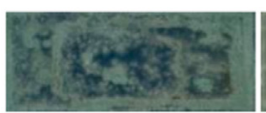

no activity

$\left[\mathrm{SiW}_{12} \mathrm{O}_{40}\right][\mathrm{TMOA}]$ good activity

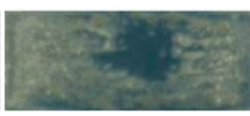

low activity

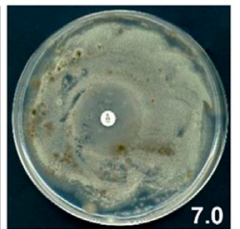

$\left[\mathrm{SiW}_{12} \mathrm{O}_{40}\right][\mathrm{TMOA}]_{4}$
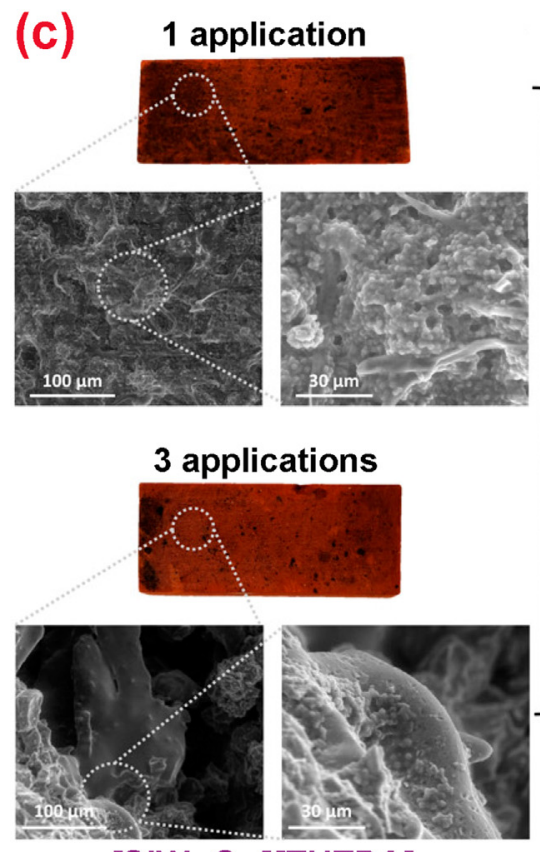

$\left[\mathrm{SiW}_{11} \mathrm{O}_{39}\right][\mathrm{THHTDA}]_{8}$
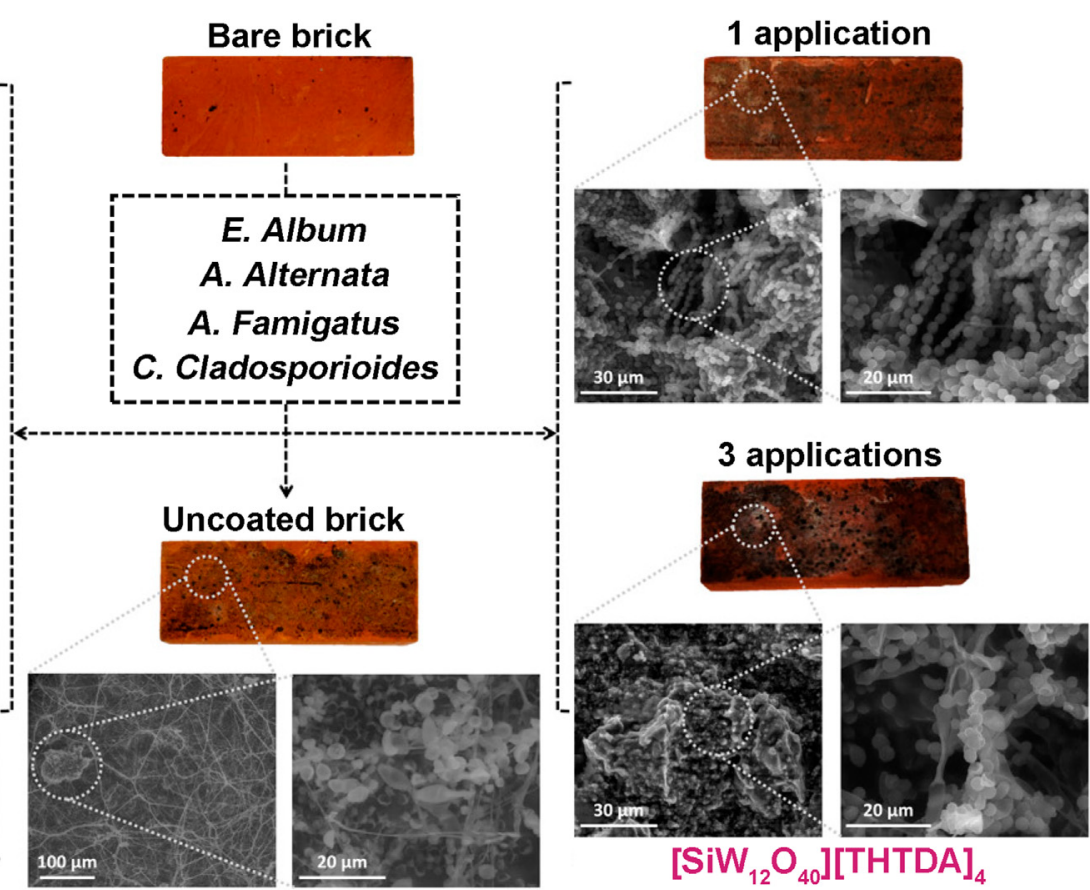

$\left[\mathrm{SiW}_{12} \mathrm{O}_{40}\right][\text { THTDA }]_{4}$

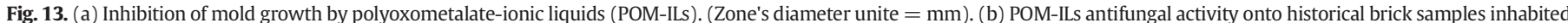

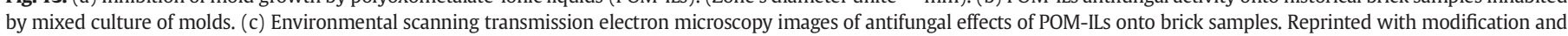
permission from [145]. 
The antibacterial and anticorrosion activities of 1-(2-hydroxyethyl)3-methylimidazolinium chloride ([OH-EMIm]Cl) and 1-ethyl-3methyleimidazolinium chloride ([EMIm]Cl) ILs were evaluated on the planktonic bacterial growth inhibition and the mild steel corrosion inhibition in $3.5 \% \mathrm{NaCl}$ solutions [143]. The employed ionic liquids demonstrated dually function as effective biocides to mitigate the bacterial growth, and as acceptable inhibitors for controlling the microbially induced corrosion. The results indicated that the [OH-EMIm]Cl displayed a better biocidal effect in comparison to the [EMIm]Cl. The enhanced antibacterial and anticorrosive activities of [OH-EMIm] Cl were related to the incorporation of hydroxyl group into the side chain of imidazolium cation leading to the synergistic effects of $\mathrm{O}$ and $\mathrm{N}$ heteroatoms. Also, the dual effects of ionic liquids were improved with increasing the concentration of ionic liquid; inhibitory effects were obtained $100 \%$ in the presence of $50 \mathrm{mg} \mathrm{L}^{-1}$ of ionic liquids during one hour.

Polyoxometalate-ionic liquids POM-ILs; POM-IL 1: $\left[\left(n-\mathrm{C}_{7} \mathrm{H}_{15}\right)_{4} \mathrm{~N}\right]_{8}$ $\left[\alpha-\mathrm{SiW}_{11} \mathrm{O}_{39}\right]$ and POM-IL 2: $\left.\left[\left(n-\mathrm{C}_{6} \mathrm{H}_{13}\right)_{3}\left(\mathrm{C}_{14} \mathrm{H}_{29}\right) \mathrm{N}\right]_{8}\left[\alpha-\mathrm{SiW}_{11} \mathrm{O}_{39}\right]\right\}$, as anticorrosion and antibacterial coatings, were assayed for protection of natural stones (Belgian Blue, Romery, and Dom) from weathering (corrosion) and biodeterioration (Fig. 12) [144]. Stone samples were coated with a transparent thin film of hydrophobic, acid-resistant POM-ILs with antibacterial activity. The POM-IL coated stones showed negligible corrosion compared to the unprotected stones in exposure to simulated acid rain (Fig. 12a). The surface POM-ILs coatings were mechanically stable and could not be removed even under harsh chemical and mechanical conditions. The biocidal effects of POM-ILs prevented the biofilms formation onto the coated stones by forming an antibacterial surface layer (Fig. 12b). The anticorrosive and antibacterial results confirmed that the modification of cation in the POM-ILs structure affected the anticorrosion effects as well as the antibacterial effects; POM-IL 1 displayed higher anti-corrosive and antibacterial properties in comparison to POM-IL 2.

The in vitro antifungal activity of POM-ILs $\left(\left[\mathrm{PW}_{12} \mathrm{O}_{40}\right]\left[\left(\mathrm{C}_{6} \mathrm{H}_{13}\right)_{4} \mathrm{~N}\right]_{3}\right.$ or $\left[\mathrm{PW}_{12} \mathrm{O}_{40}\right][\mathrm{THexA}]_{3},\left[\mathrm{PW}_{12} \mathrm{O}_{40}\right]\left[\left(\mathrm{C}_{7} \mathrm{H}_{15}\right)_{4} \mathrm{~N}\right]_{3}$ or $\left[\mathrm{PW}_{12} \mathrm{O}_{40}\right][\mathrm{THepA}]_{3}$, $\left[\mathrm{PW}_{12} \mathrm{O}_{40}\right]\left[\left(\mathrm{C}_{8} \mathrm{H}_{17}\right)_{4} \mathrm{~N}\right]_{3}$ or $\left[\mathrm{PW}_{12} \mathrm{O}_{40}\right][\mathrm{TOctA}]_{3},\left[\mathrm{SiW}_{11} \mathrm{O}_{39}\right]\left[\left(\mathrm{C}_{8} \mathrm{H}_{17}\right)_{4} \mathrm{~N}\right]_{8}$ or $\left[\mathrm{SiW}_{11} \mathrm{O}_{39}\right][\text { TOctA }]_{8},\left[\mathrm{SiW}_{11} \mathrm{O}_{39}\right]\left[\left(\mathrm{CH}_{3}\right)_{3}\left(\mathrm{C}_{8} \mathrm{H}_{17}\right) \mathrm{N}\right]_{8}$ or $\left[\mathrm{SiW}_{11} \mathrm{O}_{39}\right]$ $[\mathrm{TMOA}]_{8},\left[\mathrm{SiW}_{11} \mathrm{O}_{39}\right]\left[\left(\mathrm{C}_{6} \mathrm{H}_{13}\right)_{3}\left(\mathrm{C}_{14} \mathrm{H}_{29}\right) \mathrm{N}\right]_{8}$ or $\left[\mathrm{SiW}_{11} \mathrm{O}_{39}\right][\mathrm{THTDA}]_{8}$, $\left[\mathrm{SiW}_{12} \mathrm{O}_{40}\right]\left[\left(\mathrm{CH}_{3}\right)_{3}\left(\mathrm{C}_{8} \mathrm{H}_{17}\right) \mathrm{N}\right]_{4}$ or $\left[\mathrm{SiW}_{12} \mathrm{O}_{40}\right][\mathrm{TMOA}]_{4}, \quad\left[\mathrm{SiW}_{12} \mathrm{O}_{40}\right]$ $\left[\left(\mathrm{C}_{6} \mathrm{H}_{13}\right)_{3}\left(\mathrm{C}_{14} \mathrm{H}_{29}\right) \mathrm{N}\right]_{4}$ or $\left.\left[\mathrm{SiW}_{12} \mathrm{O}_{40}\right][\text { THTDA }]_{4}\right)$, and their efficiency in eradication of molds from historical bricks has been evaluated (Fig. 13) [145]. The antifungal effects of POM-ILs were assayed against a mixed culture of molds involving Alternaria alternata, Aspergillus fumigatus, Cladosporium cladosporioides, and Engyodontium album isolated from the surfaces of historical brick barracks. POM-ILs displayed high antifungal activity against molds because of the mold growth inhibition through toxic effects on fungal conidia, and restriction on access to oxygen and nutrients by coating the brick surface. The obtained results revealed that the POM-ILs antimicrobial effects were mostly related to cations, and their key role emanated from the amphiphilic property allowing their insertion into the phospholipid bilayer of microbes' plasma membranes. Also, the combination of two active components in the POM-ILs structure generated the water immiscibility property that reduces the microbially induced biodeterioration. These desired characteristics provide the opportunity to design new compounds as protective coatings for reducing the microbial biodeterioration of mineral-based materials.

The amino acid bearing ionic liquids have been deployed as anticorrosive and water-based lubricating additives in water. For example, tetrabutylphosphonium amino acid ionic liquids (P4444-Cys, P4444His, P4444-Lys, P4444-Met, P4444-Phe, P4444-Ser, and P4444-Trp) bearing tetrabutylphosphonium cation were prepared by using cysteine, histidine, lysine, methionine, phenylalanine, serine, and tryptophan amino acids as counter anions [146]. The results uncovered that the wear and friction coefficient was significantly diminished after the amino acid ionic liquids addition. The amino acid ionic liquids could intensely adsorb onto the metal surface to generate a physical adsorption film thus improving the anticorrosion effect. Besides, it could react with metal friction pairs to form chemical reaction films enriching the tribological properties of the additive. The tribological behavior of amino acid ionic liquids lubricant additives was associated with the synergy of $\mathrm{N}$ and $\mathrm{P}$ polar elements of boundary lubricant film on the steel-steel friction pair surface. Based on the biotoxicity and soil phytotoxicity analyses, the synthesized amino acid ionic liquids not only presented tribological effects but also displayed antibacterial activity and low toxicity to plants. Among the prepared amino acid ionic liquids, the P4444Trp demonstrated remarkable tribological and bactericide effects and was less toxic to the plant. So, the environmental influence of waterbased lubricating additives can be considerably improved by the amino acid ionic liquids.

\section{Conclusion}

Herein, the recent advances related to the environmental application of ionic liquids-based antimicrobial materials are presented. Ionic liquids have been utilized in various domains including materials science, resulting in the production of antimicrobial film membranes, nanoparticles, coatings, and surfaces and mainly demonstrating their dual-functional properties. The finding of the studies summarized throughout this review illustrated that ionic liquids-based materials are promising antimicrobial materials with an ability to combat against a wide spectrum of fungi and bacterial strains. This further highlights the potential in developing additional ionic liquids-based materials with different architectures i.e., ionic liquids macromolecular and monomer structures using hyperbranched, branched, or linear structures in order to prepare more effective antimicrobial ionic liquidsbased materials. It has been observed that cationic ionic liquids-based materials were studied extensively due to the better interaction of cationic ionic liquids moieties with the negatively charged microbial cells membrane. In terms of molecular structure, the flexibility of ionic liquids is related to their capability to modulate anions and cations as salt and benefit the properties of both. Additionally, low-cost production methods for ILs, will facilitate particularly their use as antimicrobial agents against antibacterial resistance strains [92,147,148].

However, in many cases, the studies also indicated the superior activity of anionic ionic liquids-based materials with active countercations which is associated with the mobility of the cationic moieties. Therefore, in future efforts emphasis should be on investigating the potential of anionic ionic liquids antimicrobial materials and understanding of synergistic effects between counter-ion and ionic liquids. Another challenge towards the application of ionic liquids-based materials is their low selectivity values due to associated toxicity which need to be addressed in the future.

In order to have more sustainable systems, it is essential to strive for obtaining ionic liquids from renewable resources based on natural carboxylic acids, which has benefits for other applications as well. The utilization of renewable resources will also reduce the toxicity compared to synthetic ionic liquids-based materials. To obtain effective, strong, and non-harmful antimicrobial ionic liquids materials, all the features need to be considered to overcome the global health concerns of pollution, antibiotic resistance, and all existing infection threats. Additionally, the advantages encompassing bioavailability, activity, and multifunctionality are feasible via ionic liquids chemistry thus providing an encouraging novel platform for future strategies. Despite many efforts to make antimicrobials-based materials, there have been no reports about the fabrication of medical gowns, gloves, and antimicrobial coatings on the walls and floors of hospitals based on ionic liquids-based antimicrobial materials.

In our view, the key features needing further development in both, the existing and newer applications is a better understanding of ionic liquids mixtures with other ionic liquids and with molecular species. The investigations need to focus more on the structural influence on physical and chemical properties at the nanometer level that may 
persevere after dilution into solvents and on the economic and environmental impacts of using antimicrobial ionic liquids in small- and largescale industrial processes. The cost appears to be a critical barrier in the exploitation of the advantageous features of ionic liquids and identifying pathways for large-scale applications. A better understanding of both the theoretical and practical application of antimicrobial ionic liquids would be of tremendous assistance for progress in this field. Hopefully, the research community continues these innovative investigations in hitherto unexplored areas.

\section{Declaration of Competing Interest}

The authors deny any conflict of interest.

\section{References}

[1] Muñoz-Bonilla A, Fernández-García M. Poly(ionic liquid)s as antimicrobial materials. Eur Polym J. 2018;105:135-49.

[2] Global Action Plan on Antimicrobial Resistance. WHO; 2015.

[3] Babamale HF, Sangeetha T, Tan JS, Yam W. Synthesis and characterization of Azobenzene derivatives and Azobenzene-Imidazolium conjugates with selective antimicrobial potential. J Mol Struct. 2021;1232:130049.

[4] Wang C, Makvandi P, Zare EN, Tay FR, Niu L. Advances in antimicrobial organic and inorganic nanocompounds in biomedicine. Adv Ther. 2020;3:2000024.

[5] Álvarez-Paino M, Muñoz-Bonilla A, Fernández-García M. Antimicrobial polymers in the nano-world. Nanomaterials. 2017;7:1-44.

[6] Dong K, Liu X, Dong H, Zhang X, Zhang S. Multiscale Studies on Ionic Liquids. Chem Rev. 2017;117:6636-95.

[7] Ayati A, Ranjbari S, Tanhaei B, Sillanpää M. Ionic liquid-modified composites for the adsorptive removal of emerging water contaminants: a review. J Mol Liq. 2019; 275:71-83.

[8] Pendleton JN, Gilmore BF. The antimicrobial potential of ionic liquids: a source of chemical diversity for infection and biofilm control. Int J Antimicrob Agents. 2015;46:131-9.

[9] Isosaari P, Srivastava V, Sillanpää M. Ionic liquid-based water treatment technologies for organic pollutants: current status and future prospects of ionic liquid mediated technologies. Sci Total Environ. 2019;690:604-19.

[10] Nicosia A, Gieparda W, Foksowicz-Flaczyk J, Walentowska J, Wesołek D, Vazquez B, et al. Air filtration and antimicrobial capabilities of electrospun PLA/PHB containing ionic liquid. Sep Purif Technol. 2015;154:154-60.

[11] Mehta MJ, Kumar A. Ionic liquid assisted gelatin films: green, UV shielding, antioxidant, and antibacterial food packaging materials. ACS Sustain Chem Eng. 2019;7: 8631-6.

[12] El-Shamy AM, Zakaria K, Abbas MA, Zein El Abedin S. Anti-bacterial and anticorrosion effects of the ionic liquid 1-butyl-1-methylpyrrolidinium trifluoromethylsulfonate. J Mol Liq. 2015;211:363-9.

[13] Fotovvati B, Namdari N, Dehghanghadikolaei A. On coating techniques for surface protection: a review. J Manuf Mater Process. 2019;3:1-22.

[14] Ye Q, Gao T, Wan F, Yu B, Pei X, Zhou F, et al. Grafting poly(ionic liquid) brushes for anti-bacterial and anti-biofouling applications. J Mater Chem. 2012;12:13123-31.

[15] Qin J, Guo J, Xu Q, Zheng Z, Mao H, Yan F. Synthesis of Pyrrolidinium-type poly (ionic liquid) membranes for antibacterial applications. ACS Appl Mater Interfaces. 2017;9:10504-11.

[16] Ding Y, Sun Z, Shi R, Cui H, Liu Y, Mao H, et al. Integrated endotoxin adsorption and antibacterial properties of cationic polyurethane foams for wound healing. ACS Appl Mater Interfaces. 2019;11:2860-9.

[17] Fang H, Wang J, Li L, Xu L, Wu Y, Wang Y, et al. A novel high-strength poly(ionic liquid)/PVA hydrogel dressing for antibacterial applications. Chem Eng J. 2019; 365:153-64.

[18] Wang K, Wang J, Li L, Xu L, Feng N, Wang Y, et al. Novel nonreleasing antibacterial hydrogel dressing by a one-pot method. ACS Biomater Sci Eng. 2020;6:1259-68.

[19] Yu Y, Yang Z, Ren S, Gao Y, Zheng L. Multifunctional hydrogel based on ionic liquid with antibacterial performance. J Mol Liq. 2020;299:112185.

[20] Martini Garcia I, Jung Ferreira C, de Souza VS, Castelo Branco Leitune V, Samuel SMW, de Souza Balbinot G, et al. Ionic liquid as antibacterial agent for an experimental orthodontic adhesive. Dent Mater. 2019;35:1155-65.

[21] Takahashi C, Hattori Y, Yagi S, Murai T, Tanemura M, Kawashima Y, et al. Ionic liquid-incorporated polymeric nanoparticles as carriers for prevention and at an earlier stage of periodontal disease. Materialia. 2019;8:100395.

[22] Bielas R, Mielańczyk A, Skonieczna M, Mielańczyk Ł, Neugebauer D. Choline supported poly(ionic liquid) graft copolymers as novel delivery systems of anionic pharmaceuticals for anti-inflammatory and anti-coagulant therapy. Sci Rep. 2019;9:14410.

[23] Bielas R, Siewniak A, Skonieczna M, Adamiec M, Mielańczyk Ł, Neugebauer D. Choline based polymethacrylate matrix with pharmaceutical cations as co-delivery system for antibacterial and anti-inflammatory combined therapy. J Mol Liq. 2019;285:114-22.

[24] Takahashi C, Hattori Y, Yagi S, Murai T, Takai C, Ogawa N, et al. Optimization of ionic liquid-incorporated PLGA nanoparticles for treatment of biofilm infections. Mater Sci Eng C. 2019;97:78-83.
[25] Walden P. Molecular weights and electrical conductivity of several fused salts. Bull Acad Imper Sci (St Petersburg) 1800. 1914:405-22.

[26] Dieter KM, Dymek CJ, Heimer NE, Rovang JW, Wilkes JS. Ionic structure and interactions in 1-methyl-3-ethylimidazolium chloride-aluminum chloride molten salts. J Am Chem Soc. 1988;110:2722-6.

[27] Wilkes JS, Zaworotko MJ. Air and water stable 1-ethyl-3-methylimidazolium based ionic liquids. J Chem Soc Chem Commun. 1992:965-7. https://doi.org/10.1039/ C39920000965.

[28] Ratti R. Ionic liquids: synthesis and applications in catalysis. Adv Chem. 2014;2014: 729842.

[29] Pathak AK, Ameta C, Ameta R, Punjabi PB. Microwave-assisted organic synthesis in ionic liquids. J Heterocyclic Chem. 2016;53:1697-705.

[30] Wasserscheid P, Keim W. Ionic liquids-New “solutions" for transition metal catalysis. Angew Chem. 2000;39:3772-89.

[31] MacFarlane DR, Golding J, Forsyth S, Forsyth M, Deacon GB. Low viscosity ionic liquids based on organic salts of the dicyanamide anion. Chem Commun. 2001: 1430-1.

[32] Vekariya RL. A review of ionic liquids: applications towards catalytic organic transformations. J Mol Liq. 2017;227:44.

[33] Li JG, Hu YF, Sun SF, Ling S, Zhang JZ. Ionic structures of nanobased $\mathrm{FeCl}_{3} /\left[\mathrm{C}_{4} \mathrm{mim}\right] \mathrm{cl}$ ionic liquids. J Phys Chem B. 2012;116:6461-4.

[34] Smiglak M, Holbrey JD, Griffin ST, Reichert WM, Swatloski RP, Katritzky AR, et al. Ionic liquids via reaction of the zwitterionic 1,3-dimethylimidazolium-2-carboxylate with protic acids. Overcoming synthetic limitations and establishing new halide free protocols for the formation of ILs. Green Chem. 2007;9:90-8.

[35] Paape N, Wei W, Bösmann A, Kolbeck C, Maier F, Steinrück HP, et al. Chloroalkylsulfonate ionic liquids by ring opening of sultones with organic chloride salts. Chem Commun. 2008:3867-9.

[36] Ohno H. Functional design of ionic liquids. Bull Chem Soc Jpn. 2006;79:1665-80.

[37] Varma RS, Namboodiri VV. An expeditious solvent-free route to ionic liquids using microwaves. Chem Commun. 2001:643-4.

[38] Varma RS. Expeditious synthesis of ionic liquids using ultrasound and microwave irradiation. Ion. Liq. as green solvents, vol. 856. American Chemical Society; 2003. p. 7-82.

[39] Messali M. A facile and green microwave-assisted synthesis of new functionalized picolinium-based ionic liquids. Arab J Chem. 2016;9:S564-9.

[40] Bica K, Gmeiner G, Reichel C, Lendl B, Gaertner P. Microwave-assisted synthesis of camphor-derived chiral imidazolium ionic liquids and their application in diastereoselective diels-alder reaction. Synthesis-Stuttgart. 2007:1333-8.

[41] Ohno H, Fukumoto K. Amino acid ionic liquids. Acc Chem Res. 2007;40:1122-9.

[42] Chatel G, MacFarlane DR. Ionic liquids and ultrasound in combination: synergies and challenges. Chem Soc Rev. 2014;43:8132-49.

[43] Lévêque JM, Luche JL, Pétrier C, Roux R, Bonrath W. An improved preparation of ionic liquids by ultrasound. Green Chem. 2002;4:357-60.

[44] Cravotto G, Gaudino EC, Boffa L, Lévêque JM, Estager J, Bonrath W. Preparation of second generation ionic liquids by efficient solvent-free alkylation of $\mathrm{N}$ heterocycles with chloroalkanes. Molecules. 2008;13:149-56.

[45] Kavitha T, Vasantha T, Venkatesu P, Rama Devi RS, Hofman T. Thermophysical properties for the mixed solvents of N-methyl-2-pyrrolidone with some of the imidazolium-based ionic liquids. J Mol Liq. 2014;198:11-20.

[46] Coleman D, Gathergood N. Biodegradation studies of ionic liquids. Chem Soc Rev. 2010;39:600-37.

[47] Martino W, de la Mora JF, Yoshida Y, Saito G, Wilkes J. Surface tension measurements of highly conducting ionic liquids. Green Chem. 2006;8:390-7.

[48] Klomfar J, Součková M, Pátek J. Surface tension measurements with validated accuracy for four 1-alkyl-3-methylimidazolium based ionic liquids. J Chem Thermodyn. 2010;42:323-9.

[49] Weiss VC, Heggen B, Müller-Plathe F. Critical parameters and surface tension of the room temperature ionic liquid [bmim] $\left[\mathrm{PF}_{6}\right]$ : a corresponding-states analysis of experimental and new simulation data. J Phys Chem C. 2010;114:3599-608.

[50] Paulechka YU. Heat capacity of room-temperature ionic liquids: a critical review. J Phys Chem Ref Data Monogr. 2010;39:33108.

[51] Zhang QG, Sun SS, Pitula S, Liu QS, Welz-Biermann U, Zhang JJ. Electrical conductivity of solutions of ionic liquids with methanol, ethanol, acetonitrile, and propylene carbonate. J Chem Eng Data. 2011;56:4659-64.

[52] Belieres JP, Angell CA. Protic ionic liquids: preparation, characterization, and proton free energy level representation. J Phys Chem B. 2007;111:4926-37.

[53] Greaves TL, Drummond CJ. Protic ionic liquids: properties and applications. Chem Rev. 2008;108:206-37.

[54] Ghatee MH, Bahrami M, Khanjari N. Measurement and study of density, surface tension, and viscosity of quaternary ammonium-based ionic liquids ([ $\left.\mathrm{N}_{222}(\mathrm{n})\right]$ $\mathrm{Tf}_{2} \mathrm{~N}$ ). J Chem Thermodyn. 2013;65:42-52.

[55] Lago S, Rodríguez-Cabo B, Arce A, Soto A. Water/oil/[ $\left.\mathrm{P}_{6,6,6,14}\right]\left[\mathrm{NTf}_{2}\right]$ phase equilibria. J Chem Thermodyn. 2014;75:63-8.

[56] Aparicio S, Atilhan M, Karadas F. Thermophysical properties of pure ionic liquids: review of present situation. Ind Eng Chem Res. 2010;49:9580-95.

[57] Greaves TL, Weerawardena A, Fong C, Drummond CJ. Many protic ionic liquids mediate hydrocarbon-solvent interactions and promote amphiphile self-assembly. Langmuir. 2007;23:402-4.

[58] Nishida T, Tashiro Y, Yamamoto M. Physical and electrochemical properties of 1alkyl-3-methylimidazolium tetrafluoroborate for electrolyte. J Fluor Chem. 2003; 120:135-41.

[59] Bonhôte P, Dias AP, Papageorgiou N, Kalyanasundaram K, Grätzel M. Hydrophobic, highly conductive ambient-temperature molten salts. Inorg Chem. 1996;35: $1168-78$. 
[60] Zhou Q, Lu X, Zhang S, Guo L. Physicochemical properties of ionic liquids. Ion Liq Furth UnCOILed. 2014:275-307.

[61] Zhang S, Wang J, Lu X, Zhou Q, editors. Structures and interactions of ionic liquids. 1st ed. Springer, Berlin, Heidelberg; 2014.

[62] Jin H, O'Hare B, Dong J, Arzhantsev S, Baker GA, Wishart JF, et al. Physical properties of ionic liquids consisting of the 1-butyl-3-methylimidazolium cation with various anions and the bis(trifluoromethylsulfonyl)imide anion with various cations. J Phys Chem B. 2008;112:81-92.

[63] Galiński M, Lewandowski A, Stępniak I. Ionic liquids as electrolytes. Electrochim Acta. 2006;51:5567-80.

[64] Yoshizawa M, Xu W, Angell CA. Ionic liquids by proton transfer: vapor pressure, conductivity, and the relevance of $\triangle \mathrm{pKa}$ from aqueous solutions. J Am Chem Soc. 2003; 125:15411-9.

[65] Meng Y, Liu J, Li Z, Wei H. Synthesis and physicochemical properties of two $\mathrm{SO}_{3} \mathrm{H}-$ functionalized ionic liquids with hydrogen sulfate anion. J Chem Eng Data. 2014; 59:2186-95.

[66] Seddon KR, Stark A, Torres MJ. Influence of chloride, water, and organic solvents on the physical properties of ionic liquids. Pure Appl Chem. 2000;72:2275-87.

[67] Jacquemin J, Husson P, Padua AAH, Majer V. Density and viscosity of several pure and water-saturated ionic liquids. Green Chem. 2006;8:172-80.

[68] Plechkova NV, Seddon KR. Applications of ionic liquids in the chemical industry. Chem Soc Rev. 2008;37:123-50.

[69] Hyun B-R, Dzyuba SV, Bartsch RA, Quitevis EL. Intermolecular dynamics of roomtemperature ionic liquids: femtosecond optical Kerr effect measurements on 1alkyl-3-methylimidazolium bis((trifluoromethyl)sulfonyl)imides. J Phys Chem A. 2002;106:7579-85.

[70] Shereshefsky JL. Surface tension of saturated vapors and the equation of Eötvös. J Phys Chem. 1931:35:1712-20.

[71] Kunz W, Häckl K. The hype with ionic liquids as solvents. Chem Phys Lett. 2016; 661:6-12.

[72] Sivapragasam M, Moniruzzaman M, Goto M. An overview on the toxicological properties of ionic liquids toward microorganisms. Biotechnol J. 2020;15:1900073.

[73] Hossain MI, Samir BB, El-Harbawi M, Masri AN, Mutalib MIA, Hefter G, et al. Development of a novel mathematical model using a group contribution method for prediction of ionic liquid toxicities. Chemosphere. 2011;85:990-4.

[74] Pawłowska B, Telesiński A, Biczak R. Phytotoxicity of ionic liquids. Chemosphere. 2019;237:124436.

[75] Chen B, Xue C, Amoah PK, Li D, Gao K, Deng X. Impacts of four ionic liquids exposure on a marine diatom Phaeodactylum tricornutum at physiological and biochemical levels. Sci Total Environ. 2019;665:492-501.

[76] Liu H, Wu J, Zhang X, Xia Y, Li Y, Du S. Enantioselective oxidative stress caused by chiral ionic liquids forms of 1-alkyl-3-methyl imidazolium tartrate on Scenedesmus obliquus. Sci Total Environ. 2017;595:819-27.

[77] Quraishi KS, Bustam MA, Krishnan S, Aminuddin NF, Azeezah N, Ghani NA, et al. Ionic liquids toxicity on fresh water microalgae, Scenedesmus quadricauda, Chlorella vulgaris \& Botryococcus braunii; selection criterion for use in a two-phase partitioning bioreactor (TPPBR). Chemosphere. 2017;184:642-51.

[78] Chen Z, Xiao H, Wu S, Wang J, Ji J, Qin X. Effects of amino acid ionic liquids with different cations ([ $\left.\mathrm{N}_{2} \mathrm{Py}\right],\left[\mathrm{N}_{2222}\right],\left[\mathrm{P}_{2222}\right]$, and $\left.\left[\mathrm{C}_{2} \mathrm{mim}\right]\right)$ on wheat seedlings. RSC Adv. 2021;11:1901-8.

[79] Gao K, Li B, Chen R, Qian P, Dong J, Xue C, et al. A feasibility study of using silkworm larvae as a novel in vivo model to evaluate the biotoxicity of ionic liquids. Ecotoxicol Environ Saf. 2021;209:111759.

[80] Stepnowski P, Skladanowski AC, Ludwiczak A, Laczyńska E. Evaluating the cytotoxicity of ionic liquids using human cell line HeLa. Hum Exp Toxicol. 2004;23:513-7.

[81] Jamaledin R, Yiu CKY, Zare EN, Niu L, Vecchione R, Chen G, et al. Advances in antimicrobial microneedle patches for combating infections. Adv Mater. 2020;32: 2002129

[82] Forero Doria O, Castro R, Gutierrez M, Gonzalez Valenzuela D, Santos L, Ramirez D, et al. Novel alkylimidazolium ionic liquids as an antibacterial alternative to pathogens of the skin and soft tissue infections. Molecules. 2018;23:2354.

[83] Lei J, Sun LC, Huang S, Zhu C, Li P, He J, et al. The antimicrobial peptides and their potential clinical applications. Am J Transl Res. 2019;11:3919-31.

[84] Abushaheen MA, Muzaheed Fatani AJ, Alosaimi M, Mansy W, George M, et al. Antimicrobial resistance, mechanisms and its clinical significance. Dis Mon. 2020; 66:100971.

[85] Hoque J, Ghosh S, Paramanandham K, Haldar J. Charge-switchable polymeric coating kills bacteria and prevents biofilm formation in vivo. ACS Appl Mater Interfaces. 2019;11:39150-62.

[86] Wang H, Shi X, Yu D, Zhang J, Yang G, Cui Y, et al. Antibacterial activity of Geminized Amphiphilic cationic Homopolymers. Langmuir. 2015;31:13469-77.

[87] Lu B, Zhou G, Xiao F, He Q, Zhang J. Stimuli-responsive poly(ionic liquid) nanoparticles for controlled drug delivery. J Mater Chem B. 2020;8:7994-8001.

[88] Wang C, Qiao Y, Kang Y, Guo S, Wu D, Wang J, et al. Bacteria-activated chlorin e6 ionic liquid based on cation and anion dual-mode antibacterial action for enhanced photodynamic efficacy. Biomater Sci. 2019;7:1399-410.

[89] Makvandi P, Jamaledin R, Jabbari M. Antibacterial quaternary ammonium compounds in dental materials: a systematic review. Dent Mater. 2018;34:851-67.

[90] Egorova KS, Gordeev EG, Ananikov VP. Biological activity of ionic liquids and their application in pharmaceutics and medicine. Chem Rev. 2017;117:7132-89.

[91] He B, Ou G, Zhou C, Wang M, Chen S. Antimicrobial ionic liquids with fumarate anion. J Chemother. 2013:1-8.

[92] Prud C, Vieira M, Van Der Auweraer S. Recycling old antibiotics with ionic liquids. Antibiotics. 2020;9:1-18.

[93] Zafari M, Yazdani A, Pourmotabed S, Hasanpour A, Sharifi E, Nosrati H, et al. Physical and biological properties of blend-electrospun polycaprolactone/chitosan- based wound dressings loaded with N-decyl-N,N-dimethyl-1-decanaminium chloride: An in vitro and in vivo study; 2020; $1-15$.

[94] Duman AN, Ozturk I, Tunçel A, Ocakoglu K, Colak SG, Hoşgör-Limoncu M, et al. Synthesis of new water-soluble ionic liquids and their antibacterial profile against gram-positive and gram-negative bacteria. Heliyon. 2019;5:e02607.

[95] Ferraz R, Silva D, Dias AR, Dias V, Santos MM, Pinheiro L, et al. Synthesis and antibacterial activity of ionic liquids and organic salts based on penicillin $\mathrm{G}$ and amoxicillin hydrolysate derivatives against resistant Bacteria. Pharmaceutics. 2020;12: $1-23$.

[96] Jordan A, Gathergood N. Biodegradation of ionic liquids-a critical review. Chem Soc Rev. 2015;44:8200-37.

[97] Costa SPF, Azevedo AMO, Pinto PCAG, Saraiva MLMFS. Environmental impact of ionic liquids: recent advances in (eco) toxicology and (bio) degradability. ChemSusChem. 2017;10:2321-47.

[98] Ejaz U, Sohail M. Ionic liquids: Green solvent for biomass pretreatment BT. In: Inamuddin Asiri AM, editor. Nanotechnology-based Ind. Appl. Ion. Liq. Cham: Springer International Publishing; 2020. p. 27-36.

[99] Yang Z, Pan W. Ionic liquids: green solvents for nonaqueous biocatalysis. Enzym Microb Technol. 2005;37:19-28.

[100] Boretti A, Rosa L. Reassessing the projections of the world water development report. Npj Clean Water. 2019;2:15.

[101] Ambat I, Srivastava V, Iftekhar S, Haapaniemi E, Sillanpää M. Effect of different cosolvents on biodiesel production from various low-cost feedstocks using $\mathrm{Sr}-\mathrm{Al}$ double oxides. Renew Energy. 2020;146:2158-69.

[102] Alahmadi NS, Elshaarawy RFM. Novel aminothiazolyl-functionalized phosphonium ionic liquid as a scavenger for toxic metal ions from aqueous media; mining to useful antibiotic candidates. J Mol Liq. 2019;281:451-60.

[103] Rama R, Meenakshi S. Synthesis of trialkylammonium naphthylaceteate ionic liquid: its antimicrobial and chromium extraction study. J Mol Struct. 2020;1204: 127490.

[104] Misra A, Zambrzycki C, Kloker G, Kotyrba A, Anjass MH, Franco Castillo I, et al. Water purification and microplastics removal using magnetic Polyoxometalatesupported ionic liquid phases (magPOM-SILPs). Angew Chem Int Ed. 2020;59: $1601-5$.

[105] Mirhoseini F, Salabat AR. Investigation of operational parameters on the photocatalytic activity of a new type of poly(methyl methacrylate)/ionic liquid- $\mathrm{TiO}_{2}$ nanocomposite. Iran J Chem Chem Eng. 2019;38:101-14.

[106] Rojas LMG, Huerta-Aguilar CA, Tecuapa-Flores ED, Huerta-José DS, Thangarasu P, Sidhu JS, et al. Why ionic liquids coated $\mathrm{ZnO}$ nanocomposites emerging as environmental remediates: enhanced photo-oxidation of 4-nitroaniline and encouraged antibacterial behavior. J Mol Liq. 2020;319:114107.

[107] Sahiner N, Sagbas S. Polymeric ionic liquid materials derived from natural source for adsorption purpose. Sep Purif Technol. 2018;196:208-16.

[108] Yusuf A, Sodiq A, Giwa A, Eke J, Pikuda O, De Luca G, et al. A review of emerging trends in membrane science and technology for sustainable water treatment. J Clean Prod. 2020;266:121867.

[109] Rynkowska E, Fatyeyeva K, Kujawski W. Application of polymer-based membranes containing ionic liquids in membrane separation processes: a critical review. Rev Chem Eng. 2018;34:341-63.

[110] He B, Peng H, Chen Y, Zhao Q. High performance polyamide nanofiltration membranes enabled by surface modification of imidazolium ionic liquid. J Membr Sci. 2020;608:118202.

[111] Zheng X, Ding X, Guan J, Gu Y, Su Z, Zhao Y, et al. Ionic liquid-grafted polyamide 6 by radiation-induced grafting: new strategy to prepare covalently bonded ioncontaining polymers and their application as functional fibers. ACS Appl Mater Interfaces. 2019;11:5462-75.

[112] Zheng X, Chen F, Zhang X, Zhang H, Li Y, Li J. Ionic liquid grafted polyamide 6 as porous membrane materials: enhanced water flux and heavy metal adsorption. Appl Surf Sci. 2019;481:1435-41.

[113] Jebur M, Sengupta A, Chiao Y-H, Kamaz M, Qian X, Wickramasinghe R. Pi electron cloud mediated separation of aromatics using supported ionic liquid (SIL) membrane having antibacterial activity. J Membr Sci. 2018;556:1-11.

[114] Ni C, Zheng X, Zhang Y, Zhang X, Li Y. Multifunctional porous materials with simultaneous high water flux, antifouling and antibacterial performances from ionic liquid grafted polyethersulfone. Polymer (Guildf). 2021;212:123183.

[115] Yan X, Anguille S, Bendahan M, Moulin P. Ionic liquids combined with membrane separation processes: a review. Sep Purif Technol. 2019;222:230-53.

[116] Sengupta A, Kumar Ethirajan S, Kamaz M, Jebur M, Wickramasinghe R. Synthesis and characterization of antibacterial poly ionic liquid membranes with tunable performance. Sep Purif Technol. 2019;212:307-15.

[117] Liu L, Xiong S, Zeng L, Cai C, Li F, Tan Z. Two birds with one stone: porous poly(ionic liquids) membrane with high efficiency for the separation of amino acids mixture and its antibacterial properties. J Colloid Interface Sci. 2021;584:866-74.

[118] Le Li J, Zhang Y, Zhang S, Liu M, Li X, Cai T. Hyperbranched poly(ionic liquid) functionalized poly(ether sulfone) membranes as healable antifouling coatings for osmotic power generation. J Mater Chem A. 2019;7:8167-76.

[119] Zhang S, Sukitpaneenit P, Chung TS. Design of robust hollow fiber membranes with high power density for osmotic energy production. Chem Eng J. 2014;241:457-65.

[120] Wan CF, Li B, Yang T, Chung TS. Design and fabrication of inner-selective thin-film composite (TFC) hollow fiber modules for pressure retarded osmosis (PRO). Sep Purif Technol. 2017;172:32-42.

[121] Hopke PK, Dai Q, Li L, Feng Y. Global review of recent source apportionments for airborne particulate matter. Sci Total Environ. 2020;740:140091.

[122] Schraufnagel DE, Balmes JR, Cowl CT, De Matteis S, Jung SH, Mortimer K, et al. Air pollution and noncommunicable diseases: a review by the forum of international 
respiratory societies' environmental committee, part 2: air pollution and organ systems. Chest. 2019;155:417-26

[123] Liu H, Cao C, Huang J, Chen Z, Chen G, Lai Y. Progress on particulate matter filtration technology: basic concepts, advanced materials, and performances. Nanoscale. 2020:12:437-53.

[124] Robert B, Nallathambi G. A concise review on electrospun nanofibres/nanonets for filtration of gaseous and solid constituents (PM2.5) from polluted air. Colloid Interface Sci Commun. 2020;37:100275

[125] Kim KH, Kabir E, Jahan SA. Airborne bioaerosols and their impact on human health. J Environ Sci. 2018;67:23-35.

[126] Zhang L, Li L, Wang L, Nie J, Ma G. Multilayer electrospun nanofibrous membranes with antibacterial property for air filtration. Appl Surf Sci. 2020;515:145962.

[127] Sasikumar B, Arthanareeswaran G, Ismail AF. Recent progress in ionic liquid membranes for gas separation. J Mol Liq. 2018:330-41.

[128] Zhu M, Cao Q, Liu B, Guo H, Wang X, Han Y, et al. A novel cellulose acetate/poly (ionic liquid) composite air filter. Cellulose. 2020;27:3889-902.

[129] Janani N, Zare EN, Salimi F, Makvandi P. Antibacterial tragacanth gum-based nanocomposite films carrying ascorbic acid antioxidant for bioactive food packaging. Carbohydr Polym. 2020;247:116678.

[130] Wu RL, Wang XL, Li F, Li HZ, Wang YZ. Green composite films prepared from cellulose, starch and lignin in room-temperature ionic liquid. Bioresour Technol. 2009; 100:2569-74.

[131] Tomé LC, Silva NHCS, Soares HR, Coroadinha AS, Sadocco P, Marrucho IM, et al. Bioactive transparent films based on polysaccharides and cholinium carboxylate ionic liquids. Green Chem. 2015;17:4291-9.

[132] Bhargava N, Sharanagat VS, Mor RS, Kumar K. Active and intelligent biodegradable packaging films using food and food waste-derived bioactive compounds: a review. Trends Food Sci Technol. 2020:385-401.

[133] Nguyen-Tri P, Tran HN, Plamondon CO, Tuduri L, Vo D-VN, Nanda S, et al. Recent progress in the preparation, properties and applications of superhydrophobic nano-based coatings and surfaces: a review. Prog Org Coat. 2019;132:235-56.

[134] Nazeer AA, Madkour M. Potential use of smart coatings for corrosion protection of metals and alloys: a review. J Mol Liq. 2018;253:11-22.

[135] Pang LQ Zhong LJ, Zhou HF, Wu XE, Chen XD. Grafting of ionic liquids on stainless steel surface for antibacterial application. Colloids Surf B: Biointerfaces. 2015;126: $162-8$.

[136] Strehmel V, Berdzinski S, Ehrentraut L, Faßbender C, Horst J, Leeb E, et al. Application of ionic liquids in synthesis of polymeric binders for coatings. Prog Org Coat. 2015;89:297-313.
[137] Jin L, Shi Z, Zhang X, Liu X, Li H, Wang J, et al. Intelligent antibacterial surface based on ionic liquid molecular brushes for bacterial killing and release. J Mater Chem B. 2019;7:5520-7.

[138] Elshaarawy RFM, Tadros HRZ, El-Aal RMA, Mustafa FHA, Soliman YA, Hamed MA Hybrid molecules comprising 1,2,4-triazole or diaminothiadiazole Schiff-bases and ionic liquid moieties as potent antibacterial and marine antibiofouling nominees. J Environ Chem Eng. 2016;4:2754-64.

[139] Elshaarawy RFM, Mustafa FHA, Sofy AR, Hmed AA, Janiak C. A new synthetic antifouling coatings integrated novel aminothiazole-functionalized ionic liquids motifs with enhanced antibacterial performance. J Environ Chem Eng. 2019;7:102800.

[140] Livi S, Lins LC, Capeletti LB, Chardin C, Halawani N, Baudoux J, et al. Antibacterial surface based on new epoxy-amine networks from ionic liquid monomers. Eur Polym J. 2019;116:56-64.

[141] Little BJ, Blackwood DJ, Hinks J, Lauro FM, Marsili E, Okamoto A, et al. Microbially influenced corrosion-any progress? Corros Sci. 2020;170:108641.

[142] Deyab MA, Moustafa YM, Nessim MI, Fatthallah NA, Asaad Bagato NM. New series of ionic liquids based on benzalkonium chloride derivatives: synthesis, characterizations, and applications. J Mol Liq. 2020;313:113566.

[143] Shehata MF, El-Shamy AM, Zohdy KM, Sherif E-SM, Zein El Abedin S. Studies on the antibacterial influence of two ionic liquids and their corrosion inhibition performance. Appl Sci. 2020;10:1444.

[144] Misra A, Franco Castillo I, Müller DP, González C, Eyssautier-Chuine S, Ziegler A et al. Polyoxometalate-ionic liquids (POM-ILs) as anticorrosion and antibacterial coatings for natural stones. Angew Chem Int Ed. 2018;57:14926-31.

[145] Rajkowska K, Koziróg A, Otlewska A, Piotrowska M, Atrián-Blasco E, Franco-Castillo I, et al. Antifungal activity of polyoxometalate-ionic liquids on historical brick. Molecules. 2020;25:5663.

[146] Yang Z, Sun C, Zhang C, Zhao S, Cai M, Liu Z, et al. Amino acid ionic liquids as anticorrosive and lubricating additives for water and their environmental impact. Tribol Int. 2021;153:106663.

[147] Ferraz R, Noronha J, Murtinheira F, Nogueira F, Machado M, Prudêncio M, et al. Primaquine-based ionic liquids as a novel class of antimalarial hits. RSC Adv. 2016;6:56134-8.

[148] Davarpanah A, Zare EN, Zamani M. Acidic ionic liquid-mediated preparation of shaped electrically conductive poly( $p$-phenylenediamine). J Polym Res. 2021; 28:224. 